\title{
SERTULA
}

\section{FLORAE ECUADORENSIS}

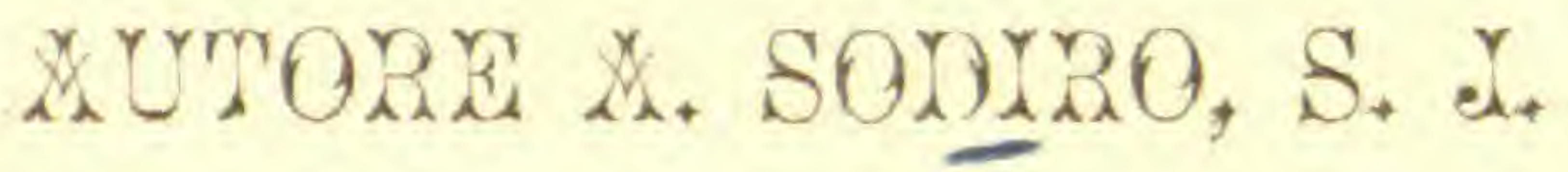 \\ I \\ ACROSTICHA
}

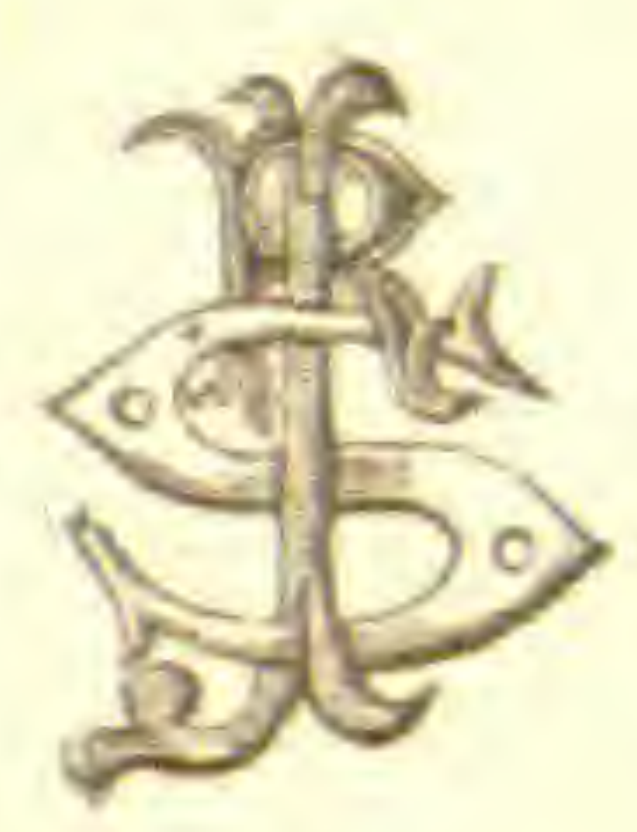

QUITI

TYPIS UNIVERSITATIS

1905

vio. dot.liarcer.

1906 


\section{SETTII I}

\section{FLORAE ECUADORENSIS Auctore ALOISIO SODIRO S. J.}

\section{I ACROSTICHA ECUADORENSIA NOVA}

(Extracto de los "Anales" de la Universidad de Quito, Tomo XIX, N" 135)

5) 19 GLABRA. Limbis sterilibus glabris;

I Rhizomate brevi erecto vel breviter repente;

A Limbis ster. coriaceis;

\section{$A$ Limbis ster. latitudine sua to ${ }^{\text {es }}-\infty{ }^{\text {es }}$ longioribn's;}

a Limbis ster. in stipites breves longissime decurrentibus;

1 Acrostichum (Elaph.) longissimum sp, nov. glabrum; vhizomate brevi, erecto, crasso; squamis hyalinis, ilnearibus, elongatis, laciniatis apice dense obtecto; stipitibus brevissimis, approximatis, cum phyllopodio brevi articulatis, limbo longissime decurrente alatis; limbis coriaceis, utrinque intense viridibus (in vivo) metallice nitentibus, metrum et ultra longis, $2 \frac{1}{2}-3 \mathrm{ct}$. latis, utro- 
versus gradatim longe angustatis; costa supra leviter exerta medio I-sulcata, subtus convexa; nervis tenuibus subtus immersis, in sicco supra leviter exertis. fere horizontaliter patentibus, plerisque iterum bifurcatis, intra maryinem cartilagineum in glandulam modice capitatam terminatis; fronde fertili ignota.

Differt a sequente: squamis rhizomatis multo longioribus, limbis in stipites 3-5 ct. longos longissime decurrentibus, nervis tenuioribus, supra basin areuatam, fere horizontaliter patentibus.

Crescit in silvis tropicalibus prov. Esmeraldas ad flumen Santiugo, altit. $70 \mathrm{~m}$. s. mare.

b Limb. ster in stipites longos angustatis.

2 A. (Elaph.) Christii sp. nov. L. I. glaberrimum; rhizomate breviter repente crasso, squamis cupreis, linearibus parce longeque laciniatis, perdense congestis obducto; stipitibus approximatis cum phyllopodio ( I 2 - I 5 $\mathrm{mm}$. longo) articulatis; sterilibus $3-4 \mathrm{dm}$. longis, $2 \frac{1}{2}-3$ $\mathrm{mm}$. crassis, antrorsum plano-convexis, obiterque unisulcatis dorso convexis, latere utroque linea parum pro minente e basi limbi decurrente notato; limbis sterilibus lineari-lanceolatis, $7-12 \mathrm{dm}$. longis, $2 \frac{1}{2}-3 \frac{1}{2} \mathrm{~cm}$. circa medium latis, utroversus gradatim angustatis acutis, margine \pm revolutis, dense coriaceis, supra cyaneoviridibus et metallice nitentibus, subtus flavido-glaucescentibus punctisque ni gris parce conspersis; costa utrinque parum prominula, supra obiter 1 -sulcata; nervis lateralibus utrobique immersis, remotis erecto-patentibus purum conspicuis, semel iterumve 1 furcatis, in glandulam capi atam intra marginem ca:tilagineum terminatis; stipitibus fert. 8-12 cm. Jongis, quam steriles graciliori bus; limbis $25 \cdot 35 \mathrm{~cm}$. longis, $\pm 2 \mathrm{~cm}$. latis, cum sterilibüs isonorphis, structura flaccidiore, supra pallide-viri- 
dibus, nervis vix conspicuis; sporangüs subrotundis v. subrotundo-obovatis, annulo Io- 12 articulato cinctis.

Species insignis nullique e speciebus mihi hactenus cognitis (praeterquam praecedenti) affinis; frondium forma, structura, consistentia et colore potius Polypodiis quibusdam e sectione Campyloneum, quam ceteris suis congeneribus accedit.

(D. i. s. v.)

Crescit in silvis suband. occ. $m$. Pichincha prope $P e$ lagallo (3/902).

B Limb. ster. latitudine sua $4_{-5}^{\text {ter }}$ longioribus, basi olntusa vel subtruncata.

3) A. (Elaph.) Angamarcanum sp. nov.; rhizom. modice crasso, erecto, brevi, apice stipitibusque iunioribus squamis tenuibus rufescentibus, lanceolatis, in apicem filiformem protractis, longe tenuiterque ciliatis, dense obtecto; stipitibus sterilibus $8-15 \mathrm{~cm}$. longis, stramineis, laevibus, cum phyllopodio nigrescente, $8-12 \mathrm{~mm}$. longo, articulatis, dorso convexis, antrorsum I-sulcatis; limbis steril. elongato ellipticis, basi subtruncatis v. obtusis, apice obtusis, saepe crispatis et margine undulatis, coriaceis, utrinque laevibus nitidis; costa straminea nuda (iuniore squamis paucis nigrescentibus deciduis conspersa) supra I-sulcata, dorso convexa; nervis tenuibus in parenchymate crasso immersis, divaricato-patentibus, 2-3 bifurcatis et quandoque irregulariter vicissim confluentibus, prope marginem cartilagineum revolutum in glandulam parvam terminatis; stipit. fertil. quam steriles parum brevioribus; limbis $10.15 \mathrm{~cm}$. longis, $2-3 \mathrm{~cm}$. latis, apice obtusis, basi subtruncata, infra partem fertilen longiuscule in stipitem producta; costa subtus squamis atris minutis, parce conspersa.

Crescit in silvis suband. occ. regionis Angamarca (11/900).

Species habitu, consistentia, aliisque caracteribus a ceteris nostratibus longe diversa (vid. infra N? 5). 
B Limb. steril. membranaceis.

A Limb. steril. in stipites brevissimos longe decurrentibus.

4 A. (Elaph.) subsessiletsp. nov. rhizomate erecto, modice crasso, apice squamis minimis subulatis caducis obtecto; stipitibus congestis cum phyllopodio brevi articulatis; $1-1 \frac{1}{2} \mathrm{~cm}$. longis; limbis ster. $40-55 \mathrm{~cm}$. longis, $68 \mathrm{~cm}$. latis, tenuiter membranaceis, pellucido-punctatis, glaberrimis oblanceolatis, a $1 / 4$ superiore erga apicem acutum contractis, deorsum longe cuneatis, basi obtusa, fere ad phyllopodium extensa; costa supra vix exerta, Isulcata, subtus validiore convexa; nervis subpatentibus, $2.3 \mathrm{~mm}$. ab invicem remotis, semel iterumve bifurcatis, intra limbi marginem in glandulam crassam terminatis; fronde fert. ignota.

Crescit in silvis trop. prov. Esmeraldas ad flumen Cachaby, prope Ventanas (8/904).

Species structura, forma et magnitudine frondium apprime distincta et Polypodio crassifolio, quoad frondis habitum, quodammodo comparanda.

\section{$B$ Limbis ster. (et fert.) longe stipitatis.}

a Lbs. fertil. utroversus acuminatis, quam ster, minorib. eisque similibus.

5 A. (Elaph.) Pangoanum sp. nov.; rhizomate brevi, modice crasso; squamis linearibus subulatis, nigris, margine dentatis obtecto; stipitibus sterilibus limbos subaequantibus, squamisque cum iis rhizomatis similibus sed raris, una cum costa conspersis; limbis oblongo-lanceolatis, $20-30 \mathrm{~cm}$. longis, $57 \mathrm{~cm}$. latis, apice obtusis vel acutis, basi cuneatis, margine undulato vel crispato, membranaceis, supra intense viridibus, subtus pallidioribus, utrinque squamulis minutis, nigrescentibus, caducis, in costa maioribus conspersis; costa modice crassa, supra fere plana, subtus convexa; neriis tenuibus, erecto-patentibus, semel iterumve bifurcatis, intra marginem in glandulam capitatam desinentibus; stipitibus fert. steriles superantibus; limbo fertili $15-20 \mathrm{~cm}$. longo, $3.4 \mathrm{~cm}$. lato, utrinque acuminato, iuniore utrobique squamoso,

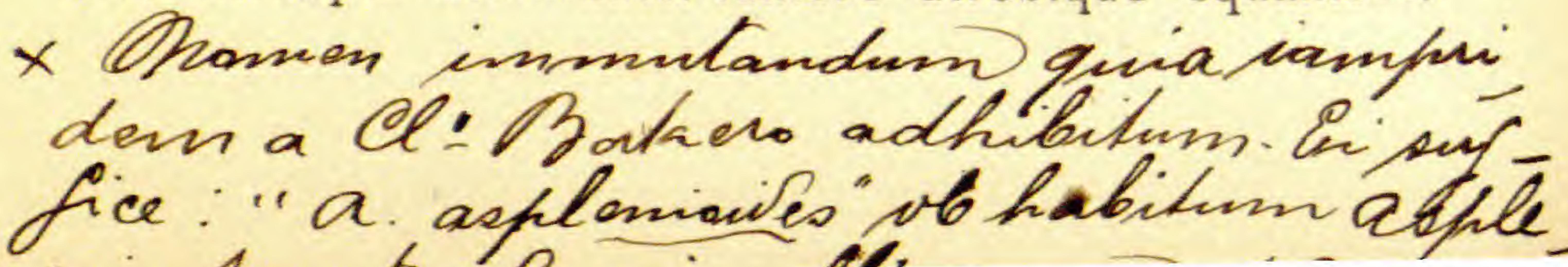


demum glabrescente, subtus area sorifera late intra marginem limitatam.

Crescit in silvis subtrop. andium occ. prope Pangoa.

Species A. Angamarcano quadantenus affinis, sed limborum textura, nervatione et forma, necnon squamis rhizomatis stipitumque diversa.

b Limb. fert. apice obtusis, basi cuneatis, quam steril. multoties minoribus.

6 A. (Elaph.) pellucidum sp. nov.; rhizom. tenui, erecto, apice squamis, parvis atris, nitidis, lanceolato-subulatis, margine denticulatis; stipit. approximatis, gracilibus, rigidis, in sicco $I$-sulcatis, squamis caulinis similibus, semirhomboideis parce conspersis, sterilibus $25-30$ $\mathrm{cm}$., fertil. $30.55 \mathrm{~cm}$. longis, subaeque crassis; limbis steril. membranaceis, supra intense, subtus pallide-viridibus; squamis minimis, nigrescentibus, cadıcis, conspersis, 35$40 \mathrm{~cm}$. longis, infra medium $8-10 \mathrm{~cm}$. latis apice aristato mucronatis, obtusiusculis, basi in stipitem subito contractis acutis; costa tenui supra complanata, subtus rotundata; nervis tenuibus, prope basin bifurcatis, $2.3 \mathrm{~mm}$. ab invicem remotis, ante marginem in glandulam capitatam terminatis; limbo fertili $12-15 \mathrm{~cm}$. longo, $21 / 2 \mathrm{~cm}$. lato, apice obtuso, basi sterili in stipitem producta; sporangiis flavescentibus.

Crescit in silvis tropic. prov. Esmeraldas, ad fl. Cachaby, prope S. Antonio (8/904).

Species A. papilloso Bak subsimilis. Differt textura tenuiore, limbis apice abrupte con.ractis (non gradatim angustatis), limbo fertili multo minore, apice obtuso, stipitibus utriusque frondis gracilioribus.

II Rhizomatc elongato, subscandente; limb. steril. chartaceis;

A Stipit cylindricis, nudis, limbos subarquantibus.

7 A. (Elaph.) Oleandropsis sp. nov.; Rhizomate erecto, late repente vel scandente, $4.5 \mathrm{~mm}$. crasso, cum phyllopodio nigrescente I. I $1 / 2 \mathrm{~cm}$. longo, squamis lanceolatis, 
integris, basi infra insertionem hinc in auriculam rotundam $11 / 2 \mathrm{~mm}$. longam productis, apice longe subulatis, hyalinis, pallide-flavescentibus obtecto; stipit. basi cum phyllopodio articulatis, tenuibus erectis, rigidis, subcylindricis, 1 $2 \mathrm{dm}$. longis, $\pm \mathrm{I} / 2 \mathrm{~mm}$. crassis; limbis oblongo-lanceo. latis, utroversus gradatim angustatis, vel basi subovatis, cartilagineis, pallide-viridibus, glaberrimis, pellucidopunctatis; costa utrobique exerta, subtus validiore; ner. wis tenuissimis, vix exertis, horizontaliter patentibus, semel iterumve bifurcatis, quandoque irregulariter anastomosantibus, in marginem callosum (more Aconiopteris) confluentibus; fronde fertili ignota.

Crescit in silvis tropic. prov. Esmeraldas (8/904).

Squamarum forma et insertione, stipitum longitudine et consistentia itemque limborum textura et venis in marginem callosum horizontaliter tendentibus et confuentibus, apicibus vix incrassatis, itemque margine hyalino limbos ambiente, optime convenit cum Aconiopteri longifolia Fée (Acrostichées pag. 8o, t. 41) a qua tamem pluribus e caracteribus enuntiatis apprime differt. Limborum consistentia numero et directione venarum Oleandram nodosam quadantenus imitatur, unde nomem desumptum.

Species uti videtur, admodum rara, cuius unicum specimem in ditione nostra hactenus repertum est.

\section{B Stipitib. quam limbi longe decurrentes multoties brevioribus.}

8 A. (Elaph.) pteropodum sp, nov. rhizomate erecto, vel subscandente stipitibusque brevibus haud articulatis, squamis parvis lineari-subulatis nigrescentibus deciduis consperso; stipitibus ster $11 / 2.2 \mathrm{~cm}$. longis, subtrigonis; limbis ster. cartila gineis, utrimque viridibus, glabris, 6.7 dm. longis, 56 ct. (supra medium) latis, sursum in apicem obtusiuicu? un, deorsum in stipitem brevem lonyissime et gradatim angustatis; costa robusta, supra profunde I-sulcata, subtus rotundata in vivo straminea; nervis tenuibus, utrinque vix exertis, semel aut iterum bifurcatis, 
erecto-patentibus, $1 \frac{1}{2} \mathrm{~mm}$. ab invicem remotis, in glandulam capitatam late intra marginem desinentibus; stip. fert. 49 ct. longis; limbis fert. quam steriles parum longioribus et $1 / 3$ angustioribus, in triente superiore tantum soriferis et oblongo lanceolatis, apice acuminatis, deorsum longissime et gradatim in stipitem productis.

Crescit in silvis subandinis occidentalibus m. Pichincha inter Chiquilpe et Pacay (2600-900 m.)

(1. SE'rosa. Stipitibus ïmbisque pilis squamisve setiformibus, plus minusve dense obtectis.

A Limbis subsessilibus flaccidis, pilis fulvis ramosis, dense obtectis,

9 A. (Elaph.) cladotrichium sp. nov. rhizomate breviter repente modice crasso, squamis linearibus fulvis, longe ciliatis dense obtecto stipitibus approximatis; sterilibus brevissimis, cum phyllopodio $3.5 \mathrm{~mm}$. longo articulatis, a dorso compressis, ancipitibus, marginatis, squamis angustissimis, longissime ramoso-ciliatis vestitis; limbis steril. late lineari-lanceolatis, deorsum ad phyllopodium usque gradatim angustatis, sursum brevius in apicem obtusum vel acuminatum contractis, pilis fulvis in costa margineque longioribus fere dendroideo-ramosis, in pagina utraque, longe radiatis, in inferiore potissimum, dense conspersis; textura flaccida; costa supra fere plana, subtus leviter prominente convexa; nervis tenuibus, I I $1 / 2$ $2 \mathrm{~mm}$. remotis, semel iterumve bifurcatis in limbi margine calloso in glandulam punctiformen desinentibus; limbis fert. longius (4-5 ct.) stipitatis, linearibus, basi longe decurrentibus (in specimine manco quod prostat) ad $10 \mathrm{ct}$. longis $4.5 \mathrm{~mm}$. latis, supra, ut steriles, setosis, margine revoluto, late cartilagineo; sporangiis parvis, abdiis, annulo incompleto sub- IO articulato cinctis.

Crescit in silv. subtropic, vallis Nanegal (10/901).

Species A. Haynaldii nostro habitu et textura similis, sed indumento prorsus diverso, stipitum longitudine, et $\mathrm{f} r \mathrm{ma}$ limbi fertilis omnino diversa. 
B Limbig ster, longe stipitat is (stipitibusque) setis simplicibus fuligineis in costa margineque indtrtis,

10 A. (Elaph.) trichophorum sp. nov rhizomate brevi, erecto, crasso, apice squamis lineari-subulatis, elongatis, denticulatis, hyalinis fulvis dense ohtecto; stipitibus ster. $25 \cdot 30 \mathrm{ct}$. longis, cum phyllopodio brevi articulatis, antice trisulcatis, stramineis una cuin costa et limborum marine setis ex basi ampliata, subulatis, fuligineis, diva ricatis vel retrorsis dense obsitis: limbagssoblongo-lanceolatis, utroversu: (deorsum brevius) angustatis, acutis, cartilagineis, fusce-viridibus, supra (costa excepta) glabre scentibus subtus dense setulosis; costa supra parum prominente, I-sulcata, subtus convexa; nera'is tentissimis, fere horizontaliter patentibus, semel aut iterum bifurcatis, apice vix incrassato prope marginem terminatis. Fronde fertiti ignota.

Crescit in silv. subtrop. oriental. vulcani Tunguxdhua (\$2/904):

Species frondium magnitudine, textura et indumento insignis. A. scolopentrifolio Raddi potissimam affinis, sed tum textura, tum indumento diversa:

6. 30 squamosa. Stipitib limbisque squamis latis plus minusve obtectis.

A Stipil ster. quam fertiles breyioribus; fquamis subrotundis, byalinis, breviter ciliatis;

II A. (Elaph.) Litanum sp. nov. rhizomate erecto, modice crasso; squamis subrotundis, cartilagineis, integris, obtecto; stipitibus sterilibus cum phyllopodio elongato articulatis, brevibus, squamis suborbicularibus inteyris et longe ciliatis, divaricatis obtectis; limbo sterili $2530 \mathrm{~cm}$. longo; $3.4 \mathrm{~cm}$. lato, utroversus, (erga basin longius) angustato, fere usque ad phyllopodium producto, tenuiter papyraceo, supra squamis tenuibus albidis, subrotundis, maryine longe ciliatis, dense consperso, subtus subglabro, minute punctato, margine squamis hyalinis longe ciliatis patentibus instructo; costa supra sparse sq amosa, demum glabrata, subtus validiore et densius 
squamosa; meruis patentibus tenuibus, utrobique leviter exertis, in glandulam parvam intra marginem terminatis; stipite fertiti gracili, $20-25 \mathrm{~cm}$. Iongo, subancipite, cum costa supra squamis suborbicularibus integris vel ciliatis, dense consperso; limbo supra squam is parvis, radiate ciliatis arcte adpresis consperso, margine cartilagineo nudo; sporangiis flavo-virentibus.

Crescit in silvis prov. Esmeratdas ad flumen Lita.

B Squm is lancenlatis ferrugimeis, longe serrato-ciliatis; stipit. ster, 8 -12 ct. ongis, sit:

12 A. (Elaph.) actinolepis sp. nov. thizomate brevi, modice crasso; squamis linearibus, cupreo-ferrugineis, ciliato-serratis dense obtecto; stipitibus steril, fasciculatis, erectis, rigidis, una cum costa dense squamosis, quam limbi 2 3 plove brevioribus: limbis oblongo-lanceolatis, $25.30 \mathrm{~cm}$. longis, $3.5 \mathrm{~cm}$. latis, a medio deorsum in stipitem angustatis, basi acutis, apice plerumque in cuspidem linearem contractis, coriaceis, supra praeter costam marginemque, squamis ovatis, subulatis, obtectis, mature glabratis, subtus squamis dim inutis ex basi ovata, sursum cuspidatis, dense conspèrsis; costa supra fere piana, subtus convexa; nerois tenuissimis, subpatentibus, prope basin bifurcatis in glandulam punctiformen iuxta marginem terminatis; stipite fortili quam fertiles tenuiore fere 2 -plo inngiore, limbo oblongo-lanceolato, $10-12 \mathrm{~cm}$. longo, $1 \mathrm{I} / 2$ $\mathrm{cm}$. laio margine non vel parcissime squamoso; sporansiis flavescentibus; annulo incompleto, 10.12 articulato.

Crescit in prov. Esmeraldas, secus flumen $\mathrm{Ca}$ chabi et Lita. frondium sterilium.

Species insignis squamis petioli, costae et marginis

B Stipit, ster, quam fertiles longioeibus; sqmamis rhizomatis et stipitum elongatis subintegris.

13. A. (Elaph.) Hieronymi sp. nov. Rhizomate crasso, erecto, apice, cum phyllopodiis brevibus, squamis li- 
nearibus hyalinis, $2 \mathrm{I} / 2-3$ ct. longis densissime comoso; stipitibus steril. robustis, limbos superantibus, basi cum phyllopodio articulatis, antice 2 -sulcatis, stramineis, squamis rhizomatis sed brevioribus aliisque parvis asteroideis nigrescentibus conspersis, demum glabrescentibus; limb. ster. oblongo-lanceolatis utrinque acutis, sursum longius angustatis, $5.6 \mathrm{dm}$. longis, IO-1 $5 \mathrm{ct}$. latis, dense coriaceis, utrinque intense viridibus, supra glabris v. mox glabratis, subtus squamis parvis, profunde multifidis fuligineis conspersis; costa supra vix exerta 1 -sulcata, subtus crassa convexa; nervis tenuibus approximatis, horizontaliter patentibus iterato-bifurcatis et in areolas elongatas irregulares crebro anastomosantibus, intra marginem cartilagineum desinentibus; stipit. fert. quam ster. brevio. ribus tenuioribus; limb. fert. 30.35 ct. longis, $7.8 \mathrm{ct}$. basin versus latis, ovali-lanceolatis, textura, quam steriles tenuiore, supra, praesertim in costa, ut pagina inferior sterilium, squamulosis; nervis tenuibus, laxe et irregula. riter reticulatis.

Crescit in silv. suband. orientalib. vulc. Tungurahua (1 2/904).

Species insignis. Statura, A. Bakeriet A. heliconiaefolii aemula; sed textura et nervatione prorsus diversa. Squamis rhizomatis et textura coriacea limborum A. latifolio eiusque contribulibus adsocianda, a quibus tamen indumento et nervatione hymenodioidea limborum facile distinguitur.

14 A. (Elaph.) decoratum Kunze. Species inter elegantiores huius generis iure merito recensenda et nunc primum intra limites Florae nostrae [in prov. Esmeraldas] reperta; eius descriptionem hoc loco omittimus, tum quia species iampridem aliunde cognita, tum etiam quia nonnisi specimina imperfectiora possidemus. 


\section{PIPER}

1 Faliis penninerviis.

I Piper sulcatum sp. nov. frutex I-2 metralis; ramis striatis membranisque e petiolorum basi decurrentibus anguste alatis, brevissime retrorso-pubescentibus demum glabratis; petiolis $5^{-1} 5 \mathrm{~mm}$. longis, basi dilatata late membranacea amplexicaulibus, anguste usque ad limbi basin alatis, plurinerviis, cum costa nervisque subtus breviter puberulis; limbis penninerviis membranaceis supra intense viridibus, glabris subtus virentibus, iunioribus punctis lineolisque pellucidis notatis, oblongo-vel ovali ellipticis, basi obtusa et profunde $[5-8 \mathrm{~mm}$. $]$ retusa, e triente vel quadrante inferiore sursum in apicem acutum gradatim angustatis; nervis [costaque] tenuibus, supra vix, subtus leviter prominulis, 8-10-iugis, omnibus intra marginem in reticulum tenuem deliquescentibus, addito nervulo tenuissimo margini subtus adpresso; pedunculis oppositifoliis, $3-4 \mathrm{~mm}$. longis, crassiusculis, puberulis; spicis, in specimine adhuc iunioribus, $4-5 \mathrm{ct}$. longis, $3-4 \mathrm{~mm}$. crassis; bractea subtrigona, puberula; stam. 3 stylo elongato, apice trilobo.

Crescit in silv. subtropic. declivium orient. vulc. Tungurahua [1 2/904].

\section{Folits multinerviis.}

? Piper candicans sp. nov. fruticosum, I- I $1 / 2 \mathrm{~m}$. altum, fere e basi subpyramidatim ramosum; ramis teneris, petiolis foliisque subtus (praesertim in nervis) pilis brevissimis, albidis, candicantibus; petiolis $4-5 \mathrm{~cm}$. longis, ad 
$1 / 2$ - $1 / 3$ vaginatis, basi amplexantibus; limbis dense membranaceis late cordato-ovatis, $10-15 \mathrm{~cm}$. longis, $8-12 \mathrm{~cm}$. latis, basi profunde $(2-3 \mathrm{~cm}$.) cordatis apice longe acuminatis, supra subglabris vel mox glabrescentibus rugosis, scabridis, subtus lacunoso-alveolatis $\infty$-nerviis; lobo terminali basi 3 nervio; nervis lateral. cum centrali in lobi apicem convergentibus; lobis lateral. 5-nerviis nervo cuiusque intimo ad $1 / 5$ partem superiorem, ceteris gradatim inferius, intra marginem in reticulum resolutis: pedunculis oppositifoliis, $1 \mathrm{I} / 2-2 \mathrm{~cm}$. longis; spicis gracilibus, cylindricis, pendulis, IO. $15 \mathrm{~cm}$. longis, $34 \mathrm{nim}$. crassis, flavescentibus; bracted apice truncato dilatato puberula; bacca fere obpyramidata, angulata, apice truncato margine hirsuto.

Crescit in silvis tropical. prov. Esmeraldas inter $C a$ chaby et Alto-tambo.

Species statura, ramificationis ordine, fcliorum forma colore et nervatione a ceteris nostratibus hactenus cognitis apprime distincta. Piperi abutilifolio c, DC. (Arthanthe abutilifolia Miq) habitu et forma foliorum valde similis; differt indumento candicante; folizs rugosis, supra scabridis, 14.15 nerviis, petiolis ad $1 / 2-1 / 3$ partem tantum vaginantibus, spicis tenuioribus limbos subaequantibus.

III Foliis multiplinerviis; lobis hasalibus valde inaequalibus;

* Lobis basal. plus minusve mutuo in limbum peltatum coalitis.

3 Piper Candollei sp. nov. L. II. fruticosum, 3-4 m. altum ramulis cum petiolis costa nervisque 1 . longiuscule denseque fuligineo-tomentoso-hirtis; internadiis elongatis; petiolis Ir). I $5 \mathrm{~cm}$. longis, usque ad $1 / 4$ partem superiorem late vaginatis; limbis subcoriaceis, supra intense viridibus glabris, subtus pallidioribus, fuliginoso-hirtis, 4.5 $\mathrm{dm}$. longis, $30-35 \mathrm{~cm}$. latis, basi inaequalibus, obliquis, ovalibus apice breviter acuminatis, inaequilateris, basi ad 
I 0 - I $2 \mathrm{~cm}$, infra petioli insertionem peltatis, nunc lobis \pm alte liberis ex parte ssmet obtegentibus, valde inaequalibus, rotundatis, maiore (limbi partem latioren continuante). IO. I $2 \mathrm{~cm}$. longo, aeque ac lato, altero $\pm 1 / 4$ parte $\mathrm{mi}$ nore, $\infty$-pli-nerviis; nervis supra impressis, subtus, exertis: I. costalibus ( $\bullet$ basi ad dimidium costae) utrinque 4 , loborum basal. 3 et 4 ; omnibus longe ante marginem in reticulum laxum resolutis; pedunculis gracilibus, petioli dimidium vix aequantibus, cylindricis, vix duo mm. crassis, reflexis: spicis limbos aequantibus vel superantibus, (50.65 ct. longis) $4.5 \mathrm{~mm}$ crassis; bractea angusta apice truncata; bacea fere obovata apice orbiculari, centro nudo, margine et deorsum hirsuta.

Crescit in silvis subtropical v. Tungurahua, secus flumen Pastasa (1 2/904).

Species inter nostrates maxima; forma foliorum, longe supra basin peltatormm et indumento facile distinguenda.

\section{** Lobis basal. liberis, maiore cochleaeformi.}

4 Piper cochleatum sp. nov. frutex 2-3 metralis; ramis striatis, pilis fuligineis retrorsis una cum petiolís foliisque subtus ad basin nervorum longe denseque hirsutis; petiolis 3-5 ct. longis, basi amplexantibus, usque ad limbi basin late alatis; limbis multiplinerviis papyraceis, opacis, in sicco fuscis, utrinque glabris, $20.25 \mathrm{ct}$. longis IO-I 2 ct. latis, ambitu subellipticis, apice acutis, inaequilateris, basi obtuse bilobatis, lobo interiore Lrami axi proximo $\pm 2 \mathrm{ct}$. longo, $3-3 \mathrm{t} / 2 \mathrm{ct}$. lato, retrorso, lobo exteriore cochleaeformi subrotundo, 6-7 ct. Iongo ac lato, ramum, petiolum et lobum interiorem tegente, apice suprab petioli insertionem converso vix 1 ct. libero; radiatim 5nervio; costa ad $1 / 4$ partem supra basin nervos laterales utrinque duos sub angulo valde acuto ascendentes et superius alios utrinque 4-5 tenuiores divaricatos mittente, 
omnibus, et costa ipsa, supra immersis, subtus prominentibus, in reticulum laxum intra marginem resolutis; inflorescentia [in specimine unico adhuc admodum iuvenili] oppositifolia; pedunculo vix $5 \mathrm{~mm}$. longo hirsuto, reflexo; spica I $1 / 2$ ct. longa; bractea suborbiculari, glabra, [-Cetera ignota.]

\section{Crescit cum praecedente.}

Species habitu ac potissimum lobi alterius magnitudine et in cochleae formam, gyro completo, super ipsum convoluti a ceteris omnibus primo intuitu facile distinguenda. 


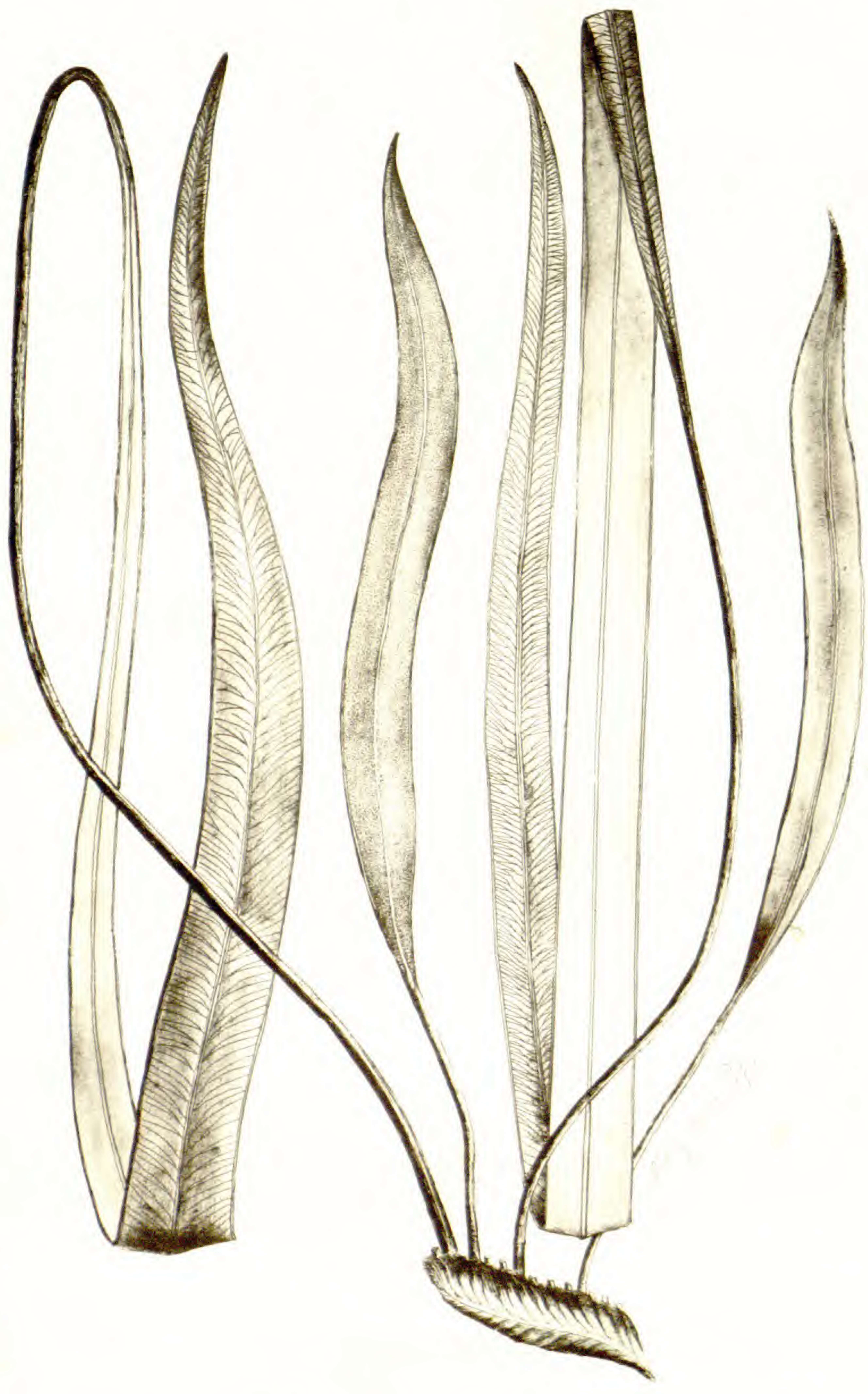

ACROSTICHUM CHRISTII SOD. 


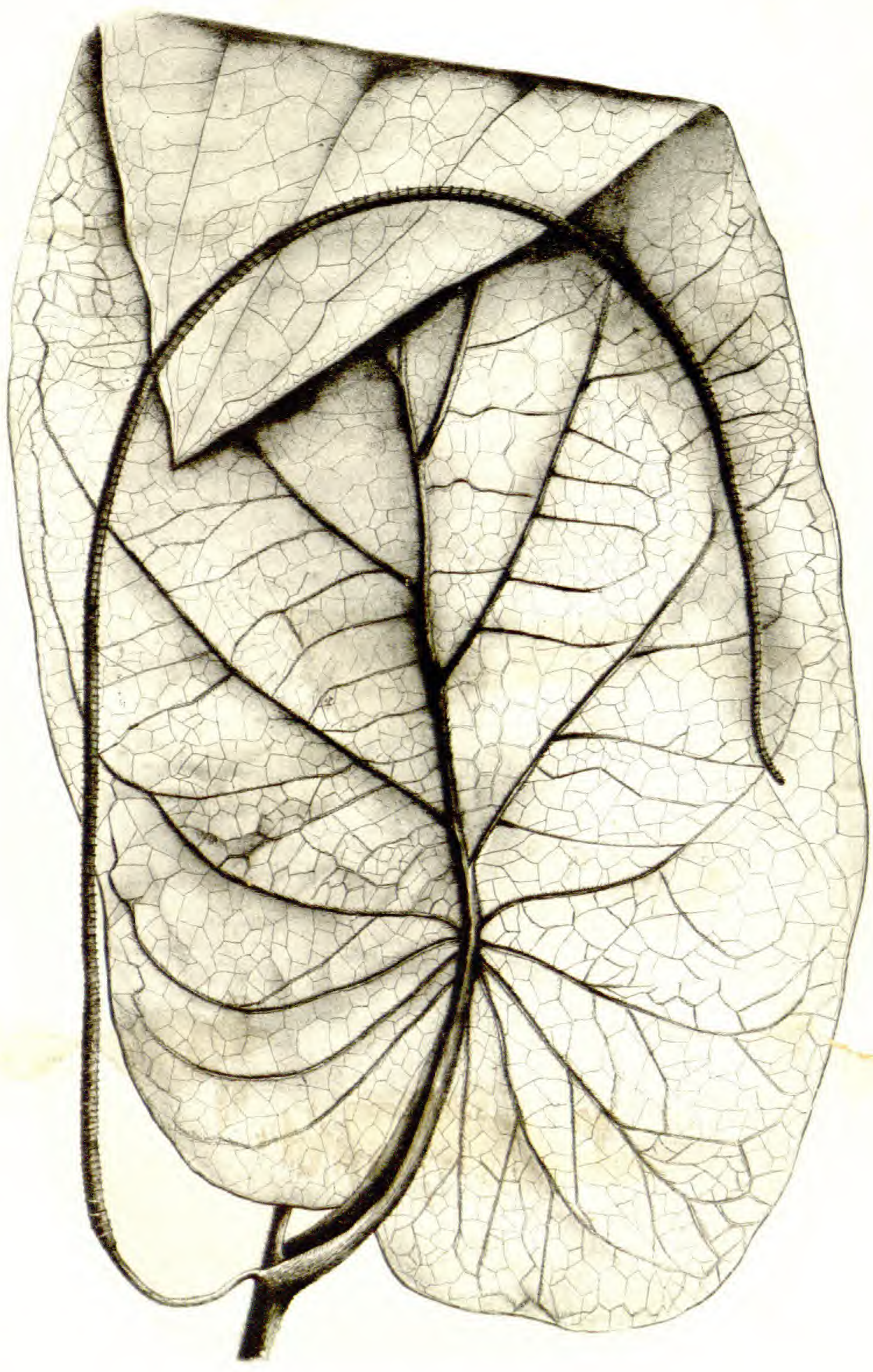

PIPER CANDOLLEI SOI. 
. 


\title{
SERTULA
}

\section{FLORAE ECUADORENSIS}

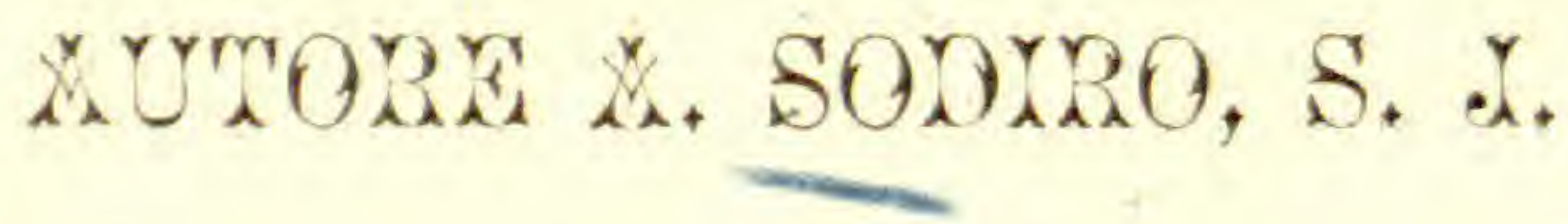 \\ I \\ I'ARIDOPHYTA
}

SERIES II

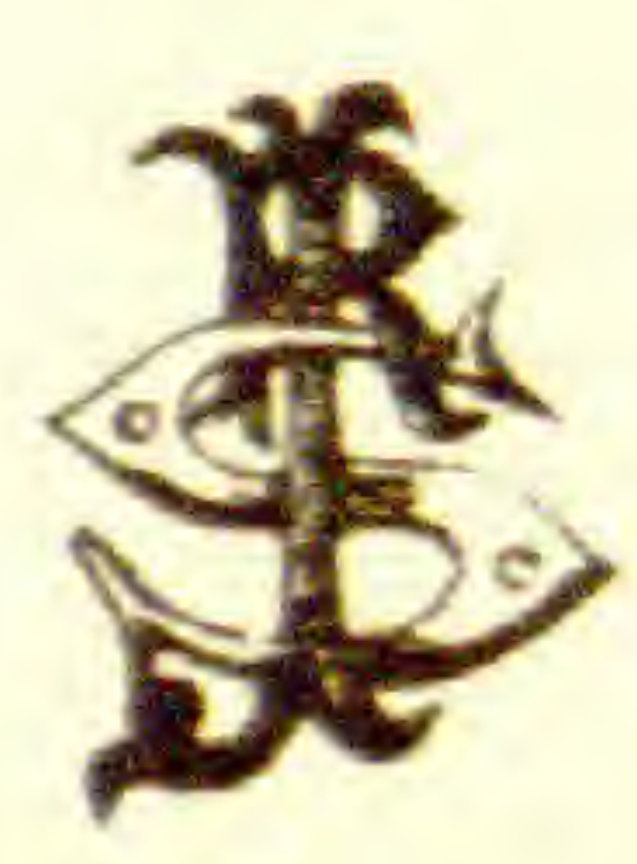

QUITI

TYPIS UNIVERSITATIS

JUN.

1908 


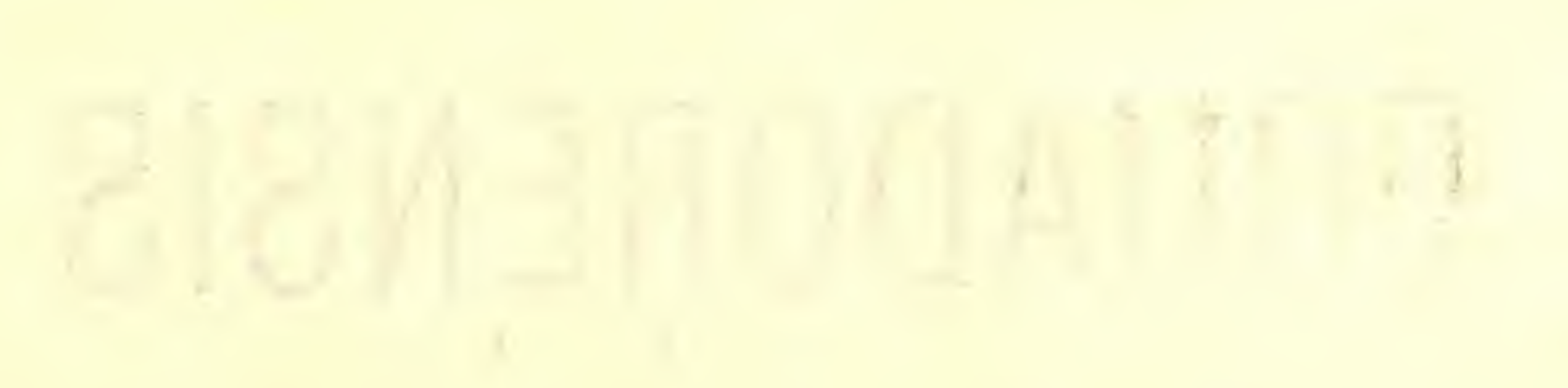




\section{SERTULA}

\section{FIORAE EOUADORENSIS}

Auctore ALOISIO SODIRO S. J.

\section{I \\ PTERTDOPHYTA}

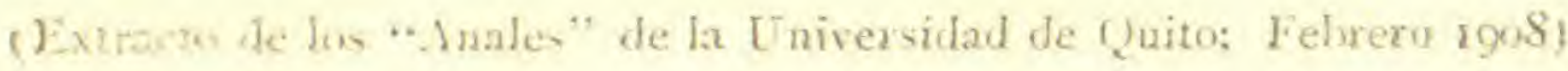

\section{(․ 1. UYATHEA SI.}

1 Froulucer cupulifurmi.

A Culke 2-4-metrali, cum stipitibus hecter muricati, squami lineari-

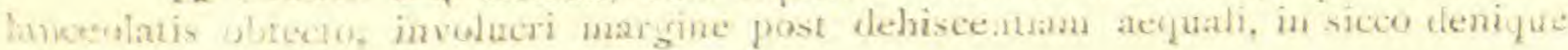
acines.

I C, milens sp. nov, arborescens; candice $2-4 \mathrm{~m}$. al10. 12 ct, crasso, cicatricibus subellipticis signato; stipitibus \pm 5 dm: longis, subsemicylindricis, stramineis, a lasi ad medium usque muricibus conicis dorso armatis, sursum rachibusque dorso vix scabridis, squamisque lanceolatis subulatis, dorso castaneis margine albidis, basi supra diu persistentibus, sursum mature deciduis et tomento furfuraceo obtectis, denique glabratis; frondibus $1,5-2$ metr. longis, $6-7 \mathrm{dm}$. circa trientem seperiorem latis, deorsum gradatim, sursum abrupte contractis, 3pinnatifidis, apice pinnatifidis; rachi rachillisque supia tenuiter hispidis, subtus glabris, stramineis; finnulis pedicello $610 \mathrm{~mm}$. longo instructis, $46 \mathrm{dm}$. longis, 1520 $\mathrm{cm}$. latis, e basi leviter contracta lanceolatis, pinnatis. apice pinnatifidis; pinnulis subsessilibus, $7.10 \mathrm{~cm}$. lon- 
gis, I $_{2}$ - $5 \mathrm{~mm}$. latis, subcoriaceis, supra intense viridibus nitidis, subtus pallide-glaucescentibus, apice cuspidato serrulatis, fere usque ad costam in segmenta margine obiter denticulata, apice obtusa divisis; venis 6-7-iugis, prope basin furcatis in bifurcatione soriferis, superioribus indivisis; soris flavido-virescentihus, 3-5-jugis; inolucro brevi cupuliformi, cartilagineo, hyalino, margine aequali, denique, exsicando, irregulariter discisso.

Crescit in silvis suband. occid. vulc. Corazon.

Species C. arboreae proxima; differt stipitibus rachibusque stramineis, laevibus, involucro tenuiore, primum cupulari, denique, exsiccando irregulariter discisso.

B Candice humili, apice cum stipitibus aculeato, sguamis setiformibus onusto; involucro piloso-ciliato.

2 C. canescens sp. nov.; caudice humili (in specimine) $30-40 \mathrm{~cm}$. alto, $7.8 \mathrm{~cm}$. crasso, apicem versus, cum stipitum basibus squamis setiformibus, centro castaneis, maryine albidis, apice mucronulo nigro terminatis, dense obtecto; stipitibus 2-5-3 dm. longis, modice ( $1 \mathrm{~cm}$.) crassis, dorso teretibus, aculeis conicis, robustis, nigris, cum $1 / 3$ inferiore rachium armatis, squamisque pracedentibus similibus, sed usque minoribus et tomento pulverulento conspersis, demum glabratis; frondibus oblongis, 1-30$1.50 \mathrm{~cm}$. Inngis, in dimidio superiore 6-7 dm. latis, deorsum angustatis, bipinnato-pinnatifidis; rachibus strami. neis, dorso semiteretibus, supra, ut stipites, plano-concavis: pinnis alternis, remotis, breviter petiolatis oblongis, apice pinnatifidis, inferioribus minoribus et lonuins stipitatis; rachillis subtus demum glabratis, supra setulosohispidis; pimnlis subsessilibus, utrinque 2025 , linearilanceolatis, profunde pinnatifidis, apice acuminato dentatis, supra, praeter costam setuloso-hispidam, glabris, subtus parce squamulosis: segmentis ligulatis, obliquis, apice obtusiusculis, margine denticulatis: vemis 7-9. plerisque simplicibus, prope costam soriferis; soris 2-5-iugis, maius culis, albidis; indusio incompleto. hyalino, piloso, post de hiscentiam cupuliformi, margine ciliato; sporangizs sessilibus, cuneatis, annulo incompleto cinctis; sporis obtuse trigonis; receptaculo clavato, pubescente. 
Crescit in silvis suband. et subtrop. vulc. Pichincha et Atacatzo.

Species C. incanae Karst. potissimum indumento, caudicis apicem obtegente, similis; a qua, iuxta auctoris descriptionem, differt caudice humiliore, squamis ipsis aliter conformatis; frondibus minorihus, venis segmentorum simplicibus raro 2-furcatis; involucio incompleto, post dehiscentiam late cupulari, margine piloso.

Probabiliter C. incanae varietas.

11 Inzolucro verticaliter et \pm irregulariter dehiscente.

A Candice apice et stipitihus squamis setaceis incanis et aculeis elongatis nigris instructis;

a Cambice arborescente; froude obovato-oblonga, 2-metra et ultra longa; incelacio crustaceo, furfuraceo, irregulariter 4 -fido.

3 C. purpurascens Sod. (Cryptog. vasc. quitens. p. $523)$ * candicc elato, gracili, aculeato, apice, ut stipites. squamis setiformibus, $5-7 \mathrm{~cm}$. longis, albidis, demum ferrugineis, obtecto et frondibus numerosis $(8-10)$ late patentibus coronato; stipitibus $25-30 \mathrm{~cm}$. longis, basi $3 \cdot 4$ $\mathrm{cm}$. crassis, aculeis, robustis, nigris, inter squamas lineares setiformes, margine denticulatas occultis armatis et (praeter squamas) cum rachibus rachillisque et pinnularum costis, tomento pulverulento-ferrugineo dense wbtectis; frondibus bipinnato-pinnati-partitis, obovatociblongis, $221 / 2 \mathrm{~m}$. longis, $120130 \mathrm{~cm}$., in $1 / 3$ superiore Iatis, deorsum longius contractis, apice pinnatifidis; pin wis infimis $12-15$ cml., superioribus $6-7 \mathrm{dm}$. Iongis, $15 \mathrm{~cm}$. latis, breviter $(5.6 \mathrm{~mm}$.) stipitatis; pinnulis nunerosis coriaceis subsessilibus, e basi breviter contracta. lanceolatis, fere usque ad rachin pinnato-partitis, in apicem leviter crenatum productis. supra intense viridibus subtus glaucescentibus, in sicco flavescentibus; segmentis linearibus, falcatis, apice obtusis, margine subintegro tevolutis; acuis utrinque $\delta$ 10, prope basin bifurcatis; sors costae approximatis, utrinque 6-7: involucro crustaceo, furfuraceo, primum bivalvi, valva utraque demum irregulariter bifida.

* Haius speciei, quam loco citato ad specimina incompleta descripsimus, hic fusiorem descriptionem exhibemus. 
Crescit in silvis subandinis occid. vulc. Atacatzo [Julio 1907$]$.

A ceteris plerisque speciebus differt trunco pro elevatione gracili, aculeato, squamarum longitudine, stipitum brevitate, aculeis rachiumque indumento, soris denique numerosis costae adpressis, involucro crustaceo, subbivalvi, furfuraceo.

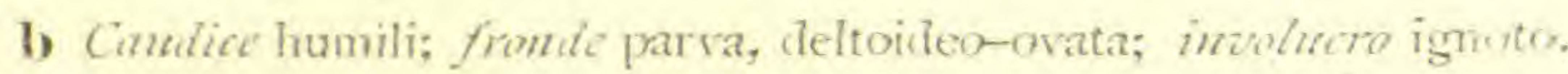

4 C. oxyacantha sp. nov.; caudice humili; stipitibus modice robustis, $\pm 60 \mathrm{~cm}$. longis, aculeis ad centimetrum longis, aduncis, nigris, sursum brevioribus, rarioribus armatis, squamisque subulatis margine albidociliolatis, centro pallide castaneis, retrorsis, sursum minoribus conspersis et, una cun rachibus rachillisque, purpurascentibus et tomentoso-hispidis, dorso subteretibus antice fere planis; frondibus $0-7 \mathrm{dm}$. longis, 4-5 dm. latis, subdeltoideis, 3 pinnatifidis, coriaceis, supra intense viridibus, subtus glaucescentibus; pinnis alternis, 2-3 infimis parum brevioribus, utrinque 30-I 2 subsessilibus, in apicem pinnatifidum gradatim angustatis, rachillisque utrinque purpurascentibus, glanduloso-hirtis; pimmulis subsessilibus, cum rachillis articulatis, lanceolatis, e basi latiore sursum in apicem serrulatum acuminatis, fere usque ad costam in segmenta linearia subfalcata, margine revoluta integra divisis, wonis utrinque $8-10$, plerisque parum supra basin bifurcatis; [soris ignotis].

Crescit in silvis suband. vulc. Atacatzo.

Huic generi, etiam fructificatione deficiente, hanc speciem adscribimus propter affinitatem cum C. purpurascente et C. canesconte.

Differt a C. canescente stipitibus longioribus, spinis longioribus aduncis armatis, squamisque brevioribus retrorsis, conspersis; fronde minore subdeltoidea, rachillisque (ut stipites) purpurascentibus, pinnis pinnulisque hrevioribus et deltoideo-lancerlatis. A C. purpurascemte. cui aculeis, et quadantenus etiam indumento accedit; differt stipitibus sub duplo longioribus et longe graciliori- 
bus, itemque forma deltoidea frondium et earundem statura longe minore.

B Candica apice stipitihusque deorsum squamis lanceolatis castaneis obtecto;

A Stifite muriculato $25-35 \mathrm{~cm}$. longo, parum supra basin pinnis 2 parvis, a ceteris remotis instructo; fronde delto:deo-ovata, 6-7 dm. longa.

5 i. parvifolia sp. nov.; caudice 2-3 m. alto, 7 $8 \mathrm{~cm}$. crasso; stipitibus $25-35 \mathrm{~cm}$. longis, et parum (I $\mathrm{dm}$.) supra basin iugo pinnarum ceteris minore instructis, una cum rachibus minute muricatis, squamisque lanceolatis, subulato-cuspidatis, margine serrulatis, cartilagineis, castaneis, nitidis et tomento brevi ferrugineo, dense obtectis, dorso mature nudatis; frondibus dense herbaceis, in sicco subcoriaceis, subdeltoideo ovatis, 7.8 dm. longis, 3-4 dm. latis, tripinnatifidis; rachibus flexuosis raquillisque subtus per vernationem squamosis, mature glabratis, supra ferrugineo-tomentosis, pinnis duobus accesoriis et 2 infimis $3-4 \mathrm{~mm}$. stipitatis, reliquis subsessilibus, plerisque alternis, divaricato-patentibus, $35-40 \mathrm{~cm}$. longis, 7-10 cm. latis; pimmlis subsessilibus, lanceolatis, 4-6 cm. longis, ro-1 $2 \mathrm{~mm}$. latis, profunde pinnatifidis, apice crenatis acutis; segmentis margine denticulatis, in sicco revolutis; venis utrinque $6-7$, plerisque furcatis; soris maiusculis, ferrugineis, costae approximatis, in quolibet segmento $7-8$; involucro tenui, hyalino, fragili, profunde et irregulariter dehiscente.

Crescit in silvis suband, occid. m. Pichincha.

Species frondibus, pro caudicis altitudine, parvis, stipite basi pinnis 2 accessoriis instructo, itemque indumento, praesertim per vernationem, singulari, insignis, nullique ex nostratibus hactenus notis affinis.

B Stifitib. haud appendiculatis, \pm muricatis;

a Stipitib. rachibusque deorsum squanosis et dense muricatis; fronte maiore.

« Stipitib. et frondith tomento pulverulento albido dense obtectis.

6 C. furfuracea Sp. nov.; caudice humili, 2-3 m. alto, I $2 \cdot 15 \mathrm{~cm}$. crasso, apice frondibus numerosis, horizontaliter patentibus coronato; stipitibus 4-5 dm. longis, IoI 2 mm. crassis, stramineis, muricatis, squamisque casta- 
neis, lanceolatis, in cuspidem subulatam contortam productis, unaque cum rachibus furfure pulverulento albido obtectis; frondibus circunscriptione oblongis, ad metrum longis, $6.7 \mathrm{dm}$. (circa medium) latis, tripinnatifidis; rachibus stramineis, deorsum dorso furfuraceis et muriculatis, supra complanatis, squamisque elongatis, quam stipitum tenuioribus conspersis: pinnis I. ordinis breviter stipitatis, a medio utroversus decrescentibus, maximis $30.35 \mathrm{~cm}$. longis, iuniorib!ns flaccidis, pendulis, rachibus gracilibus, cum pinnularum costa lepidotis, apice pinnatifidis; pinnulis sessilibus lanceolatis, apice acuminatoserrulatis, subcoriaceis, supra in costa setuloso-hispidis, 4-6 cm. longis, 8-10 mm. latis, profunde pinnatifidis; $s e g$ mentis lanceolatis, subfalcatis, apice acutis, supra primum sparse setulosis, demum glabris, subtus squamis vesiculosis conspersis, venis utrinque 8-10, inferioribus bifurcatis; soris maiusculis, costae approximatis in segmentis maioribus $4-5$.

\section{Crescit in silvis suband. $m$. Pichincha.}

\section{$\beta$ Stipitib. el frondib. parce tomentellis, glabris, vel mox glabratis;}

I Stipitib. 2-2, $5 \mathrm{dm}$. longis, acultato-muricatis; frond oblongo-elliptica, 8ro $\mathrm{dm}$. longa.

i C. brachypoda sp. nov:; Trunco humili, $(2 \cdot 21 / 2$ 11.: alto); stipitibus infra pinnas infimas vix $3 \mathrm{dm}$. longis, modice robustis, breviter et crebro muricatis, dense squamosis et, una cum rachibus, rachillisque subtus pulverulento-tumentosis; squamis $2 \frac{1 / 2}{3} \mathrm{~cm}$. longis, subcoriaceis, castaneis margine albidis, dorsalibus lineari-subulatis, antice basi latioribus; frondibus subobovatis 1,3$1.4 \mathrm{mt}$. longis, in $1 / 3$ superiore $4560 \mathrm{~cm}$. latis, deorsum contractis, in sicco fere coriaceis, bipinnato-pinnatifidis; rachibus in $1 / 3$ inferiore dorso muricatis et antice squamis linearibus conspersis, sursum scabridis, cum rachillis livido purpurascentibus, cinereo-tomentosis, demum glabratis; pinnis infimis minoribus ( $15-20 \mathrm{~cm}$. longis), anzustiontus, remotioribus, IO- $12 \mathrm{~cm}$. latis, $2-21 / 2 \mathrm{~cm}$. stipitatis, superioribus, subsessilibus, $25-30 \mathrm{~cm}$. longis, $12.15 \mathrm{~cm}$. latis, subdeltoideo lanceolatis, basi postice glandula munitis; pinnulis sessilibus, profunde pinnato. 
partitis; supra, praeter costam hispidam, glabris, subtus custa setuloso-hirta et tomentosa; segmentis linearib., falcatis, acutis, margine revoluto denticulatis, squamis heteromorphis, [plerisque vesiculosis] conspersis; venis [in segmentis mainribus] utrinque 6-8, plerisque bifurcatis; soris [in segmentis minoribus] 4-6-iugis, costae et sibi invicem approximatis; indusiis tenuibus, hyalinis, irregulariter dehiscentibus, diu persistentibus.

Crescit in silvis suband. vulc. Atacatzo.

Accedit, prae ceteris, C. Dyeri Soc, statura et habitu; sed differt pinnarum inferiorum situ, indumento, venis plerisque bifurcatis et sororum notis.

2 Stipitil. $25-35 \mathrm{~cm}$. longis nuricatis; fronde subobovata, 8-ro dm. longa.

8 C. asperata sp. nov. arborescens; trunco humili, [2-3 m. alto]; stipitibus 20-25 cm. longis, modice crassis, basi squamis castaneis, lanceolato-subulatis, 2 I/2 $3 \mathrm{~cm}$. longis, onustis, sursum rarioribus angustioribus et muricibus densis, \pm elongatis, asperatis, tomentoque pulverulento, denique deciduo, una cum rachibus obtectis; frondibus tripinnatifidis, $8-10 \mathrm{dm}$. longis, 5-6 dm. prope medium latis, circunscriptione ovato-ellipticis, coriaceis; rachibus in $1 / 3$ inferiore breviter muricatis et squamis linearibus conspersis, sursum dorso glabratis, supra, cum rachillis breviter pulverulento-tomentosis; pinnis deltoideo-lanceolatis, infimis reductis, $[15.20 \mathrm{~cm}$. longis $]$ breviter stipitatis, reliquis sessilibus, mediis $20-40 \mathrm{~cm}$. longis, I $2-14 \mathrm{~cm}$. latis, erecto patentibus, apice pinnatifidis; pinnulis sessilibus $5-7 \mathrm{~cm}$. longis, I $2-15 \mathrm{~mm}$. latis, sursum gradatim in apicem serrulatum angustatis, deorsum profunde pinnatifidis; costa supra hispidula, subtus squamis raris, polymorphis, mox deciduis, et tomento pilisque setulosis conspersa; venis utrinque $7-8$, inferioribus parum supra basin bifurcatis; soris in dimidio inferiore segmentorum, paucis [2.3-iugis] maiusculis, involucro completo, hyalino, fragili, demum irregulariter dehiscente.

Crescit in silvis suband. $m$. Pichincha $3 / 906$.

C. Schanchin proxima, sed partibus omnibus minor, stipitibus, praeter squamas muricesque, rachibusque sub- 
tus pulverulento-cinereis, demum glabris, involucro demum profunde diviso. bus, fronde minore.

$\beta$ brevipes, minor, stip. $2-2,5 \mathrm{dm}$. longis graciliori-

b Slipitib. et rachib, deorsnm parce et ohtuse muricatis, nudis stramineis;

a. Frondium textura membranaceo-cartilaginea; soris pro segmento pauci(2-3-iugis).

9 C. muriculate sp. nov.; arborescens; caudice 3$3 \mathrm{r} / 2 \mathrm{~m}$. alto, $12-\mathrm{I} 5 \mathrm{~cm}$. crasso; stipitibus $5.5 \mathrm{1} / 2 \mathrm{dm}$. longis, deorsum muricibus crebris, acutis brevibus, una cum rachium basi conspersis et squamis coriaceis, lineari-subulatis, centro castaneis, margine scarioso-albidis, denticulatis, basi confertis, sursum gradatim paucioribus et minoribus instructis; fronde tripinnatifida, $11 / 2 \mathrm{~m}$. longa, circa medium 7-8 dm. lata, atque hinc utroversus angustata, apice pinnatifida, pinnis infimis $15-20 \mathrm{~cm}$. longis, rachi flexuosa rachillisque dorso tenuiter pubescenti tomentellis, supra breviter hispidis; pimnis breviter petio latis, subpatentibus $35-40 \mathrm{~cm}$. longis, 10-1 $2 \mathrm{~cm}$. latis, basi vix contractis, sursum in apicem pinnatifidum gradatim contractis; pinmulis viridibus, subtus pallidioribus, in sicco cartilagineis, supra praeter costam hispidulam glabris, subtus in costa et secus venas hirtellis; inferioribus breviter $[2-3 \mathrm{~mm}$.] pedicellatis, ceteris plerisque sessilibus, lanceolatis, $6-7 \mathrm{~cm}$. longis, $12-15 \mathrm{~mm}$. latis, fere usque ad costam in segmenta lineari-ligulata adscendentia, margine 'sursum serrulata divisis, apice acuminato argute serrato; venis in segmentis 8-10, omnibus, pratter superiores, bifurcatis; soris costalibus 2-3 iugis, parvis, opacis; involucro tenui cartilagineo, fragili, irregulariter dehiscente; receptaculo subhemisphaerico, sessili, hispido.

Crescit in silvis suband. vulc. Cozazón. I $2 / 907$.

3 Frondinm textura firma subcoriaceat; sor's in quolibet segmento 4-8-iugis;

I Pinnulis subtus pubescentibus inter soros sparse squamosis; soris cupreb aeruginosis. 4-5-iugis.

10 C. subinermis $\mathrm{Sp}$. nov.; candice arborescente 2$3 \mathrm{~m}$. alto; stipitibus $3-4 \mathrm{dm}$. longis, robustis, cum rachi- 
bus dorso convexis, supra plano-concavis, breviter muricatis et squamis ex basi ovata lanceolato-subulatis, dorso ebeneis, margine scarioso albidis serrulatis, subtus mox denudatis supra prope basin diu persistentibus et tomento cinereo-puverulento obtectis, demum rachibusque glabratis pallide-stramineis; frondibus r,60-2 m. longis, in dimidio vel triente superiore, I m. et ultra latis, atque inde utroversus angustatis, tripinnatifidis; pinnis subsessilibus, oblongis, basi vix contractis, apice pinnatifidis, maioribus 5-6 dm. longis, $12-15 \mathrm{~cm}$. latis; rachillis subtus pulverulento-tomentellis, supra costisque pinnularum hispido-pubescentibus; pinmulis sessilibus, lanceolatis, pro. funde pinnatifidis, in cuspidem serrulatam crenatam productis; segmentis late linearibus ascendentibus, acutis, margine serrulatis, coriaceis, supra intense viridibus subtus glauco-virentibus et sparse squamulosis; venis utrinque 8 - IO, plerisque semel prope costam bifurcatis, et soriferis; soris [4-5 iugis] modice crassis, cupreo-aeruginosis; involucro tenui, cartilagineo, albido, irregulariter scisso; receptaculo elevato, pennicillato-pubescente.

In silvis subandinis vulcani Atacatzo [7/907].

2 Pinnulis subtus glabris glaucescentibus; soris pallide flavis, 6-8-iugis.

11 C. ochroleuca Sp. nov.; caudice $3-5 \mathrm{~m}$. alto, 12 I $5 \mathrm{~cm}$. crasso, apice frondibus numerosis patentibus coronato; stipitibus 4-5 dm. longis, deorsum $4 \mathrm{~cm}$. crassis, cum rachibus dorso leviter muriculatis et tomento pulve rulento deciduo conspersis, squamisque lanceolatis, subulatis, ebeneis, margine albidis et denticulatis, dorso deciduis, antice basi diu persistentibus, dense stipatis; frondibus $\mathrm{r}, 60 \cdot \mathrm{r}, 80 \mathrm{~cm}$. longis, prope medium metrum et ultra latis, atque inde utroversus \pm angustatis; rachibus rachillisque dorso [tomento denique deterso] glabris. nitidis, supra complanatis, cum rachillis et pinnularum costis adpresse hispidis; pinnis subsessilibus, cblongolanceolatis; pinnulis sessilibus, lanceolatis, profunde pinnatifidis, apice serrulato-cuspidatis, subcuriaceis, supra pallide-viridibus, subtus albidis; segmentis linearibus, ligulatis, falcatis, margine crenatis; venulis utrinque 10-12, plerisque parum supra basin bifurcatis; soris maiusculis, 
albo-flavescentibus, costae approximatis, 7-9-iugis; incolucro cartilagineo, tenui, mox in fragmenta irregularia resoluto; sporangizs anguste cuneatis, $\infty$-annulatis, receptaculo capitato, pubescente, insidentibus.

Crescit in silvis suband. occid. vulc. A tacatzo 7/907.

C Stipitibus aculeis rectis, robustis basin versus armatis, cum rachilus rachillique stramineis glabris.

12 C. Tungurahuae sp. nov.; caudice 3-4. m. alto, $12-14 \mathrm{~cm}$. crasso; stipitibus $4-5 \mathrm{dm}$. longis, modice robustis, dorso aculeis robustis, rectis, ab latere compressis, sursum gradatim decrescentibus, armatis et squamis magnis coriaceis, castaneis, nitidis, margine albidis, lanceolatis, subulato cuspidatis, tomentoque pulverulento obtectis, demum cum rachibus, dorso glabratis, stramineis; frondibus 2,20-2,60 m. longis, 8-9 dm. latis, ovatis, bipinnato-pinnatifidis; rachibus dorso breviter muricatis, cum rachillis tomento flavido pulverulento vestitis; pinnis breviter petiolatis, lanceolatis, $35-45 \mathrm{~cm}$. longis, $15-18 \mathrm{~cm}$. latis, in apicem pinnatifidum desinentibus; pinmulis sessilibus, subcoriaceis, utrinque 「praeterquam in costa supra] glabris, patentibus, suboppositis, I 5-20iugis, fere usque ad costam pinnatifidis, in apicem serrulatum acutum desinentibus; segmentis adscendentibus, margine denticulatis, apice obtusiusculis, subtus inter soros squamis maiusculis hyalinis conspersis; venis utrinque $6-8$, plerisque bifurcatis; soris maiusculis, flavidis, c)stae et sibi invicem approximatis, numerosis, 5-9 pro segmento; involucro tenui, hyalino, irregulariter dehiscente.

Crescit in silvis suband. vulc. Tunguratuade.

\section{G. 2. ALSOPHILA Br.}

1 A. Christii sp. nov; caudice $2-3 \mathrm{mt}$. alto, nunc etiam vix emerso; stipitibus $2-21 / 2 \mathrm{~m}$. longis, ad $3 \mathrm{~cm}$. crassis, basi albo-lanatis, dorso teretibus, supra late et obtuse I-sulcatis, laevibus; frondibus 3 et ultra 
metra longis, 2-2 $1 / 2 \mathrm{mtr}$. latis, subdeltoidec-ovatis, subcoriaceis, tripinnato-pinnatifidis; pinnis I. onnibus stipitatis, infimis ad $10-15 \mathrm{~cm}$., ceteris gradatim brevius stipitatis, I-I, $5 \mathrm{dm}$. longis, prope basin ad $20-25 \mathrm{~cm}$. latis; rachibus rachillisque dorso laevibus, supra tomentellis, I-sulcatis, et cum rachillis secundi ordinis (pinnulis decurrentibus) alatis; pinnis secundi ordinis breviter stipitatis, elongato-lanceolatis, maioribus $15-18 \mathrm{~cm}$. .longis, ad $3 \mathrm{~cm}$. basi latis, pinnatis, apice acuminatis, pinnatifidis, supra viridibus, subtus glaucis; pinnulis ultimis lineari-lanceolatis, $3-4 \mathrm{~mm}$. latis, basi postice decurrentibus, pinnatifidis, apice serrato acuto, subtus sparse $t$ longe pilosis; segmentis subtriangularibus acutis, integris, trinerviis; soris in basi superiore cuiusque segmenti solitariis, cupreis, tomento arachnoideo involutis.

Alsophila pruinata $\beta$ conspicua Sod. Crypt. vasc. Quit. pag. 546 .

Crescit in silvis suband. $m$. Pichincha et in and. or. ppe. Oyacachi, item in reg. trop. occid. secus fl. Toachi.

Species frondium statura et divisione insignis; A. pruinatae Kaulfs. certe affinis. Tamen, monente claro Christio, ab illa rite specifice distinguenda.

2. A. bilineata sp. nov.; caudice ignoto; stipitibus $1.5 \mathrm{dm}$. longis, basin versus $2 \mathrm{~cm}$. crassis, nitidis, obscure castaneis, secus latera (ut raches) linea cupreoflavida notatis, obtuse trigonis, antice $t \mathrm{t}$ secus latera obiter 1-sulcatis; frondibus ovato-ellipticis, 160-180 cm. longis, I20-140 cm. latis, subcoriactis, supra intense, subtus pallide-viridibus, 4-pinnatifidis; pimis I. ex basi truncata, sursum gradatim angustatis, 4-6,5 dm. longis, 3-4 dm. latis, infimis minoribus, longius $(6 \mathrm{~cm}$.) stipitatis: rachibus rachillisque dorso glabris v. mox glabratis, supra brevissime glanduloso-pubescentibus; pimmulis lanceolatis, breviter stipitatis; pimmlis tertii ordinis sessilibus, in rachilla decurrentibus, anguste lanceolatis, profunde pinnatifidis, subtus pilis nigris brevibus parce conspersis; segmentis obliquis, subtrigcnis, adscendentibus, margine revolutis, integris, apice acutis; venis utrinque 
4, indivisis; soris in venis infimis lateris superioris cuiusque segmenti solitariis, maiusculis, flavidis, in receptaculo, longe et fusce setuloso, insidentibus.

Crescit in silvis suband. occid. In. Pichincha, Nonoirualea.

\section{G. 3. PTERIS L. (LITOBRochia)}

Tripartitae. Frondibus basi tripartitis; ramis lateralibus quam centralis plerumque subduplo brevioribus.

I Ramis omnibus pinnatis; pinnis stipitatis, pinnatifudis.

A Lacinits sinu angusto seiunctis. rum sitis.

A Laciniis tenuiter cartilagineis, serrulatis; soris brevibus in basi laciuti-

I Pt. [Litobr.] aspidioides sp. nov.; stipitibus robustis, metralibus et ultra: frondibizs subaequilongis, tripartitis; ramo centrali quam laterales sub 2-plo longiore, et longius stipitato, pinnis multi-iugatis instructo; ramets lateralibus 6-7 dm. longis, $15-20 \mathrm{~cm}$. latis; pinnis lonyiuscule stipitatis, basi breviter decurrentibus, ovato-lanceolatis, externis maioribus, $12-15 \mathrm{~cm}$. longis, $6-8 \mathrm{~cm}$. latis, apice anguste serrulato-acuminatis; segmentis lanceolatis falcatis, adscendentibus, usque ad $4.5 \mathrm{~mm}$. supra costam sinu angusto seiunctis; pinnis rami centralis a medio sursum profunde pinnatifidis, in segmenta longiora dissectis; areolis angustatis, inter costam et manginem 3-4.seriatis; soris in segmentis inferioribus pinnarum brevibus, in parte pinnatifida parum sub apice desinenibus.

Crescit in silvis tropicalibus prov. Esmeraldas.

B Lainiis pergamentaceis, vix apice denticulatis; soris fere usrue al apicem lacinian um productis;

a Pinnis profunde et regulariter pinnatifidis; areolis subbiseriatis.

2 Pt. [Litobr.] Rimbachii sp. nov.; stipitibus $25-30$ cm. longis, gracilibus, cum rachibus stramineis et antice in sicco sulcatis; frondibus tripartitis, ovatis, $5.6 \mathrm{dm}$. longis $35.40 \mathrm{~cm}$. latis; ramis lateralibus quam centralis sub 
$1 / 2$ brevioribus, pinnato-pinnatifidis; pinnis omnibus subaequalibus, longe stipitatis, oblongo-lanceolatis, apice cuspidato serrulatis; infimis rami centralis, iterum tripartitis, ramis inaequalibus; segmentis lineari lanceolatis, falcatis, sinubus angustis seiunctis; areolis subbiseriatis; soris fere usque ad apicem acutum segmentorum perductis.

Crescit in prov. Chimborazo, legit Dr. A. Rimbach.

b Pinnis irregulariter parum ultra medium pinnatifidis; areolis $3^{-4}$-seriatis.

3 Pt. [Litobr.] rigida sp. nov. rhizomate breviter repente, crasso; stipitibus $4-5 \mathrm{dm}$. longis, rigidis, laevibus, stramineis, semiteretibus, antice sulcatis; frondibus stipites subaequantibus, subdeltoideo-ovatis, coriaceis, utrin que viridibus, basi tripartitis, bipinnato pinnatifidis; $r a$ mis lateralibus quam centralis subdimidio brevioribus, breviter $[2-21 / 2 \mathrm{~cm}$.] stipitatis, asymmetricis, latere exteriore latiore; pinnis 2 infimis plerumque oppositis, exteriore maiore, ceteris [utrinque 2-3] alternis, inaequalibus, internis integris vel irregulariter I-2 lobatis, terminali maiore; pinnis rami centralis 5-6 iugis; iugo inferiore inaequaliter, trifoliato, superioribus solitariis, gradatim minoribus; terminali [in speciminibus nostris non bene evoluto] proximis subaequali, omnibus basi cuneatis, margine ad $1 / 2$ vel ad $1 / 3$ a costa lobatis, laciniis ascendentibus, subtrianyularibus, obtusis, angulo acutissimo seiunctis, apice vix denticulatis; areolis inter costam et maryinem 3-4-seriatis; soris fere usque ad apicem perductis.

Crescit in silvis suband. occid. vulc. Atacatzo.

Habitu et nonnullis characteribus Pt. Kunseanao similis, atamem aliis pluribus ab illa recedit.

B Lacinits sinu lato obtuso seiunctus; arolis $\mathbf{I}-2$ seriatis; cluctis;

a Pinnis subsessilibus; laciniisqu ereciv-patentibus, parum ultra soros pro-

4 Pt. [Litobr.] Esmeraldensis sp. nov.; stipitibus robustis, rachibusque stramineis, laevibus, metrum et ultra longis; frondibus tripartitis, $6.8 \mathrm{dm}$. longis, 5.6 dm. latis, pinnato-pinnatifidis, pergamentaceis, laevibus; ramis late- 
ralibus, longe $[8.10 \mathrm{~cm}$.] stipitatis; pinnis lateralibus inferioribus deorsum in pinnulas pinnatifidas, sursum subintegras et dein in segmenta lineari-lanceolata, acuta vel acuminata, apice \pm serrulata, sinu lato obliquo seiuncta, divisis; pinnis superioribus profunde pinnatifidis, basi in petiolum cuneatis; areolis inter costam et marginem utrinque 2-3-seriatis; soris sinum totum marginemque laciniarum ambientibus et parum infra apicem terminatis.

Crescit in regione trop. et subtrop. prov. Esmeraldas et Imbabura.

Huius speciei specimina tantum imperfecta possidemus; sed a ceteris omnibus satis diversa aspectu, consistentia et pinnarum divisione videtur.

b) Pinnis laciniisque divaricato-patentibut;

¿Pt. (Litobr.) robusta sp. nov.; ampla; stipitibus robustis, metrum et ultra longis, sparse muricatis, castaneis, nitidis, lamina 3-partita, 1,30-1,40 m. longa, aeque ac lata; ramis omnibus pinnatis, lateralibus quam centralis parum brevioribus (ad $80 \mathrm{~cm}$. longis) distincte asymmetricis, rachibus omnibus stramineis, nitidis; pinnis stipitatis, externis inferioribus $30.35 \mathrm{~cm}$. longis, $6.8 \mathrm{~cm}$. latis. deorsum in pinnulas seu segmenta integra, apice denticulata, linearia, obtusa divisis, sursum in segmenta gradatim minora et ad 3 mm. a rachi sinubus obtusis latiusculis separata; pimis interioribus quam externis subduplo brevioribus, omnibus pinnatifidis; ramo centrali longius stipitato, symmetrice in pinnas longiores diviso: areolis (in segmentis singuiis) biseriatis; seriei interioris longioribus depressis; seriei exterioris elongatis, angustis vel venulis apicibus liberis in margine terminatis constitutis; soris linearibus, fere usque ad apicem serrulatım segmentorum productis.

Créscit in silvis suband. occid. vulc. Atacatzo.

C Pinnis longe petolatis; areolis $2-3$-seriatis; soris longe infra laciniarum api-
cem serrulatum desinentibus.

6 Pt. (Litobr.) falcata sp, nov.; stipitibus 8-Io dm. longis, stramineis, laevibus, basi squamis lineari-subulatis, nigrescentibus, mox deciduis instructis; frondibus 
metrum et ultra longis, $45 \mathrm{dm}$. latis, cartilagineis, viridibus, basi tripartitis; ramis lateralibus quan terminalis sub 2 - plo brevioribus, breviusque stipitatis, asymmetricis; pinna infima externa maiore, basi in pinnulas pinnatifidas 10- I 2 cin. longas, divisa, sursum [ut reliquae omnes] in lacinias lineari-lanceolatas, cuspidatas, acutas, falcatas, sinu obtusiusculo seiunctas divisa; pinnis rami centralis remotis, 4-5-iugis; iugi infimi basi in pinnas 2.4 iterum pinnatifidas divisis, mox in pinnulas lineares, remotas, ac demum sursum in segmenta lineari-lanceolata, apice serrulata cuspidata divisis; iugi inferioris bipinnato-pinnatifidis, superi ribus pinnatifidis; pimna terminali ceteris conformi at in lacinias maiores divisa; areolis $2-3$-seriatis; soris longiuscule infra apicen serrulatum desinentibus.

Crescit cum praecedente.

II Ramis basalibus lateralibus bifurcatis, punato-pinnatifirlis; lacimitis lineari. has patentibus; arolis subbiseriatis.

7 Pt. (Litobr.) procera sp. nov.; stipitibus robustis, sesquimetralibus, stramineis, laevibus, breviter et remote muricatis; frondibus stipites longitudine aequantibus vel superantibus, 3-partitis; ramis lateralibus parum supra basin bifurcatis, divisione externa graciliore, cum interna et ramo centrali pinnato-pinnatifidis; pinnis omnibus $15-20 \mathrm{~cm}$. longis, $4 \mathrm{~cm}$. latis, subsessilibus, divarica. to patentibus, in segmenta tenuiter membranacea, linearia, patentia, obtusa, obiter falcatd, sinu lato obtuso seiuncta, fere usque ad rachin divisis; areolis inter costam et marginem subbiseriatis; soris sinum totum marginemque laciniarum, fere usque ad apicem obtusum denticulatum productis.

Crescit in prov. Esmeraldas, secus fl. Santiago.

Species a praecedentibus apprime distincta frondium magnitudine, consistentia tenuiter membranacea, in sicco valde fragili, pinnis, pro longitudine, angustioribus et segmentis linearibus, obtusis, apice denticulatis, sinu amplo seiunctis, etc.

III Ramis omnibus iterum tripartitis, divisionibus pinnato-pinnatifidis.

8 Pt. (Litobr.) bitemata sp. nov.; stipitibus graci- 
libus, 3-4 dm. longis, stramineis, laevibus; frondibus stipitum longitudinem parum superantibus, tenuiter cartilagineis, stramineis, laevibus, basi tripartitis; ramis omnibus iterum tripartitis, bipinnato pinnatifidis; pinnis inferioribus rami centralis et externis lateralium suboppositis, longe stipitatis, iterum in pinnulas oblongo-lanceolatas, apice longe acuminato serrulatas, basi cuneatas $t$ in segmenta linearia falcata, apice denticulata divisis; areolis subbiseriatis; soris e sinu angusto ultra dimidium segmentorum productis.

Crescit in prov: Imbabura, prope Paramba.

Species statura aspectu, consistentia et divisionibus frondis a ceteris omnibus nostratibus apprime diversa.

\section{G. 4 ASPLENTUM (DIPLAZIUM)}

I Macrosora. Soris linearibus elongatis;

A Fronde parva pinnata aut bipinnata: pinnis pinnulisve integerrimis.

1 Aspl. (Diplaz.) anomalum sp. nov.; thizomate erecto, mediocriter robusto, apice cum stipitum basibus, squamis subcoriaceis, nigrescentibus, linearibus obtecto: stipitibus numerosis, $8.10 \mathrm{~cm}$. Iongis, rigidis, obscure castaneis, cum rachibus pinnisque infra breviter pulverulento pubescentibus, dorso subcylindricis, antrorsum 1 sulcatis; frendibus $15.25 \mathrm{~cm}$. longis, $3.6 \mathrm{~cm}$. latis, basi pinnatis, infra medium semel vel bis furcatis, ramo altero longiore validiore, utroque pinnato; pinnis omnibus coriaceis, intense viridibus, in sicco nigrescentibus, sessilibus, ex basi oblique cordata, ovato-oblongis, integerrimis. apice acutis; wentis pinnatis, bis terve dichotomis; soris linearibus, plerisque vel omnibus diplazioideis, e costa fere usque ad marginem productis; incotucro tenui fragili.

Crescit in silvis tropic. prov. Esmeraldas, secus fl. Cachaby.

Species aspectu et frondium divisione a ceteris ita diversa ut ab hoo ipso genere aliena videatur. 
B Fronde magna, pinnati-aut bipinnatifida;

A Fronde pinnata; pinnis deorsum profunde pinnatifidis; ven is semel aut iteram bifurcatis;

a Laciniis (pinnarum, apice obtusis serrulatis.

2 Aspl. (Diplaz.) costale Sw. $\beta$ robustum forma a typica nonnihil diversa statura maiore, pinnis longius petiolatis, segmentis margine integris, apice tantum denticulatis et soris maioribus.

Crescit in decl. occ. vulc. Atacatzo ad flumen Saloya.

b. Lacinis lanceolatis, apice acuminatis, serrulatis; soris longe intra marginem ferminatis.

3 Aspl. [Diplaz.] oxylobum sp. nov.; stipitibus 3-4 dm. longis, robustis, glabris, vel glabratis, antice in sicco 3-sulcatis; frondibus crali-lanceolatis, pinnatis, apice pinnatifidis, glabris, herbaceis, in sicco cartilagineis, intense viridibus, subtus pallidioribus; pinnis utrinque 8 10 , alternis; infinis parum brevioribus, longiuscule [10$12 \mathrm{~mm}$.] stipitatis; mediis I 5-25 cm. longis, 8-10 mm. latis, apice cuspidatis, ad $2.3 \mathrm{~mm}$. a costa pinnatifidis, lobulo superiore, parum, inferiore usque ad costam libero; lobis ex basi dilatata, sursum angustatis, apice acuminatis, $4.6 \mathrm{~cm}$. longis, deorsum 15.20 mm. latis; venis numerosis, tenuibus, approximatis, iterum bifurcatis; soris numerosis, anguste oblongis, plerisque asplenioideis, $t$ costa utrinque ad dimidium lobi productis.

Crescit in silvis occid. suband. vulc. Alacatzo.

Species Aspl. costali Mett. frondium magnitudine et cunsistentia affinis. Differt glabritie, pinnis lobisque longioribus, falcatis, acutis; soris minoribus, remotioribus, venis lateralibus $15 . \infty$-iugis, infimis iterato-sequentibus, 2. 3-furcatis; segmentis maioribus falcatis, acuminatis.

2 Lacinis longe cuspidatis; soris fere marginem attingentibus.

4 Aspl. (Diplaz.) procerum sp. nov.; rhizomatc erecto, crasso, vix apice squamoso; stipitibus $80.100 \mathrm{~cm}$. longis, I cm. et ultra crassis, antice I-sulcatis, vernatione squamis nigris, obliquis, lanceolatis, acuminatis, mox deciduis, dense conspersis, et cum rachibus tenuiter pulverulento-puberulis; frondibus metrum et ultra longis, ad 50 
$\mathrm{cm}$. latis, pinnatifido-pinnatis; pimnis utrinque 12.15 , longe (sursum gradatim brevius) stipitatis, profunde pinnatisectis, vel basi breviter pinnatis, $25 \cdot 30 \mathrm{~cm}$. longis, $10-12 \mathrm{~cm}$. latis, acuminatis, dense herbaceis, supra slabris, nitentibus, subtus dense et brevissime pulverulentopuberulis; lobis lateralibus subpatentibus, ex basi dilatata, súrsum gradation in apicem acutum angustatis, mar) yine vix denticulatis; soris numerosis (utrinque i6.18plerisque diplazioideis, rectis, a costa fere usque ad marginem ductis.

Crescit in silvis subtropic. val. Nanegal.

Species magnitudine et aspectu insignis.

B Fronde bipinnata; pinnulis lanceolatis \pm lobatis; venis pinnatis;

a Pinnulis subsessilibus, obscure lobatis; wenis utrinque $4-5$; soris utrinyte 2-3.

5 Aspl. (Diplaz.) Tungurahuae sp. nov.; caudice erecto, robusto; stipitibus approximatis, robustis, rigidis, 25$40 \mathrm{~cm}$. longis, stramineis, squamis ovatis, cinereo nigrescentibus, oblique adnatis, acuminatis, I-2 cm. Inngis, deorsum maioribus, densioribus, mox in fibras tenues resolutis conspersis; frondibus ovali. lanceolatis, $6.8 \mathrm{dm}$. longis, 25-30 ct. circa medium, latis, pinnatis, apice pinnatifidis, dense cartilagineis, rachi I. rachillisque stramineis, leviter arachnoideo-tomentosis, sparse squamosis; pinnis stipitatis, subdeltoideis, asymmetricis, latere inferiore maiore, basin versus pinnatis; pinmulis infimis breviter pedicellatis, lanceolatis, $4-5 \mathrm{~cm}$. logis, sursum acuminatis, margine ad medium leviter lobulatis, superioribus sessilibus, in apicem pinnatifido-dobatum gradatim transeuntibus, margine integerrimis; venulis lobulorum utrinque $5-7$ (in lobis minoribus pancioribus), binis vel ternis infmis fertilibus, superioribus sterilibus; soris lineari-oblongis, plerisque diplazioideis, e costa vix ad $1 / 2$ loborum productis.

Ab A. venuloso Bak., cui (iuxta descriptionem) affine; differt potissimum indumento sorisque vix ultra $1 / 2$ loborum vel pinnularum protensis.

Crescit in silvis subtropic. vulc. Tungurahua. 
b) innurlis manifeste lobatis;

I Frondé subcoriacea subtus pulverulento-puberula; finnis regulariter lobulatis; Eenis utrinque $6-7$, plerisque soriferis.

6 Aspl. [Diplaz.] crassifolium sp. nov. [specimen incompletum, stipitem et dimidium fere frondis tantum complectens] stipite robusto, $45 \mathrm{ct}$. longo, I ct. et ultra crasso, dorso terete, antice profunde I-sulcato, deorsum sparse squamoso et $\mathrm{cum}$ rachi rachillisque pubescente; fronde bipinnata; pinnis remotis, irregulariter alternis, longe [2.3 ct.] petiolatis, patentibus, ovali-lanceolatis, 2$2.5 \mathrm{dm}$. longis, 12 I $5 \mathrm{ct}$. [parum supra basin] latis, sursum pinnatifidis, denique in apicem serrulatum acutum terminatis; pinnulis iugo infimo breviore, proximis sequentibus, $6-7 \mathrm{~cm}$. longis, $\pm 2 \mathrm{~cm}$. latis, ex basi truncata in apicem crenatum, acuminatum productis, maioribus deorsum in lobulos obtusos ascendentes, margine denticulatos, \pm profunde divisis; venis in quoque lobulo pinnatis, utrinque $6-7$, supremis [2-3] exceptis, soriferis; soris late linearibus elongatis, ultra dimidium segmenti productis, infimis [2-3] diplazioideis, reliquis simplicibus; inwohucro crasso persistente.

Crescit in silvis suband. m. Chimhorazo, ppe. Chillanes.

2 Fronde tenuiter carthlaginea, utrinque glabra; finnis pinnulisque irregularifer lobatis.

7 Aspl. [Diplaz.] heterolobum sp. nov.? rhizomate erecto, debili, nudo; stipitibus $4.5 \mathrm{dm}$. longis, modice robustis, primum squamis parvis, ovatis, subintegris, obtectis, mox glabratis, intus bisulcatis, dorso convexic, stramineis; frondibus herbaceis, in sicco cartilagineis, glabris, 8.9 dm. longis, ovali-lanceolatis, bipinnatifidis, in apicem pinnatifrdum productis; rachibus stramineis, nudis, apicem versus marginatis; pinnis utrinque $12-15$, infimis parum minoribus, breviter stipitatis; mediis $3-4$ dm. longis, $10-12 \mathrm{~mm}$. latis, pinnatis; superioribus pinnatifidis sessilibus; pinnulis divaricato-patentibus, $4-6 \mathrm{~cm}$. longis, $15^{-20} \mathrm{~mm}$. basi latis; infimis breviter pedicellatis, superioribus sessilibus, valde inaequaliter lobulatis, in apicem subintegrum, obtusum productis; rachillis dorso 
rotundatis, antice complanatis, marginatis vel interrupte alatis; lobis maiorib. obtusis, apicem versus denticulatic, pinnato-venosis; venis utrinque $6-3$, hinc inde bifurcatis; soris anguste linearibus; inferioribus nonnullis secus ramos venarum bifurcatarum et ipsis bifurcatis, diplazioideis; superioribus asplenioideis, inter costam marginemque intermediis; involucro tenui, angusto, margine ciliato persistente.

Crescit in silvis suband. vulc. Atacatzo.

Species A. radicanti Schk. proxima et forte eiusdem varietas, aut forma monstrosa. Differt consistentia tenuiore, statura minore, divisione pinnarum et pinnularum valde inaequali; venis sorisque in lobis singulis paucioribus et minoribus.

II Microsora. Soris parvis subellipticis; fronde tripinnatifla;

A Pinnulis sessilibus; venis simplicibus, utrinque 4-5.

3 Aspl. (Diplaz.) humile sp. nov:; caudice erecto, 2$2,5 \mathrm{dm}$. alto, $5-7 \mathrm{~cm}$. crasso, apice cum stipitum basibus squamis ex basi ovata, longe acuminato-subulatis, membranaceis reticulatis, atris, vestito; stipitibus inermibus, erectis, rigidis, gracilibus, semicilindricis, antice profunde I-sulcatis, cum rachibus rachillisque tenuissime tomentellis, demum glabratis, fusco-nigrescentibus; fronde ovato-oblonga, $6-7 \mathrm{dm}$. longa, $35-40 \mathrm{~cm}$. lata, bipinnatopinnatifida, apice pinnatifida, subcoriacea, viridi, glabra; pinz:zis utrinque $12-15$, inferioribus mediisque longiuscule $(1 \mathrm{~cm}$.) petiolatis, alternis, patentibus, infimis (parum minoribus) \pm reflexis, pinnatis pinnatifidis, superioribus sessilibus pinnatifidis, lanceolatis, apice obtusis vel acuminatis, fere usque ad costam pinnatifidis; segmentis lineari-ligulatis, angulo valde acuto seiunctis, $\pm 3 \mathrm{~mm}$. longis, $2 \mathrm{~mm}$. latis, margine denticulatis, apice obtusis; venis utrinqus $4-5$ indivisis, aut in pinnis superioribus, semel bifurcatis; soris in quolibet segmento 2 -3-iugis, vel solitariis, costae approximatis, oblongis, mediocribus; involucro externo, duriusculo, oblongo.

Crescit in silvis subtrop. septentr. vulc. Tanlahua et Yanaurco. 
B Pinnis plerisque stipitatis;

A Pinnulis lanceolatis apice cuspidatis, serrulatis;

a Veni.r simplicibus; involucro parvo, diu integro persistente.

9) Aspl. (Diplaz.) Hierony'mi sp. nov.; caudice ascendente, robusto, $21 / 3-3 \mathrm{~cm}$. crasso; stipitibus approximatis, 6-7 dm. longis, $7-8 \mathrm{~mm}$. crassis, erectis, rigidis, dorso semiteretibus, secus latera et facie I-sulcatis, basi squamis nigrescentibus, $1 \frac{1}{2}-2 \mathrm{~cm}$. longis, lanceolato subulatis, tenuibus reticulatis, caducis conspersis, cum rachibus tenuiter arachneosis, primum livido-virescentibus, demum atratis; frondibus $6-7 \mathrm{~d}: \mathrm{m}$. longis, $4-5 \mathrm{dm}$. latis, ovatis, bipinnato-pinnatifidis, apice pinnatifidis, utrinque viridibus, subtus pallidioribus, herbaceis; pinnis irregulariter alternis, longiuscule stipitatis, anguste triangulari-lanceolatis, $25.35 \mathrm{~cm}$. longis, $12.15 \mathrm{~mm}$. latis, pinnatis, apice pinnatifidis, in cuspidem serrulatam productis; pinnulis breviter [ $2 \mathrm{~mm}$.] stipitatis, lanceolatis, apice cuspidatis, fere usque ad costam pinnatifidis, costa supra I-sulcata, leviter alata, pulverulenta, demum glabra, subtus squamulis ovatis, cuspidatis, tenuibus caducis, et cum segmentis pilis nigrescentibus, elongatis tortilibus conspersa; segmentis lineari-ligulatis, apice oblique obtusis, margine leviter denticulatis; venis utrinque 5.6 simplicibus, rectis, parum supra costam soriferis; soris 3-5-iugis, subellipticis, infimo lateris superioris plerumque semi-didymo, basi retuso; indusio tenui, hyaline, extrorsum irregulariter dehiscente.

Crescit in declivitate occid. vulc. Tanlahua, ppe. Yanahurco 10/907.

b Venis pluribus, parum supra basin bifurcatis; inzolucro albido laxo, vesiculo so, mox frustatim resolutu. discisso;

b Venis simplicibus aut nonnullis bifurcatis; invelucro nuagno mox frustatim

$\alpha$ Venis simplicibus v. in lobis maioribus bifurcatis; lobis late linearibus prerpe apicem denticulatis; inzolucro nigrescente.

$10 \mathrm{Aspl}$. [Diplaz.] vesiculosum sp. nov.; stipitibus $70.80 \mathrm{~cm}$. longis, ad $\mathrm{I} \mathrm{cm}$. crassis, basi squamis oblique ovatis, fuligineis, mox resolutis, basi muricata persistente obtectis, sursum nudis, dorso subteretibus, anti- 
ce I-sulcatis; frondibus bipinnato-pinnatifidis, metrum et ultra longis, 6-7 dm. latis, dense herbaceis, in sicco subcoriaceis, intense viridihus, subdeltoideis, apice pinnatifidis; pinnis alternis, remotis, utrinque 8-10, longiuscule stipitatis, rachilis [cum rachi] stramineis, subtus leviter pubescentibus; inferioribus parum minoribus, longius stipitatis; pinnulis stipitatis, lanceolatis, fere usque ad costam partitis, in apicem linearem serratum productis; segmentis patentibus, obtusis, a medio sursum remoie dentatis, lateris inferioris parum maioribus; venis utrinque 6.7, parum supra basin bifurcatis; soris utrinque 46 , crassis, elongatis, parum supra costam insertis; involucro albido laxo, vesiculoso, irregulariter dehiscente, in frusta deciduo.

Crescit in silvis suband. vulc. Pululahua.

$\beta$ Venis plerisque parum supra basin bifarcatis; Lobis obtusis, a medio sursum remote dentatis; involucro nigrescente.

11 Aspl. [Diplaz.] melanosorum sp. nov.; caudice erecto, arborescente, ad $7 \mathrm{~cm}$. diam. crasso; stipitibus approximatis, erectis, metrum et ultra longis, IO- I $2 \mathrm{~mm}$. crassis, dorso rotundatis, facie I-sulcatis, sulci lateribus complanatis, fusco-nigrescentibus, deorsum squamis magnis, nigris, mature in fila tenuia resolvendis, conspersis;

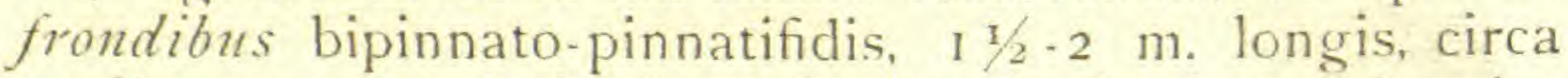
medium $7.9 \mathrm{dm}$. latis, dense herbaceis, in sicco subcoriaceis, intense viridibus; rachibus rachillisque fusco-viridibus, primum brevissime tomentellis, squamisque fibrillosis, conspersis, mox glabratis, dorso rotundatis, supra 1 -sulcatis; pinnis omnibus stipitatis, alternis, $10-15 \mathrm{~cm}$. ab invicem remotis; inferioribus parum minoribus, mediis ad $4 \mathrm{dm}$. longis, $4 \mathrm{~cm}$. latis, fere usque ad costam pinnato-lobatis; lobis late linearibus obtusis, apicem versus denticulatis; vemulis utrinque $5-7$ simplicibus, vel in lobis maioribus, supra medium bifidis; soris 3-5-iugis, costulae approximatis, ellipticis, $2 \mathrm{~mm}$. longis, fusco-nigrescentibus, asplenioideis, per raro geminatis, involucro $\mathrm{I}$-valvi, amplo tenuí, fragili involutis.

Crescit in silvis suband. occid. vulc. Pululahua, in monte Yanahurco. 
Speciem hanc frondium magnitudine insignem, habitu potius et statura, qua:n sororum structura inter Diplazia recensemus.

B Pinnis pinnulis lobisque obtusis; a zenis plerisque bifurcatis.

12 Aspl. (Diplaz.) Chimboxnum; caudice erecto, robusto, apicem usque radicante; stipitibus modice robustis, erectis, rigidis, dorso teretibus, antice $\mathrm{I}$-sulcatis, deorsum squamis lanceolatis, elongatis, atris vestito, atrato, sursum cum rachibus rachillisque stramineo, pulverulento; fronde 8-1o dm. longa, 4-5 dm. basin versus lata, tripinnatifida; pinnis modice petiolatis, infimis parum brevioribus, irregulariter alternis, utrinque I $_{5}-18$, pinnato pinnatifidis, supremis usque brevioribus, sessilibus lobulatis; pinnulis membranaceis, supra glabris subtus pulverulentis breviter petiolatis, 2-3-iugis infimis, brevioribus, ovalibus, apice obtusis, mediis parum longioribus acutis, plerisque fere usque ad costam in lobulos obtusos, apice denticulatos, divisis; venis. [in lobis maioribus] utrinque 6-7 exertis; soris utrinque 2-4, longiuscule ellipticis; infimis 2-3, diplazioideis; involucro tenui fragili, mature evanescente.

Crescit in prov. Guayas, ad Puente de Chimbo.

\section{G. 5. NEPHRODIUM (LAstrea)}

1 Venis liberis indivis;

A Frondibus pinnatis; pinnts pinnatifidis;

Caudice erecto; stipitilus fasciculatis; frondibus oblongo-lanceolatis, utrenversus longe et grarlatim angustatis; ce squamosis.

a Laciniis pinnarum lineari-lanceolatis; caudice brevi; stipitibusque par.

I Neph. (Lastr.) sanctum Bak.

HK. \& Bak. Synops. p. 267; Sodiro Crypt. vasc. quitens. p. 227.

Species rara; iterum reperta in reg. subtrop. prov. Imbabura, ppe. Paramba. 
b Candiec elongato; stipitibusque squamosis; pinnarum segmentis late linearibus-subfalcatis;

a Rachibus supra pinnisque puberulis.

2 Neph. (Lastr.) brachypus Sod.

Recensio p. 43 et Crypt. vasc. quitenses p. 228.

Iterum reperta in silvis suband. m. Pichincha et Atacatzo; candice ad $5 \mathrm{dm}$. alto, ceterum cum forma primitiva conformis.

$\beta$ Rachibus pinnisque longe setuloso-pilosis;

3 Neph. [Lastr.] longipilosum sp. nov.; caudice erecto, ad $15 \mathrm{~cm}$. longo, ad $2 \mathrm{~cm}$. crasso, dense radicante, apice r.um stipitibus, squamis bruneis lineari-lanceolatis, subulatis vestito; stipitibus fasciculatis, $10-15 \mathrm{~cm}$. longis, modice robustis, rigidis, squamis mox delapsis, una cum rachibus pilis setulosis retrorsis parce consperso, aliisque brevissimis rigidulis, retrorsis, cinereis dense vestitis; fronde oblonga, $4-7 \mathrm{dm}$. longa, I $2-15 \mathrm{~cm}$. versus medium lata, utroversus angustata, pinnata, apice pinnatifida, dense herbacea, in sicco subcoriacea, fragili, undique pilis setulosis, elongatis patentibus conspersa, et supra praeterea pilis brevibus, rigidis, adpressis vestita; pinnis sessilibus, lanceolatis, apice acutis, vel acuminatis; mediis maioribus $8-10 \mathrm{~cm}$. longis, $11 / 2-2 \mathrm{~cm}$. latis, ad $1 / 3$ supra costam divisis; segmentis subtriangularibus, oblique acutis, margine subintegro; venis utrinque $5-7$, rectis, simplicibus, summis exceptis, parum ultra medium soriferis; soris maidsculis, hippocrepicis; involucro conformi, ciliolato, mature deciduo.

Crescit in silvis suband, vulc. Corazón, locis opacis uliginosis. Lecta mense Decembre 1907.

B Frontibus oblonge-lanceolatis, deorsum breviter angustatis.

4 Neph. [Lastr.] cinereum sp. nov.; rhizomate erecto, dense radicante; stipitibus fasciculatis, tenuibus, subcylindricis, antice, cum rachibus, I-sulcatis; pilis brevissimis, erectis, adpressis, cinereis, simul cum lamina, utrinque conspersis, $6-12 \mathrm{~cm}$. longis, $\pm 1 \mathrm{~cm}$. crassis; lamina dense cartilaginea, oblongo-lanceolata, e $1 / 3$ in- 
feriore sursum longe, deorsum breviter angustata, bipinnatifida; pinnis infimis utrinque 2-3-lobatis: pinnis mediis subsessilibus, dense cartilagineis, lanceolatis, apice acutis, integris, basi parum asymmetricis, ad $2-3 \mathrm{~mm}$. supra costam in lobulos obtusos, integros divisis; venulis utrinque 4-5, erecto-patentibus, simplicibus; soris in quoque lobulo, utrinque 2-4, supra medium venularum sitis; involucro subdiscoideo, diu persistente; sporangizs sporisque flavidis.

Crescit in silvis m. Corazón 8/903.

Species Neph. gracilescenti Hk. subsimilis, a qua tamen differt rhizomate robustiore, erecto; stipitis et frondis indumento, itemque fronde basi manifeste angustata etc.

$\beta$ intermedium; differt fronde subglabra, basi breviter angustata, pinnis minoribus angustioribus, apice acuminatis, laciniis minoribus; involucro mox deciduo etc.

Crescit in silvis trop. prov. Esmeraldas.

$$
\text { G. 6. POLYPODILM I+ }
$$

\section{Phegopteris.}

I Polyp. (Phegopteris) rigidum Hk. \&. Gr. (Icon. Filic. tab. 163 . Specimen mancum haud plene evolutum); Hk. "Species" IV. pag. 246; Hk. \&. Bak. Synopsis p. 310, № 33 . Speciem in opere nostro: "Crypt. vasc. Quit." casu omissam, hic commemorandam existimamus, quippe quae in pascuis regionis andinae et in rupium fissuris haud raro ocurrit, unaque est quae, cum paucis speciebus eiusdem generis itemque Asplenii et Acrostichi, ultra 4.500 metr. habitare non renuit. Ceterum, habitu et consistentia potius Gen. Aspidio adscribenda videtur, etsi involucro careat. 


\section{Goniophlebium.}

A Fronde simplici.

2 Polyp. (Goniophlebizm) glaucophyllum Kunze (in Schkuhr's. Suppl. I. p. 227 , tab. 93).

Huius speciei, inter tropicos longe lateque diffusae, in ditione florae Ecuadorensis occurrunt formae sequentes:

\section{A ovato-banceolata}

$\alpha$ forma typica, qualis ab autore (loc. cit.) describitur et effingitur, sed limbis subtus (et rhizomate) potius albo-pruinosis quam glaucis; venarum areolis (inter costam et marginem) 6-7-seriatis, soris 4-5-seriatis; limbis fertilibus longius petiolatis quam steriles.-Cresc. inter virgulta regionis tropicalis et subtropicalis sporadice; item in silvis vulc. Tungurahua et Pululahua.

$\beta$ viride rhizomate albo-viridi-glaucescente; limbis utrinque viridibus, forma ut in praecedente sed duplo longioribus et triplo latioribus; limbis sterilibus longius petiolatis quam fertiles; areolis longioribus, $6-7$-seriatis; soris 3 -4-seriatis, quam in typo multo maioribus.

\section{B OBLONGA}

$\gamma$ rhizomate opaco vel viridi-glaucescente; petiolis $3^{-5}$ nunc $10 \mathrm{~cm}$. longis, sterilibus fertilibusque subaequalibus aut fertilibus aperte longioribus; limbis utrinque viridibus, oblongis aut subelliptico-oblongis, latitudine sua 4-5-plo longioribus; areolis depressis, utrinque 6-7; soris 3-4-seriatis.-In m. Pulutahua et Corazón.

$\delta$ Ut $\gamma$ sed thizomate crassiore; limbis minoribus, coriaceis, apice abrupte cuspidatis; areolis $3-5$, soris maioribus $1-2$ seriatis.-In reg. tropic. prov. Esmeraldas.

E tenui-caule rhizomate longissimo, tenui, squamis sero deciduis consperso, glaucescente, petiolis $3-5 \mathrm{~cm}$. longis; limbis coriaceis, viridibus, I $2-18 \mathrm{~cm}$. longis, 2 $2 \mathrm{I} / 2 \mathrm{~cm}$. latis, basi apiceque contractis, per vernationem subtus dense squamosis; areolis 3-5-soris 1-2-seriatis. Num species propria?

In silvis tropic. prov. Esmeraldas. 
B Frondibns pinnatis;

3 Polyp. (Goniophl.) scutulatum sp. nov.; rhzomate longe serpente (saepe ad truncos vetustos radicante): squamis maiusculis, subellipticis, dorso areolatis, nigrescentibus, margine cartilagineo albidis, peltatis parum in fra medium rhizomati affixis, dense imbricatis obtecto: stipitibus remotis; phyllopcdiis brevibus insertis, $\mathrm{I}-3 \mathrm{dm}$. longis, $\pm 2 \mathrm{~mm}$. crassis, stramineis nitidis, dorso teretibus, antice (in sicco) 3-sulcatis; frondibus pinnatis, 25$40 \mathrm{~cm}$. longis, ${ }_{15}-25 \mathrm{~cm}$. latis, dense cartilagineis, supra allbo-viridibus, subtus glaucescentibus; pinnis sessilibus, plerisque oppositis, 8-20-iugis, cum impari, lanceolatis, cuspidatis, \pm asymmetricis, basi rotundatis, aut latere superiore \pm acutis, margine integerrimis, aut leviter undulatis; pinna lerminali integra vel lobulata, quam laterales plerumque minore; areolis inter costam et marginem utrimque 3-4-seriatis; venis maioribus, $2-3 \mathrm{~mm}$. ab invicem remotis; soris [in venula inclusa] apicalibus, bicuatuor-raro quinque-seriatis, maiusculis, flavidis.

Crescit in silvis trop. et subtrop. passim.

A. P. fraxinifolio, cui maxime accedit, distinguenda videtur: rhizomate graciliore, longius repente ac identidem scandente, squamis sat diversis imbricato; stipitibus gracilioribus et fronde minore; pinnis basi utraque plertimque rotundata, margine continuo vel vix obiter sinuoso, nec non structura tenuiore et colore, dénique areolis $4-5$-tt soris $2-3$-non "6-8-seriatis." Specimen possidemus in quo pinnae iugi infimi usque ad basin divisae sunt, divisione inferiore parum minore, ceterum superiori conformi.

A ceteris nostratibus fronde pinnata praeditis, facile primo intuitu distinguitur forma squamarum rhizomatis, qua in re tantum in P. glaucophyllo et P. chartacea aliquid simile occurrit. 


\section{G. 7. AOROSTIOHUM (ELAPHOGLOSSUM)}

I Glabra. Rhisomate repente, squamis lineari-subulatis, integerrimis, dense obtecto. herrimis.

A Limbis oblongis, dense coriacels, utrisque nigro-punctatis, ceterum glin-

1 A. [Elaph.] Antisanae sp. nov.; rhizomate longe serpente vel scandente, sparse et remote ramoso, $21 / 2-3$ $\mathrm{mm}$. crasso, squamis lineari-subulatis, integerrimis, nigris, patentibus, diu persistentibus obtecto; stipitibus sparsis, remotis, cum phyllopodiis $\left(1 \frac{1}{2}-3 \mathrm{~cm}\right.$. longis, $\mathrm{ni}$ gris), articulatis; stipitibus frondis sterilis $5^{-15} \mathrm{~cm}$. longis, erectis, rigidis, stramineis, cupreo-maculatis; limbis sterilibus coriaceis, glaberrimis, utrinque nigro-punctatis, oblongis, basi leviter cuneatis, apice obtusis vel acutiusculis, $10-30 \mathrm{~cm}$. longis, $2-4 \mathrm{~cm}$. latis; venis tenuibus immersis, vix conspicuis, plerisque bifurcatis, prope marginem anguste cartilagineum in glandula minuta desinentibus; limbo fertili longius $[20-25 \mathrm{~cm}$.] stipitato cum sterili subconformi, nunc basi rotundato et in stipitem breviter decurrente; costa utrobique et superficie superiore glabra, inferiore usque ad marginem cartilagineum revolutum sorifera.

Crescit in pascuis andinis vulc. Antisanae, $3 \cdot 500-$ $4.000 \mathrm{~m}$.

Species proxima A. scandenti Bory et A. Linguae Raddi; differt forma et consistentia limborum et squamis rhizomatis.

B Limbis subellipticis; dense cartilagineis, fimbriatis; furtili supra sugumis lisciformibus, peltatis, dense consperso;

2 A. [Elaph.] ellipsoideum sp. nov.; rhizomate serpente, squamis ex basi ovata, lineari-subulatis, integerrimis nigrescentibus, diu persistentibus, dense vestito; stipitźbus cum phyllopodiis remotis, $2 \frac{\pi}{2}-3 \mathrm{~cm}$. longis, nigrescentibus articulatis, stramineis, erectis, rigidis, cupreo-maculatis, I $5^{-1} 8 \mathrm{~cm}$. longis; limbis sterilibus subellipticis, I 5-1 $8 \mathrm{~cm}$. longis; $4-5 \mathrm{~cm}$. latis, dense chartaceis, utrinque glabris, margine cartilagineo, squamis subovatis, ciliatis, cuspidatis, caducis, coronato cinctis; venis 
tenuibus, $1-2$-furcatis, ante marginem in glandulam capitatam desinentibus; limbis fertilibus stipite crassiore, $25 \mathrm{~cm}$. longo suffultis, subellipticis, basi apiceque obtusis, $15-18 \mathrm{~cm}$. longis, $2 \mathrm{I} / 2-3 \mathrm{~cm}$. latis, supra squamis subdiscoideis, centro peltatis, margine radiatim ciliato dense obtectis.

Crescit in silvis suband. Andium or. ppe. Oyacachi.

Species praecedenti proxima; differt limbo sterili subelliptico, consistentia tenuiore et margine fimbriato. Itemque indumento peculiari paginae superioris limbi fertilis.

II Oligolepidia. Limbis parce et minute squamosis, margine nutis.

A Limbis sterilibus ovalihus vel oblongis, utrinque \pm vernicosis;

3 A. [Elaph.] viscidulum sp. nov.; rhizomate repente, cum phy!lopodiis squamis atris nitentibus, linearibus subulatis, 4-5 $\mathrm{mm}$. longis, subintegris, dense vestito; phyllopodiis secundis, approximatis, $10-12 \mathrm{~mm}$. longis, vix I mm. crassis; stipitibus sterilibus, $6-8 \mathrm{~cm}$. longis teretiusculis, supra obsolete I-sulcatis, vernicosis, squamulis subrotundo-ovatis, basi truncatis, aliisque sublanceolatis, basi oblique truncatis, demum deciduis conspersis: limbis sterilibus ovalibus, vel oblongis, basi plerumque rotundatis, nunc acutis, apice \pm longe cuspidatis, 6 $7 \mathrm{~cm}$. longis, $2 \frac{1}{2}-3 \mathrm{~cm}$. latis, subcarnosis, in sicco coriaceis, utrinque [subtus praesertim] vernicosis, [h. e. guttulis glutinosis] et squamulis ovatis oblongisve, nunc basi \pm cordatis, deciduis, conspersis, margine squam lis consimilibus biserialibus, imbricatis instructis; nerois semel vel iterum bifurcatis, iuxta marginem in apicem clavellatum desinentibus; stipitibus fertilibus quam steriles tenuioribus et subaequilongis; limbis fertilibus ovalibus, basi apiceque obtusis, in specimine $2 \mathrm{~cm}$. longis, $13 \mathrm{~mm}$. latis, coriaceis, supra dense squamulosis, vix vernicosis.

Crescit in silvis suband. occid. vulc. Tungurahua.

Species rara! A. petioloso et A. Tambillensi habitu similis, a quibus ceterisque affinibus, differt squamis, rhizomatis et frondium itemque limbis multo densioribus, 
supra praesertim, vernicoso-nitentibus; ab Elaph. glutinoso Spruce, iuxta descriptionem clari Christii, [Monog. des Genus Elaph. p. 120 ], cui certe affine, diferre videtur, habitu, magnitudine et forma limborum, itemque nervis apice palam clavellato in margine desinentibus.

B Limbis steritibns oblongis, basi cuneatis, haud vernicosis; limbo fertili subpollicari.

4 A. [Elaph.] diversifolinm sp. nov.; rhizomate tenui, prostrato, squamis pallide badiis, tenuibus ex basi lata longe setulosis, margine remote retrorsum dentatis patentibus dense vestito; stipitibus gracilibus $5-8 \mathrm{~cm}$. longis, squamis setulosis divaricatis conspersis, demum glabratis; limbis sterilibus oblongis, $6-12 \mathrm{~cm}$. longis, circa medium I $1 / 2-2 \frac{1}{2} \mathrm{~cm}$. latis, deorsum cuneatis, sursum in apicem acuminatum vel obtusiusculum angustatis, subcartilagineis, supra intense, subtus pallide-viridibus, utrinque squamis parvis ex basi ovata lanceolatis, adpressis, subtus, basi apiceque denticulatis parce conspersis; venis tenuibus immersis, vix conspicuis, erecto-patentibus, plerisque simplicibus, parum ante limbi marginem in glandulam crassiusculam, supra impressam, subtus prominulam terminatis; limbis fertilibus longiuscule [5 $8 \mathrm{~cm}$.] et tenuiter stipitatis, $2-3 \mathrm{~cm}$. longis, $1 \mathrm{~cm}$. latis, apice obtusis, basi obiter cuneatis, margine lato cartilagineo cinctis.

Crescit inter muscos, in rupium fissuris et ad arborum truncos in silvis suband. vulc. Corazón et Atacatzo: itemque in loc. praeruptis opacis prope Quito.

Species A. Lloensi Hk. similis, sed bene distincta.

B Limbis sterilibus subtus pruinosis; fertil. 3-4-pollicari, supra squamoso.

5 A. [Elaph.] pruinosum sp. nov.; rhizomate erecto vel ascendente; squamis atris, nigris, anguste linearibus, serrulatis, dense vestito; stipitibus approximatis, rigidis, dorso teretibus, antice angustatis, $25 \cdot 30 \mathrm{~cm}$. longis, primum squamis ex basi ovata, nigrescente, sursum setaceis, incoloribus, patentibus dense vestitis, denum glabratis; fertilibus steriles aequantibus vel superantibus; limbis sterilibus herbaceis, exsiccando dense cartilagi- 
neis, supra viridibus, subtus pruinosis, $25 \cdot 35 \mathrm{~cm}$. longis, $3-6 \mathrm{~cm}$. latis, oblongis, basi angustato-cuneatis, vel obiter obtusis, primum squamis, stipitalibus similibus, dense vestitis, demum supra fere glabris, squamisve paucis ex basi ovata vel cordata, laciniata, setaceo-attenuatis, remote dentatis, subtus, praesertim secus costam et maryinem, densioribus, nigrescentibus conspersis; venis remotis, patentibus, plerisque bifurcatis, prope marginem desinentibus; limbis fertilibus 8 - $10 \mathrm{~cm}$. longis, ad $21 / 2$ $\mathrm{cm}$. latis, apice obtusis, basi acutiusculis, supra squamis minutis, rufescentibus, ovatis, acuminatis, fimbriatis, dense consperso, subtus secus costam et inter soros flavescentes, dense atrato-squamosis.

Crescit in silvis and. or. vulc. Tungurahua et in $\mathrm{m}$. Antisana, ppe. Oyacachi.

Species A, albescenti et A. boragineo nostro affinis, a quibus pluribus ex characteribus enuntiatis distinguenda videtur.

III Iaciniata. Limbis parce squamosis, margine \pm fimbriatis.

A Limbis sterilibus subtus vel utrinque albo-virentibus; fertili ro-r2 cn. longo, supra et sulitus inter soros squamoso.

6 A. [Elaph.] Engleri sp. nov.; rhizomate erecto, squamis rigidis, nigrescentibus, lineari-lanceolatis, breviter et remote serrulatis vestito; stipitibus approximatis, gracilibus, rigidis, albidis, squamis divaricatis, ex basi dilatata ciliata nigrescente, sursum setaceis albidis, mature deciduis conspersis; sterilibus $8-15 \mathrm{~cm}$. longis; fertilibus robustioribus et sub 2-plo longioribus; limbis sterilibus i $5-30 \mathrm{~cm}$. longis, $3-4 \mathrm{~cm}$. latis, oblongis, utroversus angustatis, basi acutis, apice cuspidatis; structura dense cartilaginea, utrinque albo-virentibus, squamisque rufo-flavidis ex basi rotundata fimbriata sursum setaceis, serrulatis, pagina utraque conspersis, margine fimbriatis; costa tenui, supra vix, subtus leviter exerta, squamis basi nigrescentibus, subimbricatis obtecta; venis tenuibus, vix exertis, obliquis, plerisque bifurcatis, in glandula marginali desinentibus; limbis fertilibus ro I $2 \mathrm{~cm}$. longis, fere $2 \mathrm{~cm}$. latis, oblongis, basi sub:otundis, spice breviter 
apiculatis, supra squamis minutis, rufis ovato acuminatis, longe dentatis obtectis, subtus inter soros squamis linedri-subulatis serrulatis nigris conspersis, margine angusto cartilagineo sinuoso-dentato cinctis.

Crescit in silvis suband. and. or. prp. Oyacachi et vulc. Tungurahua.

Species, ut videtur, A. Mettenii Kuhn. affinis, sed ex descriptione sat diversa.

B Limbis sterilibus utrinque viridibus (haud pruinosis) fertilibus, vix pollicarihus.

7 . . [Elaph.] fulvum sp. nov.: rhizomate erecto, brevi, squamis rufescentibus, subulatis, rigidis, margine serrulatis, $7-8 \mathrm{~mm}$. longis, dense vestito; stipitibus basi articulatis, gracilibus, erectis, rigidis, antice obiter $\mathrm{t}$-sul. catis, stramineis, iunioribus utrisque squamis setulosis, $6.7 \mathrm{~mm}$. longis, cupreo-rufescentibus, divaricato-patentibus, tenuissime serrulatis, dense vestitis; sterilibus 3-4 $\mathrm{dm}$.; fertilibus $2 \mathrm{dm}$. longis, tenuioribus; limbis sterilibus oblongis, stipites subaequantibus, circa medium 3$5 \mathrm{~cm}$. latis, utrobique \pm acutis, vel basi obtusis, membranaceis, in sicco chartaceis, pellucido-punctatis; iunioribus utrinque et secus marginem squamis cupreo rufis nitentibus, capillari-setaceis, $8.10 \mathrm{~mm}$. longis, basi rotundata, margine serrulatis densissime obtestis, demum subtus glabratis, supra, potissimum secus costam et marginem, diu persistentibus; venis tenuibus opacis, supra immersis, subtus leviter exertis, patentibus, plerisque simplicibus, $2-3 \mathrm{~mm}$. ab invicem remotis, intra marginem revolutum in glandulam supra impressam, subtus prominulam desinentibus; limbis fertilibus [in specimine nondum plene evolutis] oblongo spathulatis, ad $3 \mathrm{~cm}$. longis, $10 \mathrm{~mm}$. latis, apice obtusis, basi cuneatis, supra et secus marginem densissime squamosis,

Crescit humi inter muscos et ad truncos vetustos in silvis subandinis andium orientalium. 

tectis;

IV Polylepidia. Limbis stril. hinc vel utrinque squamis longe ciliatis ob-

A Rhisonate squamis ebeneis rigidis subulatis imbricato;

A Limbis steri . cinerescentib. squamosis;

a Squamis utriusque paginae minimis persistentibus;

a. Squam is asteroideis, pedicellatis, crispis.

8 A. [Elaph.] Guamanianum sp. nov.; rhizomate breviter repente, squamis nigris, ovali-lanceolatis, serrulato-ciliatis, dense vestito; phyllopodiis $11 / 2-2 \mathrm{~cm}$. longis, squamis ex basi ovata oblique lanceolatis, subulatis, secus marginem fuscescentibus ciliatisque obsitis; stipitibus steril. $25 \cdot 35 \mathrm{~cm}$. longis, gracilibus, subcylindricis, in sicco antice $\mathbf{I}-2$-sulcatis, squamis rufidulis, patentibus, lanceolatis, longe ciliatis, obsitis; limbis anguste oblongo-lanceolatis, a medio vel parum supra, utroversus angustatis, basi et apice acutis, vel apice acuminatis, $25-35$ $\mathrm{cm}$. longis, $2 \frac{1}{2} \cdot 3 \mathrm{~cm}$. latis, membranaceis, in sicco cartilagineis, squamis rufescentibus, longe ciliatis, supra aliis asteroideis, aliis linearibus parce conspersis, subtus et secus costam et marginem densioribus et maioribus; nervis tenuibus, subhorizontaliter patentibus, plerumque semel bifurcatis, obiter clavellatis, in vel prope marginem desinentibus: stipitibus fertilibus steriles subaequantibus, vracilioribus; limbis fertilibus oblongo-ellipticis, $\pm 8 \mathrm{ct}$. longis, 2 ct. latis, apice obtuso apiculatis, basi breviter anyustatis, subcoriaceis, supra squamis parvis ovatis acutis integris parce conspersis; sporangiis alutaceo nigrescentibus.

Crescit in pascuis andin. andium orient. in $\mathrm{m}$. Gractmani (1/900.)

b Squamis polymorphis, paginae arcte adpressis.

9 A. (Elaph.) Hikenii sp. nov.; rhisomate erecto, cum phyllopodiis ( $\pm 2 \mathrm{~cm}$. longis); squamis ebeneis nitentibus, lanceolatis, longe et anguste subulatis, tenuiter ciliatis obtecto; stipitibus fasciculatis, 3-4 dm. longis, zracilibus rigidis, dorso convexis, antice obiter 1 -sulcatis, squamis caducis, minimis, centro nigrescentibus, margine hyalinis, ciliatis, adpressis, cum lanceolatis multo maio- 
ribus, iis phyllopodiorum similibus, obtectis; sterilibus fertiles subaequantibus; limbis sterilibus $7.9 \mathrm{dm}$. 1 nuis, $3-4 \mathrm{~cm}$. latis, elongatis, oblongo-lanceolatis, basi breviter cuneatis, e $1 / 3$ inferiore sursum longe et gradatim attenuatis, membranaceis, supra squamis hyalinis parvis heteromorphis laxe conspersis, demum glabrescentibus, viridibus, subtus squamis ovali-lanceolatis et orbicularibus pallide fulvis vel alutaceis et longe ciliatis, imbricatis, obtectis; nervis subhorizontaliter patentibus, tenuissi. mis, simplicibus aut semel bifurcatis, apice clavellato intra marginem desinentibus; limbis fertilibus $\pm 4-5 \mathrm{dm}$. longis, $8.10 \mathrm{~mm}$. latis, arachnoideis, basi rotundatis, apice acutis, supra squamis griseo-fulvis, polymorphis, lonye ciliatis, dense obtectis; sporangiis pallide fuscis, minimis, densissime congestis, 78 annulatis.

Crescit in silvis suband. vulc. Tungurahua (12/904).

Differt a ceteris omnibus nostris hactenus cognitis magnitudine consistentia et indumento limborum, ac praesertim mutua inter limbum sterilem fertilesque proportione. Habitu, consistentia et magnitudine utriusque limbi, valde simile. A. praelongo Fee (Filic. Brasil, pag. 9., tab. III. 2.) sed indumento maxime recedit.

$B$ Limbo ster. utrinque squamis albidis $\mathrm{v}$. olivaceis instructo;

a Limbis stcr. elongatis, supra squamis raris polymorphis persistentib. conspersis: subtus homomorphis dense imbricatis;

$\alpha$ Limbis ster. basi obtusis v. cuneatis; fertilithes basi subcordato iruncatis.

$10 \mathrm{~A}$. Urbanisp. nov.; rhizomate brevi, erecto, squamis ebeneis, ovali-lanceolatis, longe et tenuiter serratociliatis, cum phyllopodiis (1 $1 / 2 \mathrm{~cm}$. Jongis) onusto; stipitibus ster. $15.20 \mathrm{~cm}$. Inngis, rigidis, dorso convexis, stramineis, squamis anguste lanceolatis; longe nigro ciliatis, muriculo insidentibus, demum deciduis, divaricatis, laxe obtectis; limbis $3.4 \mathrm{dm}$. longis, $2-4 \mathrm{~cm}$. latis, oblongo-lanceolatis, a medio utroversus angustatis, basi obtusis, apice gradatim angustatis, dense membranaceis, utrobique et secus marginem squanis longe ciliatis, cum muriculo supra limbum prominulo articulatis, (specie pedicellatis) laxe obtectis, squamis paginae superioris incoloribus, laxioribus, 
polymorphis, irregulariter longissime ciliatis; pag. inferioris pallide rufis, ex basi ovata umbilicata, lanceolatis, secundum venas erga marginem protensis; venis crebris, tenuibus, basi plerisque bifidis, utrobique prominulis, citra marginem desinentibus; stipitibus fertilibus quam steriles modice longioribus, iisque subaeque crassis, itemque squamosis; limbo fertili $\pm 2 \mathrm{dm}$. longo, I cm. lato, basi truncato-auriculato, sursum gradatim angustato, apice acuto, supra glabro vel mature glabrato, in costa squamis setulosis consperso, subtus secus nervum medium sparse lepidoto, sparangiis minimis, flavis.

Crescit in pasc. et dumetis andiu. orient. ad vicum Oyachchi [1/900].

Species A. plumoso valde similis, differt, inter alia, limbo fertili basi inaequaliter cordato, supra fere tomentoso, limbos steriles haud superante, etc.

$\beta$ Limh. ster. deorsum in stipitem gradatim attenuatis.

II A. [Elaph.] molle sp. nov.; rhizomate breviter repente, saepe ramoso, squamis subulatis, rigidis, nigris subintegris instructo; stipitibus ster. cum phyllopodiis (10 $15 \mathrm{~mm}$. longis). squamis is rhizomatis similibus, sel longe ciliatis, instructis, basi articulatis, $1525 \mathrm{ct}$. longis, gracilibus, et squamis lanceolatis, centro hyalinis incoloribus margine nigris et longe nigro-ciliatis, divaricatis, cum aliis mitroribus, heteromorphis dense conspersis; limbis ster. $25.40 \mathrm{ct}$. longis, prope medium $2 \mathrm{r} / 2-3 \mathrm{ct}$. latis, utroversus gradatim angustatis, membranaceis, subpellucidis, viridibus, supra squamis rufescentibus, polymorphis tenuiter et longe ciliatis, laxe consfersis, in margine squamis lanceolatis ciliatisque laciniatis; subtus squamis iisdem sed maioribus densioribus, in costa simul cum aliis margine nigrescentibus, subimbricatis; atns patentibus, plerisque bifurcatis, in $n$ argine desinentibus.

[Limbo fertili mihi ignoto].

Crescit in silvis suband. and. critntalicm ad Oyaeachi. 
Species e grege A.phumosi Feé et A. splendentis Bory, a quibus tamen, iuxta descriptionem, satis differre videtur.

b Limh. ster, supra mox glaluratis viridibus, subtus squamis cinereis longe ciliatis invicem intertextis imbricatis;

1. Limb. ster, utroversus gradatim angustatis; fertilib. elongato-Janceolatís.

12 A. (Elaph.) gossypinum sp. nov.; rhizomate repente, adscendente, squamis setiformibus, $5.7 \mathrm{~mm}$. longis, remote ciliatis, nigris, dense obsito; phyllopodits so$12 \mathrm{~mm}$. longis, squaınis prioribus similibus sed longius ciliatis, conspersis; stipitibus (fertilibus sterilibusque subaequilongis) $20-25 \mathrm{~cm}$. longis, tenuibus stramine is, squamis parvis, nigris longe ciliatis, obsitis, mox glabratis; limbis sterilibus stipites aequantibus vel parum superantibus, $20.25 \mathrm{~mm}$. latis, supra squamis parvis lanceolatis, stramineis ciliatis, parce (in costa densius) conspersis, mox glabratis, viridibus, subtus squamis albis, ovali-lanceolatis, longe ciliatis pedicellatis, supra prope basin umbilicatis, laxe imbricatis, obtectis; limbis fertilibus lineari lanceolatis, $1518 \mathrm{~cm}$. longis, I0-12 mm. latis, basin versus abrupte contractis, e quadrante superiore sursum gradatim angustatis, supra squamis ochraceis, parvis lonyissime ciliatis perdense imbricatis, contectis; spórangiis parvis, flavis, annulis $10-12$ instructis.

Crescit in pascuis andinis andium or. m. Guamani.

Species Elaph. Pichinchae potissimum affinis et forte eiusdem varietas; differt stipitibus mox glabratis, limbis tenuioribus, squamis paginae inferioris limbi sterilis albo-sericeis, etc.

$\beta$ Limb. ster, basi obtusis, apice cuspilatis; fertilib. conformib., plus duplo minoribas.

13 A. (Elaph.) cinereum sp. nov.; rhizomate repente, una cum phyllopodiis (10-12 $\mathrm{mm}$. longis), squamis atris, lineari-subulatis ciliatis dense imbricato; stipitibus ster. I $2-15$ ct. longis (fertilibus paulo longrioribus) tenuibus, rigidis, stramineis, squamis parvis, nigrescentibus, irregulariter (iliatis primum conspersis, mox glabratis; limbis ster. 10-18 ct. longis, $10-15 \mathrm{~mm}$. latis, basi plerum- 
que cuneatis, quandoque obtusis, apice acuminatis v. breviter cuspidatis, subcoriaceis, supra squamis rufescentibus, ovali-lanceolatis, longe ciliatis conspersis, demum ylabratis; subtus et secus marginem squamis albidis (in costa atratis) ex basi cordata ovatis $\mathrm{v}$. ovato-lanceolatis, longissime ciliatis dense imbricatis ac veluti mutuo intertextis: limb. fertilib. cum sterilibus subconformibus subduplo minoribus, supra squamis ovatis, cordatis, radiatim longissime ciliatis, quasi tomento rufo, dense obtectis, in costa utrinque squamis nigris imbricatis.

Crescit in rupibus andin. vulc. Antisana.

C Limb. ster utrinque vel saltem subtus squamis rufis imbricatis;

a Limbis ster, supra glabris v. mox glabratis.

14 A. (Elaph.) Pichinchae Christ rhizomate repente, ascendente ramoso, (cum phyllopodiis $12-15 \mathrm{~mm}$. longis nigrescentibus) squamis nigris rigidis, lineari-subulatis, longe serrulato-ciliatis imbricato; stipitibus approximatis, subbiseriatis, $15-25 \mathrm{ct}$. longis, tenuious, stramineis, squamis niyris, aliis ovali lanceolatis, serrulatis, adpressis, aliis subrotundis, longe ciliatis, laxe patentibus instructis; fertilibus parum longioribus; limbis ster. stipites subaequantibus, elongato oblongo-lanceolatis $1 \mathrm{I} / 2-2$ ct. latis, sursum gradatim angustatis, acutis vel subinde obtusis, denrsum in basin acutam, subabrupte contractis, dense cartilaugineis; supra parce squamosis, mature calvescentibus, nitidulis, subtus squamis rutis v. rufescentibus, ovalibus, subcordatis, longe ciliatis, arcte imbricatis, (secus costam nigris, stipitalibus similibus) dense obtectis; venis approximatis parallelis, subhorizontaliter patentibus; limbis fertilibus paulo minoribus, longius stipitatis, basi obtusis; supra squamis rufis [in costa nigris] ex basi late ovata lanceolatis, v. subrotundis longe et irregulariter ciliatis [specie tomento rufo] obductis.

Variat limbo fertili brevius stipitato, angustiore, basi angustato.

Crescit in silvis suband. occid. vulc. Pichincha, Corazón et Atacatso. 
b Limbis ster. supra squamis sero deciduis $r$ pe sistentubus obtectis;

12. Limbis squamis pag. super. heteromorphis sero deciduis.

15 A. (Elaph.) muriculatum sp. nov.; rhizomate crasso, repente, densissime radicante, phyllopodiis vetustis defoliatis, diu persistentibus, squamisque atris, rigidis subulatis, irregulariter dentatis onusto; stipitibus fasciculatis, gracilibus 8 - Io ct. longis, squamis divaricatis lineari-lanceolatis, longe ciliatis, centro hyalinis subincoloribus, margine aliisque nigrescentibus conspersis; fertilibus sterilibusque subaeque longis, v. fert. paulo longioribus, et parcius squamosis; limbis ster. 15-25 ct. longis, 10- $5 \mathrm{~mm}$. circa medium latis, atque inde sursum et deorsum gradatim attenuatis, membranaceis sed in sicco rigescentibus, pagina utraque primum rufescente concolore; squamis paginae superioris, laxioribus tenuioribus heteromorphis, ommibus longe setuloso ciliatis, muriculo parvo insidentibus, ab eoque demum deciduis, unde pagina calvescendo muriculis plurimis asperatur; pagina inferiore squamis maioribus, lineari-lanceolatis [cum minoribus asteroideis commixtis] omnibus longe ciliatis, diu persistententibus una cum margine dense imbricata; lim. bis fertilibus 10-1 2 ct. longis, basi $8-10 \mathrm{~mm}$. latis obtusis, atque inde in apicem obtusum vel breviter acuminatum angustatis, supra squamis parvis longissime ciliatis, (specie tomento tenui rufo) obtectis, subtus secus costam, squamis nigrescentibus, linearibus obiter ciliatis consjersis.

Crescit in fissuris rupium et ad truncos vetustos in silv. suband. vulc. Atacatzo et Pasochoa.

3. Squanis utriusque paginae persistentibus homomorphis;

1 Siqumis stipitum margine attatis.

16 A. (Elaph.) Chodatii sp. nov; rhizomute erecto. phyllopodiis persistentibus limborum delapsorum arcte congestis, valde incrassato, et squamis atris subulatis rigidis ciliatis inbricato; stipitibus approximatis, erectis. rigidis, basi cum phyllopodiis nigris, $5-6 \mathrm{~mm}$. longis articulatis, squamis nigris vel nigrescentibus, divaricatis, ovalibus vel lanceolatis, cuspidatis longeque ciliatis den. 
se instructis; sterilibus $3-5$, fertilibus $5-8$ ct. longis; limhis ster. lineari lanceolatis, e medio utroversus gradatim angustatis, v. apice acuminatis, basi \pm obtusis, coriaceis, utrinque concoloribus, rufescentibus, subtus (saltem in costa) nigr scentibus; squamis utriusque paginae lanceolatis, longe ciliatis, dense invicem imbricatis, margine parum protensis; anis tenuibus vix conspicuis; lim. bis fertil. $8-10 \mathrm{ct}$. longis, $5-7 \mathrm{~mm}$. latis coriaceis, basi obtusiusculis, apice breviter cuspidatis, supra subtusque in costa dense imbricato-squamosis, subtus soriferis; so$r$ is parvis flavescentibus, demum sordide rufescentibus, annulo subdimidiato, $10-1$ I articulato.

Specimen hic descriptum limbis fertilibus septem praeditum est, quorum unus ceteris maior, subtus in dimidio inferiore tomento denso e squamis fere amorphis, longissime ciliatis, invicem intertextis contegitur, reliqui vero mil eiusmodi praeseferunt.

Crescit in silv. suband. and. or. ad Oyacachi.

2 Squamis stip. concoloribus rufescentibus.

17 A. (Elaph.) rupicolum sp. nov.; rhizomate erecto, vel breviter repente, squamis atris, subulatis obiter et remote denticulatis adpresse vestito; stipitibus approximatis, cum phyllopodiis $8-10 \mathrm{~mm}$. longis, nigrescentibus articulatis; stcrilibus $5-7 \mathrm{~cm}$., fertilib. $10-1 \mathrm{I} \mathrm{cm}$. longis, utrisque yracilibus, erectis, rigidis, squamis patentibus, cupreo-rufescentibus, lineari-lanceolatis, longe ciliatis, in sterilibus maioribus multuque densioribus praeditis; limbis sterilibus coriace:s (in specimine) $14-18 \mathrm{~cm}$. lonyis, 8-12 mm. latis, lanceolatis, exsiccando revolutis, basi obtusiusculis, apice acuminatis, primum squamis petio. laribus similibus in pagina utraque (et margine late fimbriato) imbricatis, mox in pagina superiore canescentibus et demum deciduis; limbis fertilibus parum brevio. ribus, subaequilatis, basi apiceque acutis, supra squamis tenuissime longeque radiato-ciliatis, (specie tomento tenui) vestitis, in costa utrinque squamis linearibus ciliatis, supra canis, subtus nigrescentibus obtectis.

Crescit in fissuris rupium vulc. Antisana ad $4.200 \mathrm{~m}$. 
B Squamis rhizomatis, membranaceis crispatis; limbo fort. cum sterllih. conormi, parum minore.

18 A. (Elaph.) spectabile sp. nov.; rhisomate robusto, tortuoso, repente, squamis fuscis membranaceis crispatis, margine irregulariter dentatis vestito; stipitibus 2$4 \mathrm{dm}$. longis, cum phyllopodiis obscure articulatis, antice obtuse I-sulcatis, squamis ex basi ovata, vel retusa, dorso nigris, margine albidis ciliolatis, una cum costa utrobique dense vestitis; fortilibus plerumque \pm longioribus; limbis sterilibus stipites subaequantibus, $34 \mathrm{dm}$. longis, 3-6 cm. latis, coriaceis, oblongis, basi obtusis vel angustatis, apice abrupte \pm longe cuspidatis, supra primum squamis parvis, furfuraceis, subdiscoideis, incoloribus ciliatis, conspersis, mox glabratis viridibus, subtus squamis ovatis, longe ciliatis, dense imbricatis persistentibus obtectis; nervis tenuibus, parum conspicuis, valde approximatis, divaricato-patentibus, bis terve bifurcatis, intra limbi marginem cartilagineum fimbriatum, glandula crassiuscula desinentibus; limbis fertilibus conformibus vel basi obtusis vel truncatis, parum minoribus, squamis minimis, umbilicatis, longe ciliatis, secus limbi marginem cinereis, secus costam, cum aliis maioribus rufidulis, dorso atratis, densissime obtectis.

Crescit in iugis superioribus vulc. Atacatzo, ultra $3.500 \mathrm{ml}$.

Species A. Lindigii Karst, et A. argyropliyllo nostro arcte affnis, a quibus differt squamis rhizomatis et paginae superioris limbi fertilis; ab A. argyrophyllo praeterea, indumento plane diverso paginae inferioris limbi sterilis. Ab A. trivittato nostro, cui accedit, inter alia, consistentia et forma squamarum rhizomatis, recedit consistentia et indumento utriusque limbi. 


\section{II \\ PHANEROGAIMAE}

ORD. AMARYLLIDEAE Endl.

\section{G. 8. BOMAREA MIRBEL (*)}

I (Wichuraea) caule simplici, erecto, apice cernuo; foliis sessilibus, cauli adpressis.

I B. (Wich.) glancescens Bak. (Handbook of the Amaryllideae p. 147) radice tuberosa; caule humili, 5-8 dc. alto 3-3 mm. crasso, erecto, rigido, laevi apice florifero cernuo; folitis infimis squamiformibus, sursum gradatim longioribus, lineari-lanceolatis, e basi caulem semiamplectente sursum gradatim angustatis, rigidis, cauli adpressis, dorso striatis, glabris antice albo-tomentellis; supremis (umbellam involucrantibus) lanceolatis, subcuspidatis, ceterum conformibus; umbella parva, simplici, 3-6-flora, floribus folia involucrantia subaequantibus, plerumque brevioribus; fedicallis simplicibus, trectis, rigidis, $10-15 \mathrm{~mm}$. longis, angulatis, basi squamis involucralibus interioribus, lineari sululatis, $4-6 \mathrm{~mm}$. le.n-

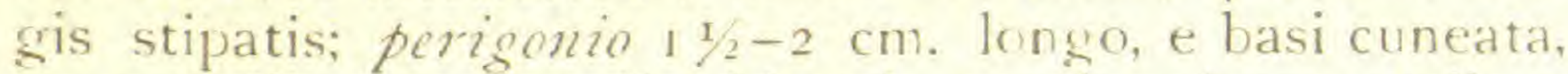
sursum dilatato; sefalis oblongis, fetala subaequantibus, subtus dorso $\propto$-nerviis, apice obtusis; petalis a medio deorsum in unguem linearem contractis, sursum oblongoellipticis, apice obtusis, flavis, reorsum purpureo-maculatis; ovario ubconico, glabro vel tenuiter tomentello; $f$ Lamentis filiformibus, quan styli brevioribus; antheris crassis, didymis, cum filamentis articulatis.

Crescit in pascuis andinis utritusque catenae and. ultra $3.500 \mathrm{~m}$.

(*) Huius generis plures aliae species in ditione Florae nostran occurrunt. Hic recensemus solummodo illas quas ipsi collegimus et quarum specimina nobis nune praesto sunt. 
II (Eubon.) caule t volubili; folits petiolatis, resupinatis.

A L intel la simplici;

A Perianthio parvo; scgmentis subaequilongis;

glabro;

a Pedicellis perianthio brevioribus vel (No 3) subaequantibus; cute

a. Umbella $\infty$-flora;

I Foliis ovalibus, subtus tomentosis.

\% B. tomentosa Herb. caule scandente, volubili, subterete, glabro, apicem versus tomentello; folizis breviter (4 $6 \mathrm{~mm}$.) petiolatis, petiolo torto resupinatis, dense cartilagineis, supra glabris nitidis, subtus tomentosis, ovalibus, $6.8 \mathrm{ct}$. longis, $2 \mathrm{r} / 2-4 \mathrm{ct}$. latis, breviter acuminatis, basi obtusis vel obiter in petiolum excurrentibus; brac teis involucri lineari-lanceolatis, acuminatis quam pedicelli brevioribus; pedicellis in receptaculo obiter elongato digestis, bracteis lineari-subulatis suffultis, bracteolisque 1.2 prope basin singulis instructis, tenuibus I 2 $15 \mathrm{~mm}$. longis, cum ovario obconico glanduloso-pilosis; perianthio $18.20 \mathrm{~mm}$. longo, campanulato; sepalis petala longitude aequantibus iisque parum angustioribus, oblanceolatis, apiculatis, rubentibus, subglabratis; petalis obovato-spathulatis, a medio deorsum in unguen linearem angustatis, aurantiacis purpureo-maculatis; filamentis petala subaequantibus, filiformibus, glabris, antheris ellipticis, secus latera marginatis, coerulescentibus.

Crescit in decliv. occidentalibus suband. vulc. Chimborazo $2.600 \mathrm{~m}$.

Forma nostra ab Alstroemeria tomentosa R. \& I', cui caeteroquin in universum concordat, differt pedicellis tantuni deorsum 1-2 bracteolatis.

2 Foliis lanceolatis, utrinque glabris.

3 A. Borjae caule tenui volubili, in sicco angulato, ylabro vel sursum tenuissime puberulo; folits breviter $(5.7 \mathrm{~mm}$.) petiolatis, resupinatis, tenuiter cartilagineis. utrinque glabris, novellis in nervis subtus sparse puberulis, supra viridibus subtus pallidioribus, oblongis, apice acuminatis, basi in petiolum contractis, $8.10 \mathrm{ct}$. longis, 
$221 / 2 \mathrm{ct}$. Jatis; bracteis [3 5$]$ foliaceis, lanceolatis $3 \cdot 5 \mathrm{ct}$. longis: umbella I 5 is flora, bracteolata; pedicellis tenuibus ovarioque puberulis, nudis v, nonnvllis basin versus 1 -bracteolatis perianthium subaequantibus; sepalis lineari ligulatis, rufescentibus, dorso tenuissime puberulis, quam petala parum [2.3 mm.] brevioribus; petalis oblonso spathulatis, in $1 / 3$ inferiore, in unguem basi latiorem contractis, luteis, purpureo-maculatis; filamentis quam petala subtriente brevioribus, subulatis puberulis.

Crescit in silvis suband. occident. vulc. Pululahua prop. Niebly.

$\beta$ Umblla pauciflora; folii lanceolatis, subtus sparse longeque pubescentibus.

4 B. microcephala sp. nov.; caule scandente, laxe volubili, glabro, apicem versus tomentello; foliis petiolatis: petiolo 8-10 mm. longo, torto, reflexo; lamina dense cartilaginea, supra glabra, subtus in nervis longe molliterque pilosa, $12-15 \mathrm{~cm}$. longa, $3 \cdot 4 \mathrm{~cm}$. lata, ovali-vel oblongo-lanceolata, sursum longe attenuata; bracteis foliaceis, sessilibus, lanceolatis, umbellam aequantibus vel superantibus: pedicellis $8 \cdot 10$, tenuibus, $12.25 \mathrm{~mm}$. longis, cum ovario tomentellis et cum bracteolis receptaculi linearibus commixtis, sepalis $20.25 \mathrm{~mm}$. longis, deorsum leviter angustatis, rubris, glabris, vix apice puberulis, petala subaequantibus; petalis spathulatis, limbo $\pm 5 \mathrm{~mm}$. lato, flavo, purpureo maculato, deorsum in ungtien contracto: filamentis subulatis, perianthio parum brevioribus, deorsum cum stylo (eo subduplo breviore), breviter pubescentibus; ovario obpyramidato, trigono, dense breviterque tomentello.

Crescit in silvis subard. occid. ad Quirosamana [8 807$]$.

b) Pedicellis perianthio longioribus;

1 L'mbelle pauciflora:

- Folits bracteisque subaequalitus, linearibus.

5 B. graminifolia sp. nov.; caule tenui, laxe volubili, obiter angulato, glabro; foliis anguste lineari-oblon- 
gis, $7-8 \mathrm{ct}$. longis, $3-4 \mathrm{~mm}$. latis, resupinatis, utrinque glabris, supra viridibus, subtus glaucescentibus, tenuiter 7-nerviis, supremis ceteris conformibus; umbella (in specimine quod prostat) biflora, bracteis 2 parvis, oblongo-lanceolatis, $45 \mathrm{~mm}$. longis viridibus; pedicellis 2, filiformibus, striolatis, perianthium aequantibus, parianthio (ovario incluso) $4 \mathrm{~cm}$. longo; sepalis oblongo lanceolatis, obtusis, cartilayineis, laevibus tenuiter plurinerviis, extus rubentibus, apice viridi-glaucescentibus; petalis sepala modice excedentibus, oblongo-spathulatis, apice obtusis rubro-virescentibus, purpureo-punctulatis.

Crescit in silv. suband. occid. vulc. A tacatzo.

* Foliis lineari-lanceolatin, quam bracteae multo maioribus.

6 B. tenuifolia sp. nov.; caule gracili, scandente, laxe volubili, breviter molliterque puberulo; foliis tenuiter cartilagineis, utrobique glabris, vel subtus, praesertim in nervis, brevissime punctulato-puberulis, angustelanceolatis, a triente inferiore sursum gradatim in apicem subulatum angustatis, deorsum in petiolum brevem, cirrhoso-reflexum, margine crispatum contractis, 8-12 cm. longis, $10-12 \mathrm{~mm}$. latis, superioribus gradatim minoribus densioribusque; bracteis lineari-lanceolatis, diminutis reflexis; umbella simplici $10-15$ flora; pedicellis perianthium superantibus, $12-12,5 \mathrm{~cm}$. longis, tenuibus, ebracteatis, cum ovario turbinato, trigono glanduloso-puberulis: sepalis quam petala $2-3 \mathrm{~mm}$. brevioribus, oblanceolatis, obtusis rubris; petalis luteis, vix $2 \mathrm{~cm}$. longis, apice $7 \mathrm{~mm}$. latis obtusis, deorsum longe unguiculatis, unsuis margine puberulo; filamentis petala subaequantibus puberulis.

Crescit in silvis suband. vulc. Atacatzo.

2 C'mbella $\infty$-flora;

* Folits utrinque glabris, elongato-lanceolatis;

+ Canle terete; bracteis parvis, quam pedicelli multo brevioribus.

7 B. polyantha sp. nov.; (Isomerae-micranthae) caule robusto, breviter puberulo angulato, laxe volubili, sursum longe infra umbellam aphyllo; petiolis $12.15 \mathrm{~mm}$. 
longis, tenuibus, cirrhoso-reflexis, puberulis; limbis lanceolatis, $20-25 \mathrm{~cm}$. longis, parum supra basin $2 \frac{1}{2}-3 \mathrm{~cm}$. latis, sursum gradatim in apicem subulatum angustatis, utrinque glabris; bracteis involucri lineari-lanceolatis, quam pedicelli multo brevioribus, pulverulento puberulis; pedicellis numerosis, (40 et ultra) simplicibus ebracteolatis, gracilibus $6-7 \mathrm{~cm}$. longis, cum ovario sepalisque puberulis; perianthio $3 \mathrm{~cm}$. longo; sepalis oblongis, rubentibus petala subaequantibus; petalis spathulatis, apice mucronatis, $6.7 \mathrm{~mm}$. latis, e medio deorsum in unguen tenuen angustatis; filamentis tenuibus fere capillaribus glabris, perianthio parim brevioribus; stylo puberulo, quam stamina breviore.

Species caulis et foliorum notis, itemque florum numero et magnitudine $\&$ ab omnibus facile distinguenda.

Crescit in silvis suband. vulc. Atacatzo [7/882].

$\beta$ micrantha var. nov. caule fere ad umbellam usque folioso, bracteis involucri minoribus, pedicellis brevioribus, perianthio minore, petalis sepalisque mature deciduis.

\section{Crescit cum typo.}

It Caule angulato; bracteis magnis foliaceis.

8 B. goniocaulon Bak. caule elongato, robusto, laxe volubili, argute-angulato; foliis breviter petiolatis vel subsessilibus, lanceolatis, longe attenuato-subulatis, I 5 . $18 \mathrm{~cm}$. longis, $20.25 \mathrm{~m}$. latis, consistentia firma, utrinque glabris, viridibus, subtus pallidioribus, nervis utrinque exertis; umbella $\infty$-flora; bracteis numerosis inaequalibus, lanceolatis, foliaceis umbellam excedentibus; pedicellis numerosis inaequalibus ( 23 et $67 \mathrm{~cm}$. longis) tenuibus, rigidis, glabris; segmentis perianthii aequalibus, $4.5 \mathrm{~cm}$. longis; sepalis lanceolatis, acutis, basin versus purpurascentibus, apice virentibus; petalis obovat:-spathulatis, apice obtusis, sinuosis, a medio deorsum unguiculatis, virescentibus, violaceo-maculatis.

Crescit in silvis suband. vulc. Corasón. 
Ex speciminibus nostris, sane incompletis, haec species potius ad sectionem sequentem (umbella composita) referenda foret, quippe pedicellis, saltem nonnullis exterioribus, palam bifidis. Praeterea, tum planta tota, tum flores intimam affinitatem cum ceter:s postremae huius sectionis praeseferunt.

** Foliis subtus tomentosis;

+ Bracteis foliaceis; pidicellis paucis, ebracteolatis.

9 B. lanata sp. nov.; caule plurimetrali, scandente, laxa volubili, terete vel exiccando, bisulcato aut obiter angulato, glabro vel sursum pubescente; folizs breviter petiolatis; petiolo reflexo, tortili limbum resupinante, margine undulato-crispato, 8-12 mm. longo, dorso pubescente; limbis subcoriaceis, $\infty$-nerviis; nervis utrobique exertis, supra glabris, subtus albido-lanato-tomentosis, $10-12 \mathrm{~cm}$. longis, $22-27 \mathrm{~mm}$. lat's, e triente inferiore sursum in apicem longe subulatum contortum attenuatis; involucri bracteis $5-7$, plerisque foliaceis, lanceolatis, supra lanatis, $2-4 \mathrm{~cm}$. longis, quandoque cum aliquot minoribus subulatis commixtis; umbella simplici, (in speciminibus nostris) 8-1 5 flora; pedicellis $4-5 \mathrm{~cm}$. longis, simplicibus, ebracteolatis, vel nonnullis prope basin bracteola subulata instructis, una cum ovariis et capsula pilis glandulosis patentibus dense obtectis; sepalis oblanceolatis, rubro-purpurascentibus, petala lonyitudine subaequantibus iisque angustioribus; petalis $22-25 \mathrm{~mm}$. longis, apice rotundato, in medio mucronulatis, deorsum in unguem puberulum angustatis, nervo dorsali puberulo, cetera flavis, haud maculatis; filamentis tenuibus subulatis cum stylo apice trifido puberulis, quam sepala brevioribus; capsula depressa argute trigona.

Crescit in silvis suband. occid. vulc. Corazón.

Species B. tomentosae Herb. (Alstreemeriae tomentosae R. \&. P.) proxima; a qua tamen pluribus notis differt ut facile constabit si descriptio nostra cum descriptionibus auctorum praedictorum, ac potissimum cum primitiva, quae Ruiziana est, conferatur. 
tt Bracteis parvis; peducellis numerosis basi bracteolatis.

10 B. subspicata sp. nov.; caule scandente, laxe volubili, terete, glabro sursum puberulo; foliis sparsis, nonnullis fere oppositis, ovatis vel ovalibus apice acuminatis, basi subrotundatis breviter $(68 \mathrm{~mm}$.) petiolatis, subcoriaceis, supra striato-nervosis, subtus tomentosis, 8 - Io ct. longis, 3.5 ct. latis; inflorescentia subspicata, id est pedicellis secus axin centralem $2 \cdot 3$ ct. longum dispositis, apicem versus densius congestis; inzolucro generale nullo; pedicellis $21 / 23$ ct. lougis basi bractea subulata, et sursum iterum bracteola una ulterave minore et quandoque rudimentum axillare foris abortivi ferente instructis, cum ovario tomentellis perianthio longioribus; segmentis perianthi subaequalibus; sepalis oblanceolato-spathulatis, utrinque glabris; petalis limbo paulo latiore subelliptico apice rotundato obtuso infra medium in unguem contractis; flamentis filiformibus sepala subaequantibus glabris; sty lo paulo longiore puberulo, profunde trifido.

Crescit in silv. ad basin occid. m. Chimborazo prp. vicum Chillanes.

$\mathrm{Ab}$ omnibus mihi notis differt inflorescentiae axi elongato et involucro generali nullo, vel ad foliola abortiva redacto, ab Alstroemeria tomentosa R. \& P. (B. tomentosa Herb. et aliorum Auctorum) cui pedicellis bracteolatis et foliis subtus tomentosis accedit, differt forma foliorum, carentid involucri et perianthio-maiore. A. B. glomerata Herb., iuxta auctoris descriptionem, differt foliis subtus tomentosis, pedunculis maioribus et bracteolatis etc,

\section{B Sepalis quam petala brevioribus;}

a Floritus parvis, quam perlicelli brevioribus; caule glabro; folis subtus glabris vel pubescentibus.

II B. Caldasiana Herb. caule scandente, laxi volubili, glabro, stramineo; foliis petiolatis, (petiolo 5-10 $\mathrm{mm}$. longo contorto) resupinatis utrinque glabris vel subtus tenuiter pubescentibus, dense cartilagineis lanceolatis vel oblongo lanceolatis 8 - ro ct. longis, I $1 / 2-3$ ct. latis apice acuminatis, basi in petiolum contractis; umbella $5-\infty$. 
flora. basi bracteis 5.7 lanceolatis acuminatis suffulta: pedicellis gracilibus, cum ovario glanduloso pilosis, 35 ct. longis, perianthium superantibus, plerisque basin versus subulato bracteolatis; perianthio $2 \mathrm{I} / 2-3 \mathrm{ct}$. longo; sepalis rubris vel rubentibus, oblanceolatis, apice obtusis, deorsum obiter cuneatis; petalis quam sepala $6.8 \mathrm{~mm}$. Jongioribus, ex apice sinuoso truncato deorsum cuneatim in unguem puberulum contractis, limbo flavido-purpureomaculato; filamentis tenuibus subulatis, minute puberulis, perianthio brevioribus antheris ellipticis, maiusculis coerulescentibus.

Crescit in silvis subandinis utriusque catenae andium usque ad 3.400 met.

b Floribus magnis perlicellisque, 3 (et ultra) cm. longis: petalis flavis;

a. Petircllis ebracteolatis; catte (foliisque subtus) pubescente; fetalis rubromaculatio;

* Pedicellis perianthio longioribus.

12 B. Patacoensis. Herb. caule robusto alte scandente, subterete, laxe volubili, puberulo; foliis remotis superioribus approximatis, oblongo-lanceolatis apice oblique cuspidatis, basi subrotundatis et (petiolo contorto) resupinatis, multinerviis, supra glabris, intense viridibus, subtus pallidioribus, tenuiter pubescentibus; umbella multi-radiata, involucrata: bracteis exterioribus, foliaceis oblongo-lanceolatis, subtus glabris, supra pubescentibus, quam pedicelli brevioribus; interioribus lineari-lanceolatis; pedicellis ebracteolatis, $6-8$ ct. longis, cum ovario sepalisque extus pubescentibus; sepalis oblongo-spathulatis, $3-4 \mathrm{~cm}$. longis, extus purpurascentibus; petalis late spathulatis, $5 \mathrm{~cm}$. longis, apicem versus $2 \mathrm{~cm}$. latis deorsum in unguem angustatis, flavis, purpureo maculatis; stam. 6 quam petala brevioribus; stylo filamenta subaequante, apice trifido.

Crescit in silv. suband. vulc. Tungurahua et Aiacatzo; item in silv. reg. Angamarca.

(3 glabrata, caule foliisque utrinque glabris vel glabratis, bracteis supra tenuiter pubescentibus. 
* Pedicellis perianthio brevioribus.

13) B. Angamarcana sp. nov.; candice modice robus to, scandente, laxe volubili, breviter pubescente-tomentoso; petiolis tenuibus, $10-12 \mathrm{~mm}$ longis, reflexis, contortis, margine-crispato-undulatis; limbis oblongo-lanceolatis, $10-12 \mathrm{~cm}$. longis, $22 / 3-3 \mathrm{~cm}$. latis, basi in petiolum breviter acutatis vel subrotundis, apice acuminatis, modice cartilagineis, subtus, cum bracteis pedicellis et ovario, pubescentibus; bracticis involucralibus, numerosis, foliaceis, oblongis, acutis, 3-4 cm. longis, 5-6 mm. latis; umbella simplici, 15-20 flora; pedicellis tenuibus. simplicibus, rarius bifidis, $3.4 \mathrm{~cm}$. longis, perianthio brevioribus, bracteolatis; sepalis lineari-oblanceolatis, rubris, leviter puberulis, $3 \cdot 3,5 \mathrm{~cm}$. longis, $6-7 \mathrm{~mm}$. latis; petalis $\pm 5 \mathrm{~cm}$. longis. apice $\mathrm{I} 2-15 \mathrm{~mm}$. latis, subrotundatis, medio apiculatis; deorsum longe unguiculatis, flavis non, vel minute, rubro-maculatis; filamentis tenuibus, slabris, petala subaequantibus.

Crescit in silvis suband. reg. Angamarca.

\section{I'ediccllis bractenlatis simplicibus;}

1 Petalis spathulatis apice acutis, flavis haud maculatis

It B. Saloyana sp. nov.: caule robusto, terete, volubili, glabro, apicem versus parce tenuiterque pubescente: folizs subcoriaceis, rigidis, multinerviis, striatis, utrinque glabris, $15-18 \mathrm{~cm}$. longis, $21 / 2 \cdot 3 \mathrm{~cm}$. latis, e triente inferiore deorsum in petiolum cirrhoso reflexum pulverulento puberulum contractis, sursum gradatim longeque attenuatis; bracteis involucralibus 68 , foliaceis, lanceolatis, $3-5 \mathrm{~cm}$. Inonis, $6-8 \mathrm{~mm}$. latis, supra ptibescentibus; $u$ bella simplici, I5-18 radiata; pedicellis 6-8 cm. longis, parum infra apicem 1 -bracterlatis, una cum ovario. sepalis et petalorum nervo medio dorsali, dense tomentoso-pubescentibus; sepalis oblanceolatis, spathulatis, apice calloso-mucronatis, $\infty$-nerviis: petalis sepala 8-10 $\mathrm{m}$. superantibus, spathulatis, deorsum in unguem margine crispatum contractis, flavis haud maculatis; filamentis subulatis, glabris, quam sepala brevioribus.

Crescit in silvis suband. occid. vulc. Atacatso, secus torrentem Saloya (7/907). 
A. B. Lutea Herb. cui ceteru'n affinis, differt foliis maioribus forma et indumento bractearum, pedicellis longioribus, petalis sepala non a teo superantibus etc. Accedit iten B. confertae Benth. et B. patacoensi Herb.. a quibus discrepat, caule foliisque glabris, pedicellis lonyioribus, subapice bracteolatis, sepalorum petalorumque indu nento et colore; a $B$. profinx Herb. petalis angustioribus, sepala parum excedentibus, luteis, haud maculatis, pedicellis longioribus etc.

2 Petulis apice truncatis, flavis, rubro-maculatis;

* Canle foliisque glabris; podicellis sepalisque glanduloro-puberulis.

$15 \mathrm{~B}$. rigidifolia sp. nov.; caule robusto, subterete, laevi; petialo reflexo, compresso, contorto, glabro, 1 1/2-2 $\mathrm{cm}$. Iongo; limbis rigidis striato-nervosis, glabris, lineari-lanceolatis, ro. $15 \mathrm{~cm}$. longis, $10-12 \mathrm{~mm}$. latis; bractcis 6.8 foliaceis, sessilibus, lanceolatis, apice cuspidato subulatis, $5-6 \mathrm{~cm}$. longis, $5-7 \mathrm{~mm}$. latis, resupinatis, supra et margine punctulato pilosis; umbella simplici, $\infty$-flora; peticellis tenuibus, $5-7 \mathrm{~cm}$. longis, infra medium plerisque $\mathrm{r}$-bracteolatis, cum ovario, sepalis dorso, petalorum ungue et filamentis deorsum pulverulento-pubescentibus; sepalis oblanceolatis, obtusis, $\pm 2 \mathrm{~cm}$. longis, rubris, striatn-nervosis, parum infra apicem extus tuberculatis; petalis $25-28 \mathrm{~mm}$. longis, apice truncato. levissime fimbriato, 8-10 mm. latis, deorsun longe cuneatis flavic. quando que magine rubellis: filanentis subulatis, petala subaequantibus; antheris ellipticis, pallide azureis.

Crescit in silvis suband. and. orient. vuic. Tungterahua et in reg. occid. prope Nono.

$\Rightarrow$ Caule foliisque sulfus Inacteis et pedicellis 1 pubsescentíns

f Caule superne aphylio.

16 B. ambigua sp. nov:; caule scandente, volubili, tenuiter puberulo, in sicco angulato; folits longiuscule [8. Io mm.] petiolatis, petiolo contorto resupinatis, supra glabris viridibus subtus dense et minute punctato pilosis, oblongo-lanceolatis, $10-12 \mathrm{ct}$. longis, $2-3 \mathrm{ct}$. latis, apice angustatis aruminatis, basi in petiolum contractis, bracteis involucri 2.4 seriatis, lanceolatis acuminatis, supra 
pubescentibus; ambella a-flora pedicellis circa $\ln l$ tlice axin ( $10.15 \mathrm{~mm}$. longum) pluriseriatim digestis, tenuibus cum ovario puberulis, infra nedium bracteolatis; feriunthio $3 \mathrm{ct}$. longo; sepalis lineari ligulatis, dorso apiceque calloso puberulis, subcucullatis; petalis quam sepala $7 . \& \mathrm{~mm}$. longioribus, afice sinuoso-truncatis et nervo medio excurrente apiculatis in unguem puberulum cuneatim contractis, flavis, dilute rubro-maculatis; filamentis tenuibus subulatis, deorsum pubescentibus, subaequantibus; sty'lo tilamenta aequante, apice trifido.

Crescit in silvis suband. and. occ. prope $\Lambda$ mo, Gmalea, Mindo, etc.

t+ Cartle usque ad umbellam clense folioso.

I7 B. foliosa sp. nov.; caule robusto, laxe volubili, breviter denseque tomentello, ad apicem usque foliose; folits dense cartilagineis, subtus pubescentibus, supra in nervis punctato-pilosis, demum glabratis, inferioribus 20 $25 \mathrm{ct}$. longis, 4 -5 ct. latis, oblongo-ellipticis, basi in petiolum I 5. $20 \mathrm{~mm}$. longum cirrhoso-reflexum, margine crispatum puberulum angustatis, apice acuminatis; superioribus densioribus oblongo-lanceolatis, gradatim minoribus densiusque pubescenti-ton entellis, supremis infra umbellam congestis minoribus in bracteas receptaculi conici lineari-lanceolatas gradatim transeuntibus; umbella simplici, $\infty .(40-50)$-flora; fedicellis 5.6 ct. longis, parum supra basin et quandoque iterum \pm infra medium bracteolatis, una cum ovario obconico puberulis; sefalis $3.5 .4 \mathrm{ct}$. longis, rubris, puberulis, oblanceolatis, apice callose-apiculatis; petalis $5 \mathrm{~cm}$. Iongis, apice $18-20 \mathrm{~nm}$. latis, rotundatis retusis, nedio apiculatis, deorsum longe curtatis, flavo-aurantiacis, purpureo-n aculatis, dorso margineque, cum filamentis styloque, puberulis.

Crescit in silvis suland. cecid. vulc. Pidimelia, Corazón, 7ungurahua et Atacalio inter $2.0 \mathrm{co}$ et $2.4 \mathrm{co} \mathrm{m}$.

A. B. patacoensi Herb. (B. confenta Penth.) differt, statura robustiore, induniento, bracteis receptaculi t $\mathrm{pe}$ dicellorum etc. 

glabro;

B Peticellis perianthio multo brevioribus; petalis purpurec-maculatis; rattle

a Folis Iracteisque (foliaceis) supra glabris, subtus cum ovario sepalisque pubescentibus;

a. Bracteis ovatis, umbella brevioribus; pelicellis bracteolatis;

18 B, brachypus Kränzl. n. sp.; "caules volubiles ad $6 \mathrm{~m}$. longi, [ex F. C. Lenuins] satis tenues glabri foliosi, folia brevi-petiolata late ovata basi subcordata acuta $v$. brevi acuminata satis firma nervosissima supra glabra subtus dense et brevi-pilosa glaucescentia, petioli tortuosi $1 \mathrm{~cm}$. longi, laminae \&-10 $\mathrm{cm}$. longae $4-5 \mathrm{~cm}$. latae superiora infra infurescentiam aygregata paulum minora involucrum magnum formantia capitulum florum subaequantia. umbella multillora densiflora, pedicelli brevissimi in involucro omnino absconditi pilosi quam flores multo breviores, ovaria semiglobosa brevi-pilosa. Sepala ligulata obtusa concava contracta, petala e basi pauJum latiore angustata, unguiculata supra spathulata antice retusa, medio apiculata quam sepala quarto longiora, stamina perigonium aequantia, stylus exeunte anthesi sublongior.-Flores magni, sepala $4.5 \mathrm{~cm}$. petala $5,5 \mathrm{~cm}$. longa, sepala sanguinea, petala alba fusco-punctulata." - Julio ad Septembrem.

Kränzlin in Engler's Botanisch. Jahrbïchern 36, Band 4 Heft., 1905 .

In silv. suband. vulc. Corazón $12 / 907$.

$\beta$ Bractcis oblongo-lanceslatis, umbella longioribus; pedicullis r-bracteolatis.

19 B. grandiceps Kränzl. loc. cit. "caulis satis firmus, glaber, certe volubilis, sed haud ita flexus ut in aliis speciebus; folic brevi petiolata, oblonga, acuminata valde nervosa, et in nervis pilosula, supra glabra; petioli s.3 ct. longi, lamina $16 \mathrm{ct}$. longa, 4 ct. lata rigidiuscula; flores in capitulum magnum densiflorum multiflorum aggregati: pedicelli breves, I ct. et vix ultra longi, quam flores multo breviores, ipsi et ovaria et flores extus dense pilosi, bracteae radiorum exteriores multo majores quam interiores, omnes foliaceae, umbella ceterum foliis ad in dense confertis quam umbella longioribus, involucri instar vestita; sepala oblonga obtuse acutata; petala aequi- 
longa vel vix longiora, ad 2,5 totius longitudinis late linearia, deinde oblonga obtusa apiculataque; filamenta quam petala vix breviora glabra flores maximi sicci nigricantes; sepala 4 ct. petala 4,2 ct. longa; omnia supra I ct. lata."

In silv. occid. suband. vulc. Chimborazo inter Aturas et Chillanes.

b Foliis bracteisque glabris; pudicellis ebracteolatis.

20 B. pulchella sp. nov.; caule gracili, sarmentoso, scandente, laxe aut vix volubili, glabro, 4-5 metrali, apicem versus tenuiter breviterque pubescente; pctiolis 10 - 15 $\mathrm{mm}$. longis, cirrhoso-contortis, reflexis; limbis cartilagineis onerviis, utrinque glabris, supra nitentibus, subtus inter nervos exertos glaucescentibus, oblicuis, oblongolanceolatis, basi acutis, in petiolum decurrentibus, sursum attenuatis subulatis; bracte is involucralibus $5-7$ ovatis, basi contractis et \pm retusis, apice acuminatis, $3-5 \mathrm{~cm}$. longis, 5-10 mm. latis, umbellae approximatis; pedicellis (in specimine circiter 20), $1022 \mathrm{~mm}$. longis, I floris, vel prope basin bifidis, et altero plerumque abortiente, raro bifloris, bracteolatis, cum bracteolis, ovario sepalisque dorso (saltem apicem versus) pubescentibus; sepalis roseo-rubentibus, oblanceolatis, $\pm 25 \mathrm{~mm}$. longis; petalis 4.5 mm. sepala superantibus, spathulatis, sursum rotundatis, medio apiculatis, deorsum in unguem longum attenuatis, in vivo albis purpureo maculatis; filamentis filiformibus, sparse puberulis, sepala subaequantibus; antheris subellipticis, azureis.

Crescit in silv. suband. occid. regionis Angamara. $11 / 905$.

Species elegans; B. brachypodae Kränzl. proxima; sed differt caule graciliore; foliis tenuioribus, multoque angustioribus, utrinque glabris, bracteis item floribusque minoribus, pedicellis longioribus, etc.

B Tmbilla composita;

A Umbella magna; featirellis fasciculatis, 2-3-floris;

a Camie terete foliisque glabris: petliellis $\mathbf{2}$-foris, perianthio brevioribu. a. Foliis ovali-lanceslatis. latitudine sua subduplo longioribus.

21 B. vemustr sp. nov.; caule laxe volubili, alte scan- 
dente, glabro, infra umbellam longe aphyllo; foliis petiolatis; petiolo recurvato compresso, marginato $2 \mathrm{~cm}$. longo, glabro; limbo oblongo elliptico, $12.14 \mathrm{~cm}$. longo. $5 \frac{1}{1 / 2} \cdot 7 \mathrm{~cm}$. lato, basi rotundato, apice longiuscule acuminato, cartilagineo, $\infty$-nervi, supra glabro nitente, subtus pallidiore, in nervis vix punctulato, bracteis involucri 56 foliaceis, breviter petiolatis, ceteris conformibus, sed triplo minoribus; umbella simplici (aut in speciminibus

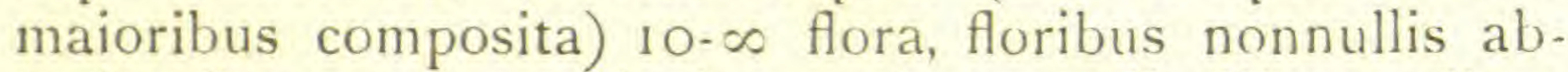
ortientibus, receptaculo bracteolato; pedicellis tenuibus, angulatis pubescentibus, $1.2 \mathrm{~cm}$. longis, simplicibus, aut (in speciminibus maioribus) bifidis, in divisione bracteolatis, bifloris; ovario sepalis, petalisque extus pubescentibus; sepalis oblongo-lanceolatis, deorsum \pm angustatis, purpureis, $4,5 \mathrm{~cm}$. longis, apicem versus $4 \mathrm{~mm}$. latis, obtusis; petalis quam sepala $4-5 \mathrm{~mm}$. longioribus, spathulatis, apice obtusis et nervo medio, dorso piloso, apice \pm exerto apiculatis, e $1 / 3$ superiore deorsum angustatis, albis, intus purpureo maculatis; filamentis glabris, deorsum marginatis, sursum subulatis inaequalibus, maioribus petala, minoribus sepala subaequantibus.

Crescit in silvis suband. vulc, Atacatzo ( $7 / 907)$.

B. minor var. nov.; caule tenuiore, foliisque minoribus; bracteis, 4; pedicellis brevioribus, basi bracteolatis, floribus pluribus abortientibus, ceteris typo conformibus.

Crescit cum typo.

$\beta$ Folizs ovali-lanceolatis, falcatis, latitudine sta subquartruplo longioribus.

22. B. falcata sp. nov.; caule laxe volubili, alte scandente, in sicco angulato, cum petiolis, foliis bracteisque utrinque, glabro; fetiolis cirrhoso-reflexis, compressis, $10-12 \mathrm{~mm}$. longis; limbis dense cartilagineis, $\infty$-nerviis, ovali-lanceolatis, falcatis, basi subrotundis, sursum angustatis, acuminatis, $20-25 \mathrm{~cm}$. longis, - in triente inferiore $4.5 \mathrm{~cm}$. latis, superioribus resupinatis, involucrantibus 6 biseriatis, ovali-lanceolatis, haud falcatis, breviter petiolatis, 3 extimis maioribus unbellam superantibus, 3 intimis minoribus; umbella os-flora; pedicellis $20.25 \mathrm{~mm}$. longis, tenuibus angulatis, parce breviterque puberulis, 
inferne bracteolatis; ovario trigono 6-sulcato, puberulo; sepalis lineari-oblongis, $4.5 \mathrm{~cm}$. longis, $4 \mathrm{~mm}$. latis, apice calloso-cucullatis, dorso puberulis; petalis sepala $7.8 \mathrm{~mm}$. excedentibus, albis, purpureo-maculatis, ab apice dilatato, oblique truncato (nervo medio vix excurrente) leviter apiculato, deorsum in unguen linearem anyustatis; filamentis sepala aequantibus, tenuibus maryinatis sparse breviterque puberulis; stylo gracili, trigono, demum exerto.

In silvis suband. vulc. Atacatzo ad torrentem $Y a m$ boya.

Species B. brachypolae, B. grandicipiti Kränzl. et B. pulchrae nostrae aspectu et florum magnitudine similis et venustate aemula. A duobus praecedentibus differt glabritie et forma foliorum, pedicellis longioribus, bracteolatis; a tertia foliorum et involucri forma et magnitu. dine, pedicellis brevioribus, etc.

b Caule angulato glabro; pedicellis 2-3-floris, perianthio longioribus;

a. Foliis supra pubescentibus;

I Sepalis petala suba equantibus; pedicellis perianthio subduplo longioribus

23 B. elegans sp. nov.; caule robusto, angulato, glabro, scandente, vix volubili; foliis breviter $(35 \mathrm{~mm}$.) petiolatis, oblongo-lanceolatis, I $5.20 \mathrm{~cm}$. longis, 20.25 $\mathrm{mm}$. latis, subcoriaceis, striato- $\infty$-nerviis, supra glabris, subtus pubescenti-tomentellis; bracte is foliaceis, late lanceolatis, sessilibus, sipra to nentosis, subtus glabris, 3 extimis umbellam aequantibus, inti nis gratatim minoribus; umbella multiradiata; rutizs basi bracteolatis, ple. risque parum $([-2 \mathrm{~cm}$.) supra basin bifurcatis, ibidemque iterum bracteolatis, ramis I - floris, $8.9 \mathrm{~cm}$. longis, rigidis, nitidis; ovario campanulato, obtuse trigono, glabro, sefalis dense cartilagineis, glabris, oblongo lanceolatis, acutis; petalis sepala parum $(2.3 \mathrm{~mm}$.) superantibus, ex apice dilatato, medio mucronulato, deorsum cuneatim in unguem angustatis, albis?, purpureo maculatis; filamentis tenuibus, petala subaequantibus, glabris; antheris subellipticis, azureis; stylo filamenta subaequante, apice trifido, ramis contortis, papilloso-stigmatosis.

Cresscit in declivitate occid. m. Corazón et Atacustso. 
3 amoena differt $\mathrm{ab}$ antecedente foliis bracteisque angustioribus, longioribus; ovario breviore latiore, petalis parum latioribus, sepala $56 \mathrm{~mm}$. superantibus.

2 Sepalis quam petala brevioribus; pedicellis perianthio 3-plo longioribus.

24 B. comata sp. nov:; caule robusto, argute angulato giabro; foliis breviter $(510 \mathrm{~mm}$.) petiolatis, subcoriaceis, supra glabris, nitentibus, subtus secus nervos pubescenti-pilosis, lanceolatis, basi in petiolum contractis, sursum longe et gradatim angustatis, I 2 I $5 \mathrm{~cm}$. longis, parum supra basin $21 / 2 \cdot 3 \mathrm{~cm}$. latis, superioribus in bracteas involucri sessiles homomorphas, numerosas, supra pubescentes, quam pedicelli breviores immutatis; umbelli

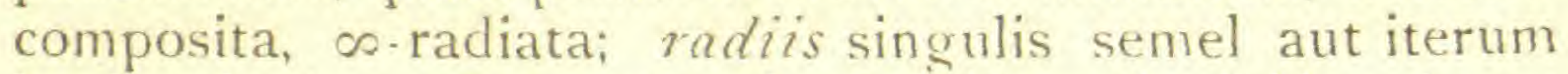
basi vel ad $1.2 \mathrm{~cm}$. supra basin bifurcatis; ibidem bracteolatis, $10-15 \mathrm{~cm}$. longis, rigidis, glabris, glaucescentibus; ovario obpyramidato, trigono, glabro, glaucescente; sepalis cartilagineis, oblongis, purpureis, apice acuto glaucescentibus, $4.4 \frac{1}{2} \mathrm{~cm}$. longis; petalis ad $5 \mathrm{~cm}$. longis, IO- $12 \mathrm{~mm}$. latis, spathulatis, (nervo medio e limbo exerto) apice mucronulatis, deorsum in unguen longum attenuatis, in vivo albis?, purpureo maculatis; filamentis tenuibus, subulatis, glabris, quam petala parum brevioribus; antheris ellipticis, azureis; stylo trigono, $\pm 3 \mathrm{~cm}$. longo, glabro, apice profunde trificlo, in stigmata 3 , extrorsum, arcuata, intus papillosa diviso.

Species, florum numero et venustate, inter nostrates insignis.

Crescit in silvis subandinis $m$. Corazón, ad 2.0002.500 metr.

PFoliss hracteisque glalhis; sepalis quam petala longioribus.

25 B. hexagona sp. nov:; undique glabra; caule robusto, scandente, laxe volubili, argute hexagono, folioso, folizs breviter ( $3.5 \mathrm{~mm}$.) petiolatis, reflexis, resupinatis; subcoriaceis, striato- $\infty$-nerviis, elongato-lanceolatis, parum supra basin 15 - $10 \mathrm{~mm}$. latis, in apicem subulatum, gradatim angustatis; bracte is foliaceis, numerosis, umbellam $\infty$-radiatam subaequantibus; radiis semel iterumve (basi et parum supra basin) bifurcatis, il,idemque 
bracteolatis; pedicellis $7.8 \mathrm{~cm}$. longis, tenuibus, rigidulis, cum ovario sepalisque (in vivo) glaucescentibus; sopalis cartilagineis, oblongo-lanceolatis, apice acutis, circa medium 7-8 mm. latis, dorso purpureis, apice glaucescentibus, quam petala I0-1 $5 \mathrm{~mm}$. longioribus; petalis \pm $4 \mathrm{~cm}$. longis, plerumque inaequilongis in dimidio inferiore in unguem contractis, sursum in limbum subellipticum purpureo-maculatum, dilatatum; filamentis quam peta'a brevioribas, a pice subulatis, desrsum maryinati; antheris subellipticis, azureis.

Crescit in silv. suband. occid. vulc. Atacatzo 7/907.

Species insignis, et characteribus expositis ac potissimum sepalis petala longe superantibus, facile distinguenda.

Postremae haec species intimo nexu inter se conectuntur simulque a plerisque omnibus characteribus apprime perspicuis secerni possunt.

B Umbella magna, pauciradiata; radiis plurifloris, secundifloris.

26 B. edulis Herb. Huic speciei adscribimus sequentes formas, quae inter se et a typo parumper differre videntur.

A. caule glabro, foliis longe subulato-cuspidatis, glabris; umbella 5 -radiata, bracteis totidem anguste-lanceolatis, subulatis, ciliatis suffulta; radiis divaricatis, i 5 cm. longis, 3-4-floris, cum pedicellis, ovario sepalisque (obovatis) pubescentibus; petalis quam sepala parum minoribus, flavis, purpureo-maculatis.

Crescit in silvis subtrop. ppe. Angamara.

B. caule superne, radiis, pedicellis sepalisque extus pubescentibus; radiis, $20-25 \mathrm{~cm}$. longis, subsexfloris; $s e$ palis obovato-spathulatis, petala aequantibus altero ceteris petalisque longiore.

Crescit in silvis trop. occid. secus fl. Peripa.

C Cimbelía parva; pedicellis $2-3$-floris cum 1 -floris intermixtis,

a Foliis elongato-lancenlatis; pedicellis $3-5 \mathrm{~mm}$. Iongis.

27 B. subtriflora sp. nov.; caule tenui I I/2-2 metra- 
li, laxe volubili, foliisque glabris; foliis in triente inferiore (caulis) squamiformibus, sessilibus, ceteris petiolatis, petiolo 8-10 mm. longo contorto, resupinatis, utrinque glabris, nitidis, subtus albidis, lanceolato-subfalcatis v. leviter sigmoideis, basi breviter contractis, sursum in apicem acuminatum attenuatis, mediis (inspecimine) $15-18 \mathrm{ct}$. longis, $2-21 / 2 \mathrm{ct}$. latis, superioribus gradatim minoribus, ad so ct. in ira umbellam desinentibus; bracteis tribus, linearibus, vix I ct. Jongis; pedicellis bracteolatis, $3.5 \mathrm{~mm}$. longis, puherulis, altero bifido, 2 floro, altero I-floro; perianthio (in alabastro clavato) $15 \mathrm{~mm}$. longo; sepalis petali aequantibus vel longioribus, obovatis cucullatis, rubro-aurantiacis, glabris; petalis late cuneatis, apice sinuoso-truncatis, breviter unguiculatis flavis, hand maculatis; filamentis brevibus, perianthii dimidiun vix aequantibus.

Crescit in silv, tropic. prov. Imbabura.

b Folitis cblongis; pedicellis $3-4$ ct. longis.

28 B. gracilis sp. nov. Undique glabra; caule tenui angulato, laxe volubili; folizs oblongis vel oblongo-lanceolatis, apice acutis, basi plus minusve ohtusis, et petiolis cirrhoso-contortis, margine transverse crispato, resupinatis, 4-5 cm. longis, $11 / 2-2 \mathrm{~cm}$. latis, supra intense viridibus, subtus pallidioribus, nervoso-striolatis; bracteis sub umbella $3-5$, cum foliis conformibus, vel parum latioribus; umbella $3-4$ radiata, radiis bracteisque $(3-4 \mathrm{~mm}$. longis) bracteolatis, simplicibus vel semel bifurcatis, sub bifurcatione iterum bracteolatis; bracteolis ovali- lanceolatis acuminatis, hyalinis rubentibus; pedicellis secundariis $2.21 / 2$ $\mathrm{cm}$. longis; ovario obconico; sepalis rubentibus, cartilagineis, plurinerviis obovatis apiculatis; petalis obovatospathulatis apiculatis, flavo virentibus, $20.22 \mathrm{~mm}$. longis IO-I 2 mm. latis, sepala parum excedentibus; staminibus quam petala parum brevioribus; filamentis subulatis et columna stylina glabris.

Crescit in silvis subtrop. prov. Imbabura. 


\section{III \\ ORD. AROIDEAE}

\section{G. 9 ANTHURIUM SCHOTT}

(Supplem. III)

\section{INTEGRIFOLIA-PINNINERVIA}

I (18*) A. acutissimum Engl. $\beta$ maius var nov. limbis ad metrum longis, ad medium i 6 i 8 ct. latis, nervo collectivo (ibidem) I $2.14 \mathrm{~mm}$. a margine remoto, spatha ad $2 \mathrm{dc}$. longa, in triente inferiore $3 \mathrm{t} / 2-4 \mathrm{ct}$. lata; spadace [adhuc inmaturo] $24 \mathrm{ct}$. longo, $I 1 / 2 \mathrm{ct}$. crasso.

\section{Crescit cum forma speciei}

2(26*) a) A. ophites Sod. sp. nov.; caule brevi, crasso; internodiis subcontiguis; cataphyllis dense cartilagineis, nitidis, albidis, exsiccando brunneis, sero et frustratim deciduis; petiolis gracilibus, cylindricis, rigidis, basi breviter $(\mathrm{I} 1 / 2 \mathrm{~cm}$.) vaginatis et (cum pedunculis) livido-maculatis; geniculo $\mathrm{x} 1 / 2 \mathrm{~cm}$. longo instructis; limbis subcoriaceis, nitidis, supra pallide viridibus, subtus albo-glaucescentibus, oblongo-ellipticis, basi acutis, apice breviter acuminatis, $20-45 \mathrm{~cm}$. longis, $12-18 \mathrm{~cm}$. (circa medium) latis; nervo medio subtus robusto, arglite carinato, supra tenui, in dimidio superiore limbi, vix exerto; nervis I.utrinque $12-15$, remotis, arcuato-ascendentibus, supra impressis, subtus exertis, cum II totidem tenuissimis anastomosantibus et in nervum collec-

a) Numerus uneis inclusus, qui species singulas precedit, indieat locum in quo, juxta Monographiae nostre ordinem, species illa colocanda erit. 
tivum robustum, a margine $8-10 \mathrm{~mm}$. remotum confluentibus; pedunculo quam petiolus tenuiore, eqque (10-15 $\mathrm{cm}$.) longiore ab latere modice compresso; spatha late lineari-lanceolata, basi haud decurrente, apice breviter acuminata, consistentia firma cartilaginea, diu persistente; spadice breviter (4-6 mm.) stipitato, subcylindric, sursum leviter attenuato, $8-15 \mathrm{~mm}$. longo, primum albido, demum sordide virescente; tepalis obovatis, concavis, apice dilatato, umbonato, ovarium obtegentibus; bacca globuliformi, apice alba, deorsum rosea, pericarpio crasso instructa.

\section{Crescit in silvis subtrop. prope. San Florencio.}

Species elegans'. A. maculoso nostro maxime affinis, nisi forte veluti eiusde $n$ varietas reputanda sit. Differt potissimum statura minore et forma limborum. lindrico.

Limbis ellipticis, latitudine sua snbluplo longioribus; spafice livido tenui cy

$3\left[4 \mathrm{I}^{*}\right]$ A. pyrifolium Sod. sp. nov. late scandens; internodiis $41 / 2-5 \mathrm{ct}$. longis, vix $3 \mathrm{~mm}$. crassis; catapyllis internodia vaginantibus, mox dissolutis; petiolis $\mathrm{I} / \mathrm{s}$ $21 / 2$ ct. longis, subcylindricis, supra I sulcatis; limbis subcoriaceis, nitentibus, supra intensius viridibus, ellipticis, basi obtusis, apice acutiusculis, 8 - Io ct. longis, $4 \frac{1}{2}-5 \mathrm{ct}$. latis; costa utrinque modice prominente obtusa v. leviter carinata; nervis tenuissimis, in planta viva utrinque immersis, in sicco prominulis, I cum II binis ternisve alternantibus, obnibus in nervum collectivum a margine $4 \cdot 5$ mm. remotum, quam I paulo crassiorem confluentibus; $p e$ dunculo (per anthesin) ad $6 \mathrm{ct}$. longo, rigidiusculo, ancipiti, $\infty$ striato; spatha oblonga, pluri nervia, $2-21 / 2 \mathrm{ct}$. longa, $78 \mathrm{~mm}$. lata basi amplexante, apice subito contracto mucronulata; spadice sessili, per anthesin $4 \frac{1}{2} 5$ ct. longo, ad $4 \mathrm{~mm}$. crasso purpureo-livido; perigonio rhombeo-tetragono, longitudine sua multo latiore; ovario biovulato; stigmate vix prominulo.

Crescit ad rupes et arborum truncos in silv. ad fl. 
Napa. Primo intuitu ad Tetraspermia referendum videtur, sed ovario biovulato prorsus recedit.

Folia Pyri communis glabra satis fideliter refert.

4 (5 $\left.{ }^{*}\right)$ A. oreodoxum sp. nov.; caule erecto, robusto; cataphyllis triangulari-lanceolatis, $20-25 \mathrm{~cm}$. longis, 5-6 cm. latis, subcoriaceis, in fibras intertextas mature dissolvendis; petiolis approximatis, erectis, rigidis, limbos subaequantibus, ab latere parum compressis, basi incrassatis, breviter vaginatis, dorso semiteretibus antice, cum geniculo complanatis, I-sulcatis, sulci lateribus acutis; limbis coriaceis, intense viridibus, subtus crebro, supra parcius nigro-punctatis, 35-40 $\mathrm{cm}$. longis, 24-28 $\mathrm{cm}$. latis, subellipticis, sursum obsolete asymmetricis, basi \pm acutis, apice obtusis, 7-9-nerviis; nervis I. 4 intimis, cum centrali in apice limbi desinentibus, ceteris gradatim inferius in margine evanescentibus, omnibus, ut II, supra immersis, subtus exertis; pedunculis quam petioli crassioribus et subduplo longioribus, compressis, in sicco - -sulcatis; spatha dense cartilaginea, oblongo-lanceolata, 15-20 cm. longa, 3-4 cm. (circa medium) lata, basi semiamplexante et longe decurrente, in apicem callosum desinente; spadice breviter (5-7 mm.) stipitato erecto, cylindrico, per anthesin flavido, $5_{5-18} \mathrm{~cm}$. longo, I $\mathrm{cm}$. crasso, maturescendo aucto, purpureo; stylis per anthesin vix emersis, in spadice maturo, tepala longe superantibus, subtetragonis.

Crescit in silvis suband vulc. Pululahua 10/907.

$\beta$. stipitatum var. nov.; limbis 7-9 nerviis, ovato-ellpticis; pedunculo quam petiolus longiore; spadice longius stipitato flavido.

$\gamma$ cupreum var. nov.; limbis 9 -nerviis, ovato-ellipticis; pedunculo quam ue. tiolus longiore; sfadice crassu, postice subsessili; tepalis per anthesin apice cupreis.

\section{CORDIFOLIA - RHITIDOPHYLLA}

$5\left(69^{*}\right)$ Anthurium Treleasei spec. nov.; caule crasso erecto; cataphyllis coriaceis, $20-25 \mathrm{~cm}$. longis, 
e basi dilatata, sursum gradatim angustatis, dorso pulverulento-puberulis; petiolis $7-8 \mathrm{dm}$.longis, robustis, basi breviter (6-8 $\mathrm{cm}$.) vaginatis, subcylindricis, antice leviter I-sulcatis, apice cum geniculo ( $1 / 2.2 \mathrm{~cm}$.longo, ) articulatis; limbis ovatis, basi profunde cordatis, latitudine sua $1 / 3$ longioribus; coriaceis, nervis subtus valde prominentibus rugosis et tenuiter pulverulento-puberulis lobis posticis quam anticus subtriplo brevioribus, conniventibus, 6-7 nerviis, sinu oblongo, ad medium costis denudatis, circunscripto seiunctis; nevvis interlobaribus utrinque 3-5, una cum nervis I lobi antici (utrinque 20-25) cum totidem tenuioribus alternantibus, et cum superioribus 3-4 loborum basalium in nervum collectivum a margine $2-3 \mathrm{~mm}$. remotum confluentibus, omnibus supra glabris, subtus pulverulento-puberulis; pedunculis quam petioli tenuioribus et subdimidio brevioribus; spatha cubcoriacea, erecta, antice breviter decurrente, lanceolata, acuminata, per anthesin quam spadix parum breviore; spadice breviter $(1 \mathrm{r} / 2 \mathrm{~cm}$.) stipitato, viridi-cinarescente, subcylindrico, $20-25 \mathrm{~cm}$. longo, IO. I5 mm. crasso; tepalis 5-6 mm longis; bacca tetragona-elliptica, sepala aequante.

Crescit in silvis suband. occid, vulc. Pichinche.

Planta Anthurio Umbraculo Sod. omnino hat itu ct statura similis, Differt potissimum spatha subcoriacea, erecta, spadice longiuscule stipitato, subcylindrico, rigido, spathain parum superante. \&. Ab A. bulloso restro (Anth. Ecuat, Suppl I p. 5I) differt nervis numercsioribus, valde exertis, lobis basal. maioribus magis coninventibus; sinu basali angustiore, costis brevius denudatis etc-Ab A, procero eiusque affinibus, quibus statura et forma limborum, spathae etiam et spadicis rationibus quadantenus accedit, differt, caule erecto, limbisque valde rugosis, nervis, crebrioribus, subtus valde exertis etc.

Spadice spatham subduplo snperante (Sp. post. A Tungurahune collc canca).

$6\left(127^{*}\right)$ A. Candolleanum Sod. sp. nov. caudice scandente, radicante; catapyllis lanceolatis, supra basin dilatatam amplexantem, abrupte contractis, acuminatis, to- 
I 2 ct. longis, diu persistentibus; internodiis $68 \mathrm{ct}$. Iongis, ad $2 \mathrm{ct}$. crassis, viridibus; petiolis $5.6 \mathrm{dc}$. longis, gracilibus, [vix $3 \mathrm{~mm}$. crassis] angulatis, basi antice longe vaginatis, sursum [cum geniculo ad $4 \mathrm{ct}$. longo incrassato] I- sulcatis; limbis cordatc-sagittatis, subcoriacess, saturate viridibus, nitentibus, utrinque subconcoloribus $4^{-}$ $4.5 \mathrm{dc}$. longis, ad petioli insertionem 2,5 dc. latis, atque inde sursum linea convexa, gradatim in apicem cuspidatum angustatis; lobis basalibus quam terminalis 3-plo brevioribus, obtusissimis retrorsis, sinu basi semicirculari, costis ad 2-ct. nudis circumscripto seiunctis, sursum (latere interno non nihil evoluto) modice convergentibus; costa supra modice, subtus alte prominente obtusa; nervis omnibus supra impressis, subtus exertis obtusis; laborum basalium 5, e quibus 4-inferioribus reflexis, dein erga marginem abrupte arcuato-ascendentibus, quinto cum interlobaribus [utrinque 1 ] et I. lobi terminalis (utrinque 67 ) in nervum collectivum a margine $8.3 \mathrm{~mm}$. remotum confluentibus; pedunculis quam petioli $10-12$ ct. brevioribus, gracilibus, subancipitibus, angulatis; spatha oblongo-lanceolata, subcoriacea, viridi, plurinervia I O. 12 ct. Jonga, in triente inferiore ad 4 ct. lata, basi antice modice aperta et spadicis stipitem paulo denundante, apice calloso-mucronata; spadice longe (2-21/2 ct.) stipitato, snbcylindrico, aut anthesiad I, $3 \mathrm{ct}$, longo, I2-14 $\mathrm{mm}$. crasso, atrato-purpureo, flexili cernuo; tepalis cuneatis, dcrso argute carinatis; filamentis linearibus, dorso infra c picem purpureo-maculatis; antheris vix exertis.

\section{Cre cit in silvis subtrop. occid. secus fl. Tandapi.}

Species e grege A. scabrincrvis, tamen a ceteris atfinibus fecile distinguenda.

\section{PALMATO TRILOBA}

$7\left(14.3^{*}\right)$ A. heteroclitum sp. nov.; caule plurimetrali, alte scandente, nodoso, parce radicante; internodiis inae- 
qualibus, ( $3-5 \mathrm{~cm}$; $8-10 \mathrm{~cm}$. longis) $2 \mathrm{~cm}$. crassis, teretibus, laevibus, glauco-nitentibus; cataphyllis cartilagineo-herbaceis, laevibus, lanceolatis, apice obtusis, demum in fibras reticulatas resolutis; petiolis robustis, cylindricis, $50-65 \mathrm{~cm}$. longis, basi breviter $(6-7 \mathrm{~cm}$.) vaginatis, apice geniculo parum incrassato, cylindrico, instructis; limbis dense herbaceis, laevibus, utrinque viridibus, ovato-cordatis, apice breviter acuminatis, duplo $\mathrm{f}$ re longis ac latis; lobis basalibus $10-12 \mathrm{~cm}$. longis, obtusis, obiter divergentibus, sinu semicirculari vel leviter reniformi, basi breviter nudato seiunctis, cum lobo terminali linea uniformiter convexa continuis, 6-nerviis; nevoiis omnibus, et interdum cum 2 interlobaribus et iugo infimo lobi terminalis in margine desinentibus; nervis lobi terminalis (utrinque $9^{-10}$ ) in nervum collectivum submarginalem (iugo infimo quandoque excepto) confluentibus; pedunculo petiolum longitudine subaequante eoque vix graciliore; spatha lanceolata, sursum in apicem subulatum gradatim attenuata, basi breviter obliqua, ad $2 \mathrm{dm}$. longa viridi spadice (in specimine adhuc in spatha incluso) breviter ( $1 \mathrm{~cm}$. stipitato) $12 \mathrm{~cm}$. longo, cylindrico, apice optuso (Cetera ignota).

Crescit cum specie sequente, cui valde affine. Differt statura maiore, limborum forma et nervatione et pedunculis magis robustis, spatha antice non decurrente, spadice modice stipitato, etc. Foliorum forma et structura nonnullis Lciophyllis nostris e sectione Achroostachya, haec species et quae proxime sequitur, admodum accedunt, sed caeteris characteribus ad Palmatinervia manifeste adcensendae sunt, quorum seriem quodammudo aperiunt, nexumque evidentem ostendunt, quo haec postrema sectio cum priore coniungitur.

8 (143*) Anthur bimarginatum sp. nov, caule plurimetrali, alte scandente, nodoso, e nodis radices numerosas, tenues verticillatim mittente; internodizs $12-15 \mathrm{~cm}$. longis, Io-1 $2 \mathrm{~mm}$. crassis, laevibus, plumbeo-nitentibus; petiolis 3-4 dm. longis, 6-7 $\mathrm{mm}$. crassis, subcylindricis, antice leviter $\mathrm{I}-\mathrm{sulcatis,}$ basi incrassati, intus vagina $5-7$ 
$\mathrm{cm}$. longa instructi, in sicco sub 5 -angulatis, apice geniculo $\pm 2 \mathrm{~cm}$. longo, tereti, incrassato instructis; limbis blande carnosis, pellucido-punctatis, supra intense glauco-viridibus, subtus viridi-flavescentibus, late ovatis, \pm $40-45 \mathrm{~cm}$. longis, $35-40 \mathrm{~cm}$. látis, profunde cordatis, trilobis; lobis basalibus subsemirotundis, retrorso-divergentibus, sinu reniformi $10-12 \mathrm{~cm}$. alto seiunctis, in lobum terminalem ovatum, apice breviter cuspidatum, lí. nea concava transeuntibus; nervis loborum hasalium utrinque $5-7$ in costas sinus coniunctis, 2 infimis parum supra basin a costa liberis, ceteris gradatim apicem versus a costa flabellatim solutis. omnibus marginem arcuatim petentibus, et, ut interlobari et $3-4$ infimis lobi terminalis in nervo collectivo margini aproximato et fere ad limbi apicem ducto desinentibus, superioribus 4-6 lobi terminalis. in nervum collectivum late (IO-I $2 \mathrm{~mm}$.) intramarginalem et in limbi apice terminatum confluentibus; pedunculis teretibus, gracilibus petiolos aequantibus vel superantibus; spatha lineari-lanceolata, I8.20 $\mathrm{cm}$. longa, vix $2 \mathrm{~cm}$. lata, basi antice longe decurrente in apicem subulatum gradatim angustata; spadice breviter $(10-15 \mathrm{~mm}$.) stipitato (in specimine nondum plane evoluto) $25 \mathrm{~cm}$. longo, $10 \mathrm{~mm}$. crasso, subcylindrico, apice obtuso, primum flavido, demum viridi-fuscescente, tepalis subellipticis, apice cucullato trigonis; staminibus inclusis, vix tepalorum dimidium aequantibus.

Crescit in silvis subtrop. occid. vulc. Pululahua, ad Yanaurco. 10/907.

\section{G. IO. STENOSPERMATIUM SCHOTT,}

Flores hermaphrod. apetali; stam. 4, antheris dithecis. extrorsum dehiscentibus; ovarium obpyramidatum, I-2-

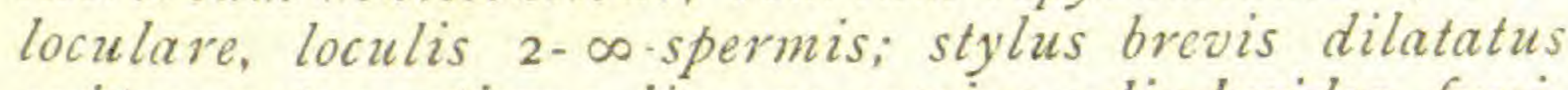
subtruncatus; stigma lineare, semina cylindroidea, funiculo longulo placente basilari affixa; embryo axilis, albuminosus. 
I. Petiolis omnibus ad geniculum usque vaginatis, quam limbi breviorihas;

A. Pedunculis 8-10 cm. longis, supra folium (bracteam) supremum $3-5 \mathrm{~cm}$. longis; spadice subsessili ellipsoideo;

a Petrolts $3-4 \mathrm{~cm}$. longis, quam limbi subquadruplo brevioribus.

I St. brachypodum Sod. sp. nov. caudice ascendente vel erecto; internodiis $2.4 \mathrm{~cm}$. longis, $4-5 \mathrm{~mm}$. crassis, in sicco striato-rugosis; petiolis $3-4 \mathrm{~cm}$. longis, basi dilatato amplexantibus, sursum usque ad limbi basin (geniculo vix distincto) vaginantibus, vagina apice oblique, retusa; limbis oblongis, vel oblongo-ellipticis, basi acutis, apice breviter acuminatis, subcoriaceis, glabris, subtus pallidioribus; costa supra immersa, subtus ad limbi dimidium obtuse exerta; nervis tenuibus, sub angulo valde acuto, erecto áscendentibus, I paullo validioribus, II. 2.3 interiectis; pedunculis in caulis apice, sæpe geminatis, $4.5 \mathrm{~cm}$. longis, erectis, 3.3 bracteatis, sub apice constrictis fere articulatis; spatha virescente, vix pollicari, mox decidua; spadice breviter [sub $3 \mathrm{~mm}$.] stipitato, ellipsoideo, demum maturesscendo cylindraceo, $3-4 \mathrm{~cm}$. longo, vix I cm. crasso; pistillis latitudine sua parum longio. ribus; filamentis lineari-ligulatis; antheris minimis instructis; fructu I-loculari, 9-10 ovulato.

\section{Crescit in silvis trop. prov. Esmeraldas.}

b. Fetiolis 5-6 ct. longis, quam limbi plus duplo brevioribus;

2 St. subellipticum Sod. sp. nov. caudice assurgente v. breviter scandente; internodiis $5.6 \mathrm{ct}$. longis, vix I ct. crassis, laevibus; petiolis basi dilatata fere amplexantibus, usque ad limbi basin (geniculo vix distincto) vaginatis; limbis leviter asymmetricis, subellipticis, I 5-I 8ct. lonyis, 8 io ct. latis. basi acutis, apice breviter acuminatis, supra intense, subtus pallide viridibus, subcoriaceis, glabris, utrinque minute punctulatis; costa supra immersa, subtus ultra limbi dimidium obtuse exerta, striolata; nervis tenuibus, in sicco utrinque prominulis, sub angulo valde acuto ad marginem protensis, I cum II geminis alternantibus; pedunculo 6.7 ct. longo erecto, ultra dimi- 
dium petiolo folii supremi vaginato, eiusdemque (limbo fere abortivo,) bracteato, apice articulato, spatha, vix pollicem longa ovata acuta; spadice subsessili primum ovato-conico, maturo ignoto.

Crescit in silv., tropic. prov. Esmeraldas.

B. Peduneulis longioribus; spadice cylindrico,

A. Internodits $1 \frac{1 / 2-3}{2}$ longis,

a. Pedunculis petiolos aequantibus v. parum superantibus

$\alpha$. Fetiolis quam limbi brevioribus; dice stipitato.

I. Petiolis pedunculos subaequantibus, quam limbi subduplo brevioribus; spa-

3 St. Porteri Sod. sp. nov. caudice erecto vel ascendente; internodiis $2-3 \mathrm{~cm}$. longis, vix cm. crassis; epidermide glaucescente; petiolis basi dilatata, subamplexantibus, sursum ad geniculum usque angustius vaginatis, IO $12 \mathrm{~cm}$. longis; limbis ad $2 \mathrm{dm}$. longis, $6 \cdot 7 \mathrm{~cm}$. latis, leviter asymmetrici, oblongis, deorsum in geniculum $\pm 1 \mathrm{~cm}$. longo, cuneatim angustatis, apice acuminatis, mucronulatis, supra viridibus, subtus pallidioribus; costa supra immersa, subtus fere usque ad apicem obtuse exerta: nervis tenuissimis, sub angulo acuto arcuatim marginem petentibus, I. a II. vix distinctis; pedunculo tenui, $8.10 \mathrm{~cm}$. longo; spatha?. . valde caduca; spadice longiuscule ( $57 \mathrm{~mm}$.) stipitato, cylindrico, $8 \cdot 10 \mathrm{~cm}$. longo, ad $10 \mathrm{~mm}$. crasso; pistillis obpyramidatis, apice dilatato, longitudine sua paullo latioribus; ountis numerosis 2025 .

Crescit in silvis subtropic. reg. occid. m. Pichincha.

Species St. densiovulato Engl. valde similis; differt petiolis quam limbi subduplo brevioribus, itemque pedunculis climidio brevioribus; id est, vix unquam I $\mathrm{dm}$. longis, itemque spadice evidenter stipitato et æque torgiore.

2. Petiolis quam limbi vix triente breviorihus spadice sessili.

4 St. densiovulatum Engl. sp. nov. caudice I ct. 
crassc; internodiis, 2-3 ct. longis foliorum petiolus laminam subaequante, circ. 2 dm. longo: vagina basi amplectente, sursum angustata instructo, lamma subcoriacea, subtus pallidiore, lanceolata $2-3.5 \mathrm{dm}$. longa $6 \cdot 7$ ct. lata, acumine I. I,5 ct. longo instructa; pedunculus fere $2 \mathrm{dm}$. longus; spatha elongata, longe acuminata, 8 $7 \mathrm{ct}$. longd, convoluta. $6-8 \mathrm{~mm}$. ampla; spadice sessili, 5-6 ct. longo; pistillis crassitudine sua paullo longioribus; ovario infra stylum paullum constricto, dense multiovulato; ovulis $20-30$, funiculo brevi affixis.

Englcr, Beiträege zur Kenntnis der Araceac. X, p. I12

Crescit in silv. subtropicalibus Nanegal-Gualea et in tropical. ad fl. Tanti.

\section{B. Petiolts limbos et pedunculos subaequantibus}

5 St. longifolium Engl. loc. cit. p. 111, sp. nov.Caudice circ. I $\mathrm{cm}$. crasso, internodiis $2 \mathrm{~cm}$. longis. Foliorum petiolo laminae subaequilongo vel ea longiore, vagina utrinque fere $1 \mathrm{~cm}$. lata, basi amplexa, sursum paullum angustata, circ. $1 \mathrm{~cm}$. infra laminae basin desinente instructo, lamina rigida, elongato-oblonga, utrinque aequaliter angustata, basi acuta, apice acuminata, majorum $3-3,5 \mathrm{dm}$. longa, I dm. lata, superiorum circ. 1, $8 \mathrm{dm}$. longa, $7-8 \mathrm{~cm}$. lata. Pedunculo $3-3,5 \mathrm{dm}$. longo. Spatha..... Spadice stipite $\mathrm{I} \mathrm{cm}$. longo suffulto, $1 \mathrm{dm}$. longo, I $\mathrm{cm}$. crasso. Pistillis subquadrangulis, latitudine sua paullo longioribus, unilocularibus; ovulis circ. 6 funiculo brevi basi insertis.

Crescit in silvis trop. et. subtrop. ad vicum Gualea $800 \mathrm{~m}$. supra mare.

b. Pedunculis folium integrum aequantibus $v$. superantibus.

6 St. Mathewsii Schott. caudicis; intemodizs brevibus, foliorum petiolis quam lamina brevioribus, ad geniculum usque vaginatis; lamina oblique, oblongo-elliptica, 
basi obtusiuscula, apice acuminata; nervis lateralibus I. utrinque circ. 8-I 5, angulo acutissimo patentibus, nervis lateralibus II. solitariis interiectis; pedunculo folium totım antecedens superante, subnudante; spatha subcoriacea, alba, apice acuminata; IO-1 2 ct. longa, spadace... cylindrico, brevissime stipitato; ovariis breviter turbinatis, loculis 4 ovulatis; baccis obovoideis, vertice truncatis, loculis 4 spermis.-(Engler)

$\beta$ stipitatum Engler.-var. nova Caudice erecto, internodiis abbreviatis. Foliorum petiolo quam lamina longiore, fere ad ejus basin usque vaginato. Pedunculo folia superante. Spatha oblonga, fere I dm. longa. Spadice stipite $1 \mathrm{~cm}$. longo, suffulto, $5 \mathrm{~mm}$. crasso. $\mathrm{O}$ varii loculis 34 ovulati. (Engl. loc. citato, p. I00).

Occurrit etiam internodiis ad 45 , ct. longis.

Crescit, forma utraque, in silvis subtrop. occid. vallis Nanegal 900-I000 supra mare, et ad Angamarca.
$\alpha$ caudice subscandente; internodiis $3-5 \mathrm{ct}$. longis, vix $3 \mathrm{~mm}$. crassis
B. Internoduis $3-8 \mathrm{ct}$. longis;

7 St. gracile Sod. sp. nov. caudice subscandente, elongato; internodiis 3-5 ct. longis, laevibus glaucescentibus, vix $3 \mathrm{~mm}$. crassis; petiolis I 2 - I $5 \mathrm{ct}$. longis, tenuibus; vagina basi parum supra insertionem antice truncata atque inde petioli latera anguste marginante; limbis oblongis, asymmetricis, subfalcatis, 20-25 ct. longis, $57 \mathrm{ct}$. latis, basin versus cuneatim angustatis, apice argute longeque acuminatis, tenuiter cartilagineis, subtus subglaucescentibus; costa supra immersa v. complanata, subtus leviter et obtuse exerta; nervis omnibus tenuibus, vix exertis, sub angulo valde acuto ascendentibus, plerisque intra marginem in nervulum collectivum ad apicem usque ductum confluentibus; I utrimque 8-10, a II pluribus interiectis bene distinctis, omnibus per venas venulasque in reticulum valde irregulare coniunctis; $p e$ dunculis quam petioli parum $(1 / 2 \cdot 2 c t$ c.) longioribus et aeque gracilibus; spatha?... spadice sessili, ad $3 \mathrm{ct}$. lon. 
go, $67 \mathrm{~mm}$. crasso, in specimine quod prostat, sursum leviter incrassato.

Crescit in silv. tropic prov. Esmeraldas.

Non obstante deficentia speciminis unici quod possidemus, hanc formam describere visum est ob characteres nonnullos, quibus facile a ceteris omnibus discerni potest.

a. Petiolis quam limbi subluplo brevioribus; spalice sessili

$\delta$ St. Sodiroanum Engl. sp. nov.; caudice I $\mathrm{cm}$. crasso; internodiis longitudinaliter sulcatis, $4.5 \mathrm{~cm}$. longis; pe tiolis quam lamina duplo brevioribus, ad $4.5 \mathrm{~mm}$. infra lamina basin late vaginatis; lamina coriacea, elliptico-ovata, basi obtusa, apice breviter acuminata 9-12 $\mathrm{cm}$. longa, $41 / 2-51 / 2 \mathrm{~cm}$. lata; pedunculo I $5 \mathrm{~cm}$. longo; spatha $5 \mathrm{~cm}$.longa, convoluta, I $\mathrm{cm}$. lata, vix acuminata; spactice sessili, $4 \frac{1}{2} \mathrm{~cm}$. longo, $5 \mathrm{~mm}$. crasso; pistillis crassitudine sua sexquplo lon gioribus; ovario incomplete uniloculari, 68 ovulato; ovulis funiculo tenui suffultis.

(Engl. loc. cit. p. I I 2) sal.

Crescit in silvis subtrop. in valle Mindo et Nane-

b. Pctiolis quam limbi subtriplo brevioribus; sputice breviter stipitato

9 St. Peripense sod. sp. nov.; caudice subscandente; e nodis remote radicante internodizs $35 \mathrm{~cm}$. longis, 34 $\mathrm{mm}$. crassis, longitudinaliter striatis; petiolis $3-4 \frac{\mathrm{T}}{2} \mathrm{~cm}$. longis, $6-7 \mathrm{~mm}$. infra laminae basin vaginatis; vagina lata, basi amplexante, ad geniculum evanescente; limbis dense cartilagineis, subellipticis vel obovato-ellipticis, asymmetricis, basi obtusis, apice breviter acuteque acuminatis, IO- $12 \mathrm{~cm}$. longis, $5-6 \mathrm{~cm}$. latis; costa supra plana, subtus tenuiter obtuseque exerta; nervis omnibus tenuissimis, subangulo acuto in marginem protensis, I. quam 
II. vix crassioribus; pedunculo 9-10 cm. longo, ad $1 / 2$ usque petiolo folii supremi $56 \mathrm{~cm}$. longi vaginato; $s p a$ tha?... - spadice breviter ( $2 \mathrm{~mm}$.) stipitato, $5 \mathrm{~cm}$. longo, 4. $5 \mathrm{~mm}$. crasso.

\section{Crescit in regione trop. secus fl. Peripa.}

c. Petiolis limbos superantibus; spartice stipitato

10. St. latifolium (Engl. loc. cit. p. I I 2) sp. nov.Caudice vix I cm. crasso, internodits $6.8 \mathrm{~cm}$. longis. foliorum; petiolo quam lamina longiore, fere ad laminate basin usque vagina utrinque $3.4 \mathrm{~mm}$. lata instructo, lamina ovata, basi obtusa, apice acuta vel breviter acuminata, 0.9 I, $2 \mathrm{dm}$. longa, medio $6.7 \mathrm{~cm}$. lata. pedunculo 2, $5 \mathrm{~cm}$. longo; spathaoblonga, $6 \mathrm{~cm}$, longa, convoluta $1,5 \mathrm{~cm}$. ampla, breviter acuminata; spadice stipite $2.3 \mathrm{~mm}$. longo suffulto, cylindrico, $5.5 \mathrm{~cm}$. longo, $4.5 \mathrm{~mm}$. crasso; pistillis depressis, crassitudine sua paullum brevioribus; ovario uniloculari, 5.6- ovulato; ovulis funiculo tenui, paullum breviore suffultis.

Crescit epiphyticum in silvis subtrop. secus fl. Pilatón, ppe. San Nicolás.-r.200 m. supra mare.

\section{$\beta$. Internodiis aliis brevibus foliatis; aliis elongatis aphyllis.}

11 St. intermptum Sod. sp. nov.; caudice elongato, subscandente, vix $\mathrm{cm}$. crasso; internodiis nunc brevibus, IO $12 \mathrm{~mm}$. longis, foliis normalibus instructis, nunc longioribus ( $7.8 \mathrm{~cm}$. longis) vaginis, (limbo abortiente) aphyllis, apice aristatis, vestitis; petiolis normalibus, ex basi lata sursum ad geniculum usque anguste vaginatis; geniculo $78 \mathrm{~mm}$. longo, dorso carinato; limbis asymmetricis, $2520 \mathrm{~cm}$. longis, $5.5 \mathrm{~cm}$. latis, basi acutiuscula, apice ad I cm. acuminatis, subcoriaceis, subtus pallidioribus; $\cos l a$ supra immersa, subtus ultra dimidium exerta, obtusa; nervis tenuissimis, sub angulo valde acuto marginem petentibus, I. a II. vix distinctis; pedunculis (e basi partis apyllæ exortis), $2025 \mathrm{dm}$. longis, in dimidio inferiore petiolo folii peduncularis, ceteris minoris va- 
ginatis; spatha?... stipite $23 \mathrm{~mm}$. longo; spadice $7 \cdot 8$ $\mathrm{mm}$. longo, ad $8 \mathrm{~mm}$. crasso.

Crescit in silvis trop. prov Esmeraldas ad fl. Lita.

II; Vagina petiolari \pm infra geniculum desinente;

A. Cautice gracili ascendente

a. Petiolis inferioribus ad $2 / 3$, supremo ad geniculum usque vaginato

12 St. adsimile Sod. sp. nov. caule ascendente vel modice scandente, praeterquam ad basin, arrhizo; internodiis inferioribus $11 / 2-2 \mathrm{ct}$. longis, $58 \mathrm{~mm}$. crassis, superioribus paulo brevioribus; peliolis $15-18$ ct. longis, basi late vaginatis, vagina inferiorum ad petioli dimidium, supremi ad geniculum ( 10 I $2 \mathrm{~mm}$. longum) usque producta, apice ubtuse truncata; limbis petiolos longitudine subaequantibus, inferioribus parum brevioribus, $7-9 \mathrm{ct}$. latis, asymmetricis, basi subacutis, apice breviter acuminatis, in sicco cartilagineis, supra glabris, subtus sub lente minute punctulatis; costa supra immersa, subtus modice exerta, obtusa, in limbi acumen mucronatum producta, nervis tenuibus, I. a II. vix distinctis, venulisque tenuissimis, mutuo remote reticulatis, omnibus a costa subangulo valde acuto ad marginem protensis; pedunculo $25-35 \mathrm{ct}$. longo, ultra dimidium folii supremi, ceteris plus duplo minoris, vagrina ad geniculum usque producta, involuto; $s p a$ tha in vivo carnoso-membranacea, in sicco dense cartilaginea, alba, subelliptico lanceolata, cuspidata, 9 ro ct. longa; spadice cylindroideo, ( $5 \mathrm{~mm}$.) stipitato, luteolo, ad 6 ct. longo, $56 \mathrm{~mm}$. crasso; fructu obconico, apice dilatato hexagono, longitudine sua subduplo latiore.

Crescit in silv. tropic. prov. Esmeraldas (8/904).

adsimile diximus propter quamdam similitudinem quam praesefert cum St. spruceano, Schott, a quo tamen nonnullis excharacteribus enuntiatis, satis differre videtur.

b. Vagina folionum omnium vix ad petioli dimidiuu producta;

13 St. longipetiolatum Engl. sp. nov.; caudice gra- 
cili, ascendente; internodiis $3-4 \mathrm{~cm}$. longis, $4.5 \mathrm{~mm}$. crassis, striolatis; petiolis $10.13 \mathrm{~cm}$. longis, vagina basi dilatata, amplexante, sursum angustata, infra petioli $1 / 2$ desinente; in folio pedunculari ad $2.3 \mathrm{~cm}$. infra laminam producta; lamina oblongo-elliptica dense cartilaginea, subtus pallidiore, basi obtusa, apice acuta vel breviter acuminata, $10-13 \mathrm{~cm}$, longa, circa medium, $4.5 \mathrm{~cm}$. lata; pedunculo I $6.18 \mathrm{~cm}$. longo, ad $1 / 2$ usque vagina folii peduncularis, arcte involuto; spatha?... spadice breviter (2-3 mm.) stipitato, cylindrico ad $5 \mathrm{~cm}$. longo, $5.6 \mathrm{~mm}$. crasso; pistillis crassitudine sua paulo longioribus; ovario incomplete 1-loculari, 4-ovulato; ozulis funiculo brevi suffultis (Engl. loc. cit. p. I I 2)

Crescit in silvis subtrop. occid. M. Pichincha inter Nanegal et Gualea.

B. Candice crasso, internodits brevibus; limbis magnis;

a. Petiolis quam pedunculi limbique longioribus,

It St. Hilligic Sod. sp. nov.: caudice brevi, erecto; internodiis $1 \mathrm{~cm}$. longis, ad $2 \mathrm{~cm}$. crassis; petiolis $3 \mathrm{dm}$. longis, limbos parum superantibus, multistriatis; vagina basi I cm. utrinque lata, sursum modice angustata, ad dimidium usque intructis; limbis coriaceis $2-2,5 \mathrm{dm}$. longis, subobovato-ellipticis, in triente superiore, $13-15 \mathrm{~cm}$. latis, atque inde sursum in apicem acuminatum vel breviter abrupteque apiculatum et deorsum in basin obtu. sam contractis, geniculo I $520 \mathrm{~mm}$. longo suffultis; costa supra \pm immersa, subtus exerta obtusa, prope apicem evanescente; nervis tenuibus I. a II. vix distinctis, sub angulo acuto a costa ad marginem arcuatim divergentibus; pedunculo $25 \mathrm{~cm}$. longo, quam petioli tenuiore; spatha? ... spadice sessili, cylindrico, ad io $\mathrm{cm}$. lougo, 4 $\mathrm{mm}$. crasso; pistillis subrequilongis ac latis, 2 locularibus, loculis dispermis; seminibus asymetricis, arcuatoobclavatis, funiculo longulo suffultis.

Crescit in silvis tropc. prov. Esmeraldas. 
Species eximia nullique, ex nostratibus hactenus cognitis, affinitate coniuncta.

\section{b. Petiolis quam pedunculi longioribus, limbos \pm superantibus}

15 St. maximum Engl. caudice ascendente v, erecto; internodiis $2-3 \mathrm{~cm}$. longis, $2 \mathrm{~cm}$. crassis; petiolis $35^{-}$ $40 \mathrm{~cm}$. longis, basi late vaginatis, vagina $8-10 \mathrm{~cm}$. infra apicem desinente, quam limbi parum brevioribus; limbis oblongis, $35.45 \mathrm{~cm}$. longis, circa medium ad $15 \mathrm{~cm}$. latis, subcoriaceis basi in geniculum angustatis, apice breviter acuminatis, supra intense viridibus, albido-muriculatis, subtus viridi-glaucescentibus, nervis omnibus tenuibus, sub angulo acuto erga marginem arcuatim ascendentibus, I. a II. aegre distinctis, supra exertis, subtus immersis; costa supra plana, subtus ad apicem usque exerta; pedunculis $35.40 \mathrm{~cm}$. longis, ultra dimidium vagina folii supremi involutis; spatha alba, coriacea, ad $20 \mathrm{~cm}$. longa, 3-4 cm. lata, apice acuminata, mucronata; spadice varie (I-3 cm.) stipitato, $\mathrm{I} 2-15 \mathrm{~cm}$. longo, $10-12 \mathrm{~mm}$. crasso pistillis crassitudine sua parum longioribus; ovario 12 I5-ovulato; ovulis funiculo brevi suffultis.

(Engl. loc. cit. p. I13)

Crescit in silvis subtrop. occid. inter Nanegal et Gualea.

\section{G. II RHODOSPATHA P0EPP.}

Flores in spadice inappendiculato hermaphroditi v. inferiores foeminci, apetali; Stam. 4, filamentis late linearibus; antheris 2-4 thecis lateraliter dehiscentibus; ova. rium, stylo tetragono, prismatico, apice truncato, medio stigmatifero superatum, 2-loculare; loculis polyspermis; semina lenticularia, campylotropa, funiculo brevi affixa; embryo hippocrepicus. 
I. Pedunculo monostachyo nudo;

A. Vagina petiolari 7-IO $\mathrm{mm}$. utrinque lata; ad geniculum usque producta.

a. Varrina petiolari integra persistente; spadice stipitato;

a. Petiolis $12-15 \mathrm{~cm}$. longis, late vaginatis.

1 Rh. Kraenzlinii Sod. sp. nov. caudicis assurgentis internodiis inferioribus IO-I $2 \mathrm{~mm}$. longis, aeque et crassis; petiolis quam limbi adulti subaequilongis vel ad trientem brevioribus, basi amplexante late, sursum usque ad geniculum 8 io $\mathrm{mm}$. longum gradatim angustius vaginatis, vaginae lateribus apice obtuse truncatis; limbis dense cartilagineis laevibus, $2 \frac{1}{2}-3$ dc. longis, $8-$ I 2 ct. latis, oblongo-ellipticis, \pm asymmetricis, basi obtusis, apice breviter ( $3.5 \mathrm{~mm}$.) acuminatis; nervis I. utrinque I 2 - I 5, cum. II. pluribus alternantibus, omnibus arcuatim ascendentibus et in limbi margine evanescentibus; pedunculo quam petiolus tenuiore subduplo breviore; spatha adulta ignota, iuvencula ad I dc. longa, cuspidata spadice longe (IO-I 5 mm.) stipitato, post anthesin ad 10 - I 2 ct. longo, circa medium IO- I $2 \mathrm{~mm}$. crasso, utroversus modice attenuato, apice obtuso; bacca prismatica hexagona, apice truncata seminibus imbricatim superpositis, lenticularibus subreniformibus, margine acietato.

Crescit in regione subtrop. occid. ad basin vulc. $\mathrm{Pu}$ lulahua et regionis Angamarca.

B Pelwlis 20-25 ct, longis; pelmucnlos triente superantibus.

2 kh. robusta caudice ascendente, basi radicante, internodiis $2 \mathrm{~mm}$. longis aeque ac crassis, interioribus cataphylla lanceolata apice acuta, 9-10 ct. longa, ad $2 \mathrm{ct}$. basi lata gerentibus; petiolis 2-3 uc. longis, vagina basi itrinque fere $1 \mathrm{~cm}$. lata, sursum ad geniculum usque gradatim angustata instructis; limbis subellipticis, (in specimine) 25-35 ct. longis, I $825 \mathrm{ct}$. latis, \pm asymmetricis, basi parum inaequaliter rotundatis, apice breviter acuminatis, dense cartilagineis, glaucescenti-viridibus; costa supra complanata, subtus prominente obtusa; nervis a costa divaricato-patentibus, marginem versus arcuato-ascendentibus, I. fere I ct. abinvicem remotis, II. pluribus pedunculis robustis, $25 \cdot 30 \mathrm{ct}$. longis, ex basi ad apicem 
vel ad trientem superiorem usque, cataphyllo, utrimque ad $15 \mathrm{~mm}$. lato, apice acuto involutis; spatha coriacea I $5 \mathrm{ct}$. longa convoluta angusta apice subulata alba, $s p a$ dice breviter $(7.8 \mathrm{~mm}$.) stipitato, cylindraceo (basi apiceque sterili?) $15-18 \mathrm{ct}$. longo, I 1/2-2 ct. crasso; pistillis prismatico-tetragonis, apice complanato, medio stigmatifero, vix margine dilatato; ovario biloculari: seminibus in loculis 2 -seriatim superpositis, in serie qualibet $4-5$ lenticularibus, campy lotropis, funiculo brevi affixis; texta nitida, sub lente minutissime areolata, dorso callose aristata.

Crescit in silvis tropc. prov. Esmeraldas at fl. Lita. et Cachaby.

b. Vagina petiolari lata, sursum denique in fibras \pm resoluta;

$\alpha$ Nervis I 8 -1o $\mathrm{mm}$. ab invicem remotis

3 Rh. Dammeri Sod. sp. nov. internodits brevibus, IO-I $2 \mathrm{~mm}$. crassis e nodis radicantibus; petiolis, 25-40 ct. longis, in sicco castaneis, deorsum profunde striatis, antice vagina basi I ct. utrinque lata, sursum angustiore, ad geniculum usque producta, demum in fibras \pm dissolverda, instructis; genicuto I $1 / 2-2 \mathrm{ct}$. longo antice unis!n cato, marginato; limbis subellipticis, $4 \frac{1}{2} \cdot 5 \mathrm{I} / 2 \mathrm{dc}$. longis, prope medium $20.25 \mathrm{ct}$. [atis atque inde utroversus lineis convexis gradatim angustatis, basi obtusis v, in geniculum angustatis, apice breviter acuminatis, asymmetricis, (late: altero 4.5 ct. alio latiore) dense cartilagineis, supra intense viridibus, subtus viridi-rufescentibus, coste supra impressa v. plana, subtus, fere usque ad apicem, prominente obtusa, et (cum nervis) tenuissime pulverulento-puberula; nervis a costa sub angulo fere recto pro$\mathrm{f} e \mathrm{ctis}$ arcuatim ascendentibus, in nervulum submarginalem confluentibus, I ab ivicen $8.10 \mathrm{~mm}$, remotis, cum II et III interiectis alternantibus et irregulariter reticulatis; pedunculo (in specimine adhuc iuniore) ad i 6 ct. longo gracili; spatha alba, mature caduca convoluta, I 2-15 ct. longa; spadice sessili cylindraceo, I2-I5 ct. longo, per anthesin I ct. crasso. 
Crescit in reg. snbtropic. prop. Gualea (7/903)

Spec. fere intermedia inter $\mathrm{Rh}$. robustam et $\mathrm{Rh}$. macropyllam; cum illa mutua nervorum uiistantia, concordat, differt statura maiore, limborum forma, pedunculis brevioribus etc., a secunda facile distinguitur nervis paucioribus et remotioribus.

\section{B Nontis I $4-5 \mathrm{~mm}$. ab invicem remotis.}

4 Rh. macrophylla Sod. sp. nov. caudice assurgente; internodizs $5-6 \mathrm{ct}$. longis, $\mathrm{I}-1 \mathrm{I} / 2 \mathrm{ct}$. crassis, e nodis radicantibus; petıolis $2 \mathrm{I} / 2-3 \mathrm{dc}$. longis, dorso (in sicco) sulcatis, intus vagina ultra geniculum producta, utrimque ad I $5 \mathrm{~mm}$. lata, sursum obiter angustata, aetate longitudinaliter lacera et geniculo $\pm 2 \frac{1}{2} \cdot 3 \mathrm{ct}$. longo instructis; limbis 35-45 ct. longis, prope medium 25-30 ct. latis, utroversus arcuatim angustatis, basi rotundatis, apice acuminatis coriaceis, supra intense viridibus nitidis, subtus pallidioribus, pilis punctiformibus dense conspersis, in sicco utrinque fuscis; costa supra impressa, subtus prominente robusta, a medio deorsum carinata; nervis numerosis, subtus valde prominentibus, sub angulo magno á costa ad marginem arcuato-ascendentibus, I 4.5 mm. ab invicem remotis, cum II et III paucis alternantibus et valde irregulariter reticulatis; peduncules petiolos subaequantibus, robustis ancipitibus, cataphyllo petiolorum vaginae simili, arcte vaginatis; spatha .... alba mox decidua; spadice postice sessili, antice stipiti $6.8 \mathrm{~mm}$. nudo instructo (in specimine nondum maturo) ad $2 \mathrm{dc}$. longo, IO-I $2 \mathrm{~mm}$. crasso, subcylindrico, sursum obiter attenuato; pistillis stylo prismatico, apice convexo, medio stigma prominulum oblongum gerente instructis; orurio biloculari pluriovulato; ow lis numerosis, campylo tropis, funiculo longo suffultis.

Crescit in silv, tropic. Prov. Esmeraldas et in reg. inferiore vallis Nanegal. 
Vagina petiolari angusta. denique fere tota in fibras resoluta.

5 Rh. Statutii Sod. sp. nov. caudice ascendente; internodiis $2 \cdot 4 \mathrm{ct}$. longis, I $\mathrm{x} / 2 \mathrm{ct}$. crassis; petiolis (in specimine) 3. $3 \frac{1}{2}$ dc. longis, dorso striatis, antice basi lata sursum ad geniculum usque anguste vaginatis; geniculo $2-2 \mathrm{I} / 2$ ct. longo, marginato; limbis subellipticis, 3 dc. longis, circa medium I 2 ct. latis, basi acutis, v. in geniculum breviter cuneatis, apice breviter acuminatis, subcoriaceis (in sicco fragilibus) supra intense viridibus, subtus pallidioribus; costa supra immersa subtus prominente obtusa; nervis supra immersis, subtus exertis, patentibus marginem versus arcuatim patentibus et in margine desinentibus, I ab invicem $3-4 \mathrm{~mm}$. remotis, cum II tenuissimis, unoalterove alternantibus et reticulatis; pedunculo (adulto) petioli dimidium aequante, graciliore; spatha (in spadice adhuc iuvenculo,) IO 12 ct. longa angusta, sursum subulato angustata, spadice (adhuc immature) longiuscule ( 8 - Io mm.) stipitato, cylindrico, 10- I $2 \mathrm{ct}$. longo, $7.8 \mathrm{~mm}$. crasso stam. 4, filamentis late linearibus, compressis basi dilatatis; antheris dithecis, thecis ultra connectivum modice productis; ovario obpyramidato prismatico 2-loculari; loculis $\infty$-ovulatis, ouulis parvis lenticularibus, anatropis; stylo coriaceo, apice trunrato, tetrayono, medio stigmatifero, stiginate oblongo;

Crescit in silv. subtrop. vall. Nanegal et Gualea.

II Pedunculo 2-3 1) racteato, cum ruclimentis alterius iuflorescentiae.

6? Rh.? dissidens Sod. sp. nov. caudice ascendente; internodiis $1-1$ 1/2 ct. longis acque ac crassis; petiolis basi late, sursum ad geniculum usque grad atim angustius vaginatis, 20-25 ct. longis; limbis geniculn i $8-25 \mathrm{~mm}$. longo suffultis, petiolos longitudine subaequantibus, is i 8 ct. latis, ellipticis v. ovato-ellipticis, asymmetricis, basi inaequali rotundatis, apice obtusis breviter acuminatis, subcoriaceis; costa supra plana, subtus prominente obtusa; neris subtus prominulis, patentibus, prope marginem ascendentibus, I $4-6 \mathrm{~mm}$. ab invicem remotis, clim II quinis-senis alternantibus; pedunculo terminali, I-fo- 
liato $\mathrm{v}$. distiche bibracteato, supra folium vel bracteam superiorem 5-8 ct. longo, subterete, cum rudimento, alterius inflorescentiae in axilla bracteae inferioris; spatha coriacea subelliptica, arcte convoluta, apice breviter acuminata, oblique decidua; spadice breviter (4-5 mm.) sti. pitato, cylindraceo, I $2-15 \mathrm{ct}$. longo, ad I $2 \mathrm{~mm}$. crasso; filamentis anguste linearibus; pistillis prismatico-hexagonis; stylo ad $2 \mathrm{~mm}$. longo, $\pm 3 \mathrm{~mm}$. crasso, apice modice convexo, medio stigmatifero-(ovula et semina in spadice nincedine pereso, recognoscere non licuit; hinc dubium an huic generi, cui praecipue ob habitus similitudinem adscribimus, revera pertineat).

Crescit in silv. tropic, prov. Esmeraldas.

\section{G. I 2 HETEROPSIS KUNTH.}

Flores, in spadice stipitato, innappendiculato, nudi, sessiles; stam. 4, filamentis late linearibus, antheris 2 thecis, apice dehiscentibus; ozarium obpyramidato-prismaticum, apice truncato, medio stigmatiferum, superne biloculari; loculis biovulatis; ovulis anatropis, erectis, placentae basi septo adnatae affixis.

Frutices scandentes ramosi; folizs alternis. vagina petioli axi adnata petiolo (seu geniculo) brevi; lamina subcoriacea lanceolata, oblonga, v. oblongo-elliptica; spadice pedunculato stipitato cylindraceo; spatha brevi, convoluta, apiculata, mox caduca.

1 H. Ecuadorensis sp. nov. caule lignoso, scandente, ramoso; ramis tenuibus, striolatis, basi persistente foliorum delapsorum annulatis; internodiis $3-4 \mathrm{ct}$. longis; petiolis (seu geniculis) 3-4 mm. longis, basi amplectentibus, sursum compressis in sicco convulutis; limbis sub- 
coriaceis, sub lente minutissime pellucido punctatis, 0 blongo-ellipticis, basi obtusiusculis, apice I-2 ct. cuspidatis; costa supra impressa, subtus leviter prominente, obtusa; nervis tenuibus, in sicco utrinque prominulis, I in nervum collectivum sinuosum, $\mathrm{I} / 2 \mathrm{~mm}$. a margine remotum (alteri sub marginali parallelum) confluentibus, II (inter I binis-ternis) tenuioribus, cum I valde irregulariter reticulatis et plerisque ad nervum collectivum pertingentibus vel antea deliquescentibus; pedunculi 8 - Io mm. longis, subclavatis; spatha subelliptica, 4 ct. longa 2 1/2 ct. lata, apice breviter aristato-acuminata, subcuriacea, mature caduca; spadice breviter (3-4 mm.) stipitato, subcylindrico, 4-5 ct. longo, 5-6 mm. crasso.

Crescit in silv. subtropic. secus fl. Pilatón prov. Quitensis et in tropicalibus prov. Guayas prope "El Naranjito." 
Acrostichum L. (Elaph

Antisanae Sod.

cinereum Sod.

Chodatii Sod.

diversifolium Sod.

ellipsoideum Sod.

Engleri Sod.

fulrum Sod.

Guamanianum Sod.

gossypinum Sod.

Hikenii Sod.

molle Sod.

muriculatum Sod.

Pichinchae Crist

pruinosum Sod.

rupieolum Sod.

spectabile Sod.

Urbani sod.

viscidulum Sod.

ALSOPHILA Br.

bilineata Sod.

Christii Sod.

A M A T Y Y IIDE A E Findl.

ANTHURIUm Sehott.

acutissimum Engl

3 maius Sod.

bimarginatum Sorl.

Candolleanum Sod.

heteroclitum Sod.

ophites Sod.

oreodoxım Sod.

pyrifolium Sod.

AROIDEAE

Treleasei Sod.

AsPLENIUM L.(Diplaz.)

anomalum Sod.

costale Sw.

crassifolium Sod.

Chimboanum Sot.

heterolobum sod.

Hieronymi Sod.

humilesod.

melanosorum Sorl.

oxylobum Sod.

procerum Sod.

Tungurabuae sod. vesiculosum Sod.

Bomarea Mirbel ambigna Sod.
30

38

40

32

30

33

34

3.5

38

35

37

40

39

32

41

42

36

31

13

12

\section{.}

$6 \mathrm{i}$

61

66

64

65

61

63

62

63

21

23

22

24

19

19

20

23

52
Angamareana Sod, $\quad 51$

Borjae Sod. $\quad 44$

brachypus Kränzl. 54

Caldasiana Herb. $\quad 49$

comata Sod. 58

edulis Herb. $\quad 59$

elegans Sod. $\quad 57$

3 amoena Sod. $\quad 58$

falcata Sod. $\quad 56$

fuliosa Sod. 53

glaucescens Bak 43

goniocaulon Bak $\quad 47$

gracilis Sod. $\quad 60$

graminifolia Sod. $\quad 45$

grandiceps Kränzl 54

hexagona Sod. $\quad 58$

lanata Sod. $\quad 48$

microcephala Sod. $\quad 4.5$

Patacoensis Herb. $\quad 50$

3 glabrata Sod. $\quad 50$

polyantha Sod. $\quad 46$

3 micrantha Sod. $\quad 47$

pulchella Sod. 5.5

rigidifolia Sod. $\quad 52$

Saloyana Sod. 51

subspicata Sod. $\quad 49$

subtriflora Sod. $\quad 59$

tenuifolia Sod. $\quad 46$

tomentosa Herb. 44

venusta Sod. 55

CYathea S. M.

asperata Soul. 9

brachypoda Sod. 8

canescens Sod. 4

furfuracea Sod. 7

muriculata Sod. $\quad 10$

nitens Sod. 3

ochroleuca Sod. 11

oxyacantha Sod. 6

parvifolia Sod. 7

purpurascens Sod. 5

subinermis Sod. $\quad 10$

Tungurahuae Sod. $\quad 12$

HETERopsis Kunth
Ecuadorensis Sor.

NePHRODIUM (Lastrea)
brachypus Sod.

cinereum Sod. $\quad 26$ 


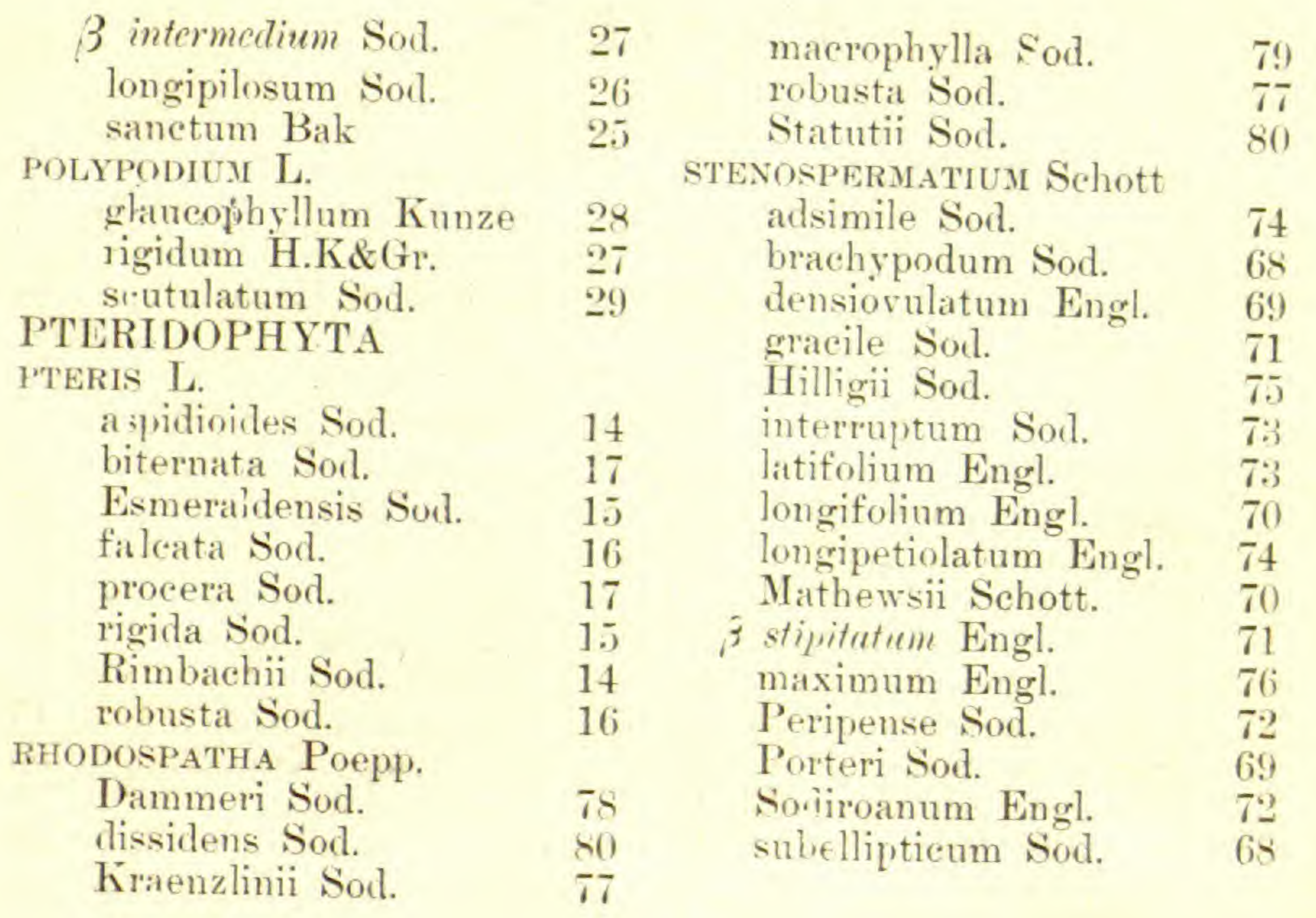

